\title{
Influence of Winkler-Pasternak Foundation on the Vibrational Behavior of Plates and Shells Reinforced by Agglomerated Carbon Nanotubes
}

\author{
Damjan Banić $^{1}$ (D), Michele Bacciocchi ${ }^{2}$ (D), Francesco Tornabene ${ }^{2, *}$ (D) \\ and Antonio J. M. Ferreira ${ }^{3}$ \\ 1 Department of Engineering Mechanics, Faculty of Engineering, University of Rijeka, HR-51000 Rijeka, \\ Croatia;dbanic@riteh.hr \\ 2 Department of Civil, Chemical, Environmental and Materials Engineering (DICAM), \\ School of Engineering and Architecture, University of Bologna, 40136 Bologna, Italy; michele.bacciocchi@unibo.it \\ 3 Departamento de Engenharia Mecânica, Faculdade de Engenharia da Universidade do Porto, \\ 4200-465 Porto, Portugal; ferreira@fe.up.pt \\ * Correspondence: francesco.tornabene@unibo.it
}

Received: 28 October 2017; Accepted: 23 November 2017; Published: 28 November 2017

\begin{abstract}
This paper aims to investigate the effect of the Winkler-Pasternak elastic foundation on the natural frequencies of Carbon Nanotube (CNT)-reinforced laminated composite plates and shells. The micromechanics of reinforcing CNT particles are described by a two-parameter agglomeration model. CNTs are gradually distributed along the thickness direction according to various functionally graded laws. Elastic foundations are modeled according to the Winkler-Pasternak theory. The theoretical model considers several Higher-order Shear Deformation Theories (HSDTs) based on the so-called Carrera Unified Formulation (CUF). The theory behind CNTs is explained in detail. The theoretical model presented is solved numerically by means of the Generalized Differential Quadrature (GDQ) method. Several parametric studies are conducted, and their results are discussed.

Keywords: Functionally Graded Carbon Nanotubes; natural frequencies; Winkler-Pasternak elastic foundations; numerical analysis; Higher-order Shear Deformation Theories
\end{abstract}

\section{Introduction}

In the last few decades, due to their high potential in terms of mechanical and thermal properties such as tensile and yield strength, Carbon Nanotubes (CNTs) have attracted the interest of many scientists and researchers trying to find convenient applications for these types of nanostructure [1-11]. The application of CNTs has mainly been as a reinforcement constituent of composite materials, which are, nowadays, widely used, especially in the aerospace field and in the automotive industry [12-29]. This has led to the birth of a new class of composites called nanocomposites. In spite of the numerous works that have been written on this subject, CNTs still remain an open topic for discussion. The curiosity with regard to the effects of CNT reinforcement on various structures has led to the development of different techniques and approaches for estimating these effects as well as possible, optimized between the goals of simplicity and accuracy [27]. The theory of mixtures, due to its simplicity, is the most common approach used to describe the mechanical properties of these types of nanostructure [30,31]. Despite its simplicity, this approach neglects several aspects of the micromechanics of CNT particles, which, due to their characteristic shape, tend to agglomerate in different areas of the reinforced polymer composite. A more precise approach has been proposed in the work by Shi et al. [32], presenting a two-parameter theoretical model that closely describes the agglomeration effect of the CNT particles, whereby the homogenization, 
based on the Eshelby-Mori-Tanaka scheme for granular composite materials [33], and mechanical properties are obtained. This scheme uses the so-called Hill's elastic moduli [34,35] to describe the constitutive relations of the CNT particles. For the sake of completeness, some examples concerning the agglomeration of CNTs can be found in the papers [36-38].

The present paper aims to use this approach to study the effect of agglomeration on the natural frequencies of functionally graded carbon nanotube-reinforced laminated composite plates and shells resting on the elastic foundation. Although the high structural performance of plates and shells made from conventional composites has been proved by a number of papers [39-56], by employing CNTs as a reinforcing phase, their performance can be improved even further. A gradual variation of the volume fraction of the CNT particles trough the thickness of the composite has been employed, which is characteristic to functionally graded materials (FGMs). FGMs are a recent class of composite materials designed to deal with problems of stress concentration and mechanical discontinuity [57-84]. Therefore, the term Functionally Graded Carbon Nanotubes (FG-CNTs) was introduced to refer on this type of CNT-reinforced composite. For the sake of completeness, it should be mentioned that several papers concerning structural models suitable for the mechanical analysis of these kinds of structure have been published recently [85-93]. In particular, the gradient elasticity theory was proposed by Barretta et al. [85] to this end. Alternatively, a nonlocal model can be used for this purpose, as proved in the papers by Romano and Barretta [86], Romano et al. [87], Marotti de Sciarra and Barretta [88], and Apuzzo et al. [89].

To capture the proper mechanical behavior of these structures, adequate structural models must be considered. The use of classical shell theories may result in inaccurate results; therefore, the use of Higher-order Shear Deformation Theories (HSDTs) is required. Recent developments in the area of HSDTs are found in the works by Carrera [94-98], introducing the so-called Carrera Unified Formulation (CUF). This formulation is explained in detail in the books by Tornabene et al. $[99,100]$. CUF represents one of the most efficient and complete approaches when studying the mechanical behavior of multilayered composite beams, plates, and shells [101-110].

In this paper, various HSDTs based on the CUF Equivalent Single Layer (ESL) approach are employed to investigate the effect of agglomeration on the natural frequencies of FG-CNT-reinforced laminated composite plates and shells resting on the elastic foundation. The elastic foundation is modeled according to the Winkler-Pasternak theory. Papers describing this type of linear elastic foundation model can be found in [111-128]. As far as nonlinear analyses are concerned, the reader can find further details in the works [129-135].

Due to its complexity, the problem is solved numerically by the means of the Generalized Differential Quadrature (GDQ) method. The GDQ is an accurate, reliable, and stable numerical technique developed by Shu in the nineties [136]. This numerical technique is described in detail in the review paper by Tornabene et al. [137]. Further details concerning this numerical approach, as well as several numerical applications, can be found in the papers [138-140]. Finally, it should be mentioned that the present approach was implemented in MATLAB code [141].

\section{Theoretical Model}

\subsection{Geometry}

The two-dimensional shell model considered in this paper is defined by the vector $\mathbf{r}\left(\alpha_{1}, \alpha_{2}\right)$ over the middle surface of the shell (Figure 1). The parameters $\alpha_{1}, \alpha_{2}$ stand for the orthogonal and principal curvilinear coordinates of the middle surface of the shell. Examples for this notation can be found in the books by Tornabene et al. [99,100]. As can be seen in Figure 1, the position vector $\mathbf{R}\left(\alpha_{1}, \alpha_{2}, \zeta\right)$ defines each point $P$ of a generic three-dimensional shell element of constant thickness $h$. Position vector $\mathbf{R}\left(\alpha_{1}, \alpha_{2}, \zeta\right)$ is defined as

$$
\mathbf{R}\left(\alpha_{1}, \alpha_{2}, \zeta\right)=\mathbf{r}\left(\alpha_{1}, \alpha_{2}\right)+\zeta \mathbf{n}\left(\alpha_{1}, \alpha_{2}\right)
$$


where $\zeta$ is the coordinate that identifies the normal direction along the shell thickness. The outward unit normal vector $\mathbf{n}\left(\alpha_{1}, \alpha_{2}\right)$, defined along $\zeta$, can be expressed as

$$
\mathbf{n}=\frac{\mathbf{r}_{1,} \wedge \mathbf{r}_{2}}{\left|\mathbf{r}_{, 1} \wedge \mathbf{r}_{2,2}\right|}
$$

The symbol " $\wedge$ " stands for the vector product, also $\mathbf{r}_{, i}=\partial \mathbf{r} / \partial \alpha_{i}$ for $i=1,2$ is introduced. The following limitations are included for $i=1,2$

$$
\alpha_{i} \in\left[\alpha_{i}^{0}, \alpha_{i}^{1}\right]
$$

where $\alpha_{i}^{0}, \alpha_{i}^{1}$ denote respectively the minimum and the maximum values of the coordinates at issue. The third coordinate $\zeta$ must be defined within the limits of the shell thickness; therefore, it is bounded as

$$
\zeta \in[-h / 2, h / 2]
$$

For a laminated composite structure made of $l$ plies (Figure 1), the total thickness of the shell $h$ can be expressed as

$$
h=\sum_{k=1}^{l} h_{k}
$$

where $h_{k}$ denotes the thickness of the $k$-th ply.

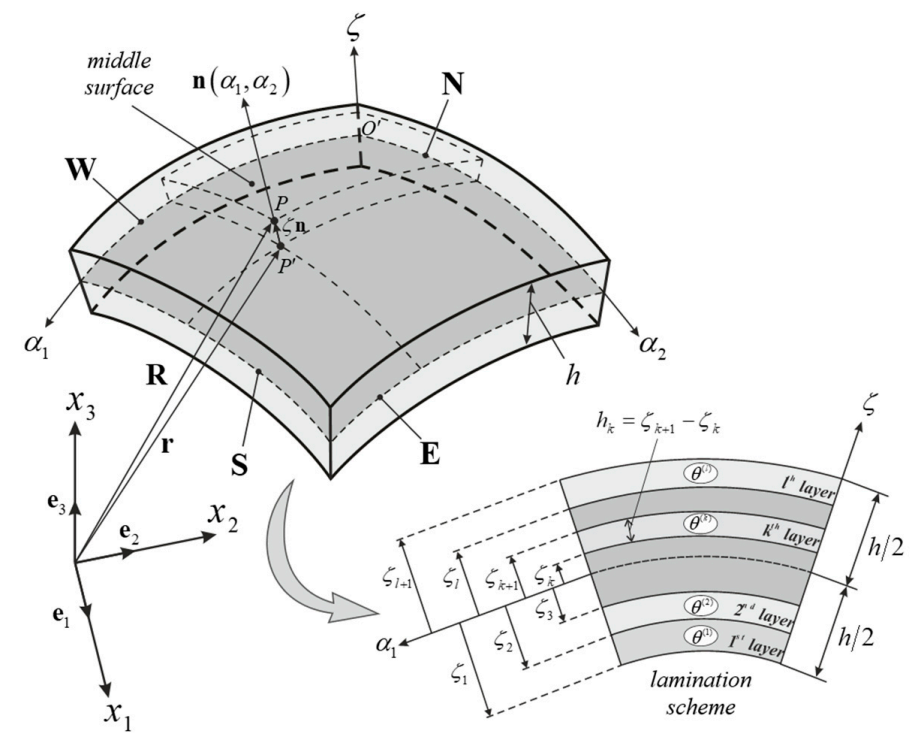

Figure 1. Doubly-curved panel representation and lamination scheme.

With the defined position vector $\mathbf{r}\left(\alpha_{1}, \alpha_{2}\right)$, the Lamé parameters $A_{1}\left(\alpha_{1}, \alpha_{2}\right)$ and $A_{2}\left(\alpha_{1}, \alpha_{2}\right)$ of the surface can be computed as

$$
A_{1}=\sqrt{\mathbf{r}_{1} \cdot \mathbf{r}, 1}, \quad A_{2}=\sqrt{\mathbf{r}_{, 2} \cdot \mathbf{r}_{, 2}}
$$

where the symbol "." denotes the scalar product. Radii of curvature $R_{1}\left(\alpha_{1}, \alpha_{2}\right)$ and $R_{2}\left(\alpha_{1}, \alpha_{2}\right)$ of the doubly-curved reference surface, due to the hypothesis of orthogonal and principal coordinates, can be evaluated as follows

$$
R_{1}=-\frac{\mathbf{r}_{1,1} \cdot \mathbf{r}_{1}}{\mathbf{r}_{, 11} \cdot \mathbf{n}}, \quad R_{2}=-\frac{\mathbf{r}_{2,2} \cdot \mathbf{r}_{, 2}}{\mathbf{r}_{, 22} \cdot \mathbf{n}}
$$


with the notation $\mathbf{r}_{, i i}=\partial^{2} \mathbf{r} / \partial \alpha_{i}^{2}$, for $i=1,2$. The parameters $H_{1}\left(\alpha_{1}, \alpha_{2}, \zeta\right)$ and $H_{2}\left(\alpha_{1}, \alpha_{2}, \zeta\right)$, which must be introduced to consider the three-dimensional size effect of the structure, are evaluated by

$$
H_{1}=1+\frac{\zeta}{R_{1}}, \quad H_{2}=1+\frac{\zeta}{R_{2}}
$$

\subsection{Shell Formulation}

The three-dimensional displacement field of the laminated composite shell can be expressed by the Carrera Unified Formulation (CUF), which was conceived to study the structural response of beams and plates. The displacement components, according to a general higher-order Equivalent Single Layer (ESL) approach, are given by

$$
\begin{aligned}
& U_{1}\left(\alpha_{1}, \alpha_{2}, \zeta, t\right)=\sum_{\tau=0}^{N+1} F_{\tau}(\zeta) u_{1}^{(\tau)}\left(\alpha_{1}, \alpha_{2}, t\right) \\
& U_{2}\left(\alpha_{1}, \alpha_{2}, \zeta, t\right)=\sum_{\tau=0}^{N+1} F_{\tau}(\zeta) u_{2}^{(\tau)}\left(\alpha_{1}, \alpha_{2}, t\right) \\
& U_{3}\left(\alpha_{1}, \alpha_{2}, \zeta, t\right)=\sum_{\tau=0}^{N+1} F_{\tau}(\zeta) u_{3}^{(\tau)}\left(\alpha_{1}, \alpha_{2}, t\right)
\end{aligned}
$$

where $U_{1}, U_{2}, U_{3}$ are the three-dimensional displacements; $F_{\tau}$ represents the thickness or the shear functions and $\tau=0,1,2, \ldots, N, N+1$ stands for the order of kinematic expansion; $u_{1}^{(\tau)}, u_{2}^{(\tau)}, u_{3}^{(\tau)}$ are the generalized displacement components or degrees of freedom of the problem. The thickness functions can be chosen freely or according to the functions listed in the book [99]. In this paper, the thickness functions are given by the power function $F_{\tau}=\zeta^{\tau}$ for $\tau=0,1,2, \ldots, N$. The last order of expansion or the $(N+1)$-th order is related to the Murakami's function, by which the so-called zig-zag effect can be captured. More details about the zig-zag effect and the Murakami's function can be found in $[96,97]$. The Murakami's function $Z=Z(\zeta)$ is defined as

$$
\mathrm{Z}=(-1)^{k}\left(\frac{2}{\zeta_{k+1}-\zeta_{k}} \zeta-\frac{\zeta_{k+1}+\zeta_{k}}{\zeta_{k+1}-\zeta_{k}}\right)
$$

where $\zeta_{k}$ and $\zeta_{k+1}$ represent, respectively, the bottom and the top coordinates of the $k$-th layer along the thickness direction, as shown in Figure 1. By varying the maximum order of kinematic expansion $N$, one can obtain different shear deformation theories. For easier denotation of these theories, the acronyms EDN and EDZN are introduced, where "E" stands for the ESL approach, " $\mathrm{D}$ " denotes the use of generalized displacement, and the letter " $\mathrm{Z}$ ", if present, denotes the use of the Murakami's function.

Once the displacement field (9) is set, the generalized strains evaluated on the shell middle surface can be computed as follows

$$
\mathcal{\varepsilon}^{(\tau)}=\mathbf{D}_{\Omega} \mathbf{u}^{(\tau)}
$$

in which vector $\mathbf{u}^{(\tau)}=\mathbf{u}^{(\tau)}\left(\alpha_{1}, \alpha_{2}, t\right)$ collects generalized displacement components as

$$
\mathbf{u}^{(\tau)}=\left[\begin{array}{lll}
u_{1}^{(\tau)} & u_{2}^{(\tau)} & u_{3}^{(\tau)}
\end{array}\right]^{T}
$$

Also, the kinematic operator $\mathbf{D}_{\Omega}$ takes the following form

$$
\mathbf{D}_{\Omega}=\left[\begin{array}{ccccccccc}
\frac{1}{A_{1}} \frac{\partial}{\partial \alpha_{1}} & \frac{1}{A_{1} A_{2}} \frac{\partial A_{2}}{\partial \alpha_{1}} & -\frac{1}{A_{1} A_{2}} \frac{\partial A_{1}}{\partial \alpha_{2}} & \frac{1}{A_{2}} \frac{\partial}{\partial \alpha_{2}} & -\frac{1}{R_{1}} & 0 & 1 & 0 & 0 \\
\frac{1}{A_{1} A_{2}} \frac{\partial A_{1}}{\partial \alpha_{2}} & \frac{1}{A_{2}} \frac{\partial}{\partial \alpha_{2}} & \frac{1}{A_{1}} \frac{\partial}{\partial \alpha_{1}} & -\frac{1}{A_{1} A_{2}} \frac{\partial A_{2}}{\partial \alpha_{1}} & 0 & -\frac{1}{R_{2}} & 0 & 1 & 0 \\
\frac{1}{R_{1}} & \frac{1}{R_{2}} & 0 & 0 & \frac{1}{A_{1}} \frac{\partial}{\partial \alpha_{1}} & \frac{1}{A_{2}} \frac{\partial}{\partial \alpha_{2}} & 0 & 0 & 1
\end{array}\right]^{T}
$$


All of the strains are collected in the algebraic vector $\varepsilon^{(\tau)}=\varepsilon^{(\tau)}\left(\alpha_{1}, \alpha_{2}, t\right)$, defined as

$$
\boldsymbol{\varepsilon}^{(\tau)}=\left[\begin{array}{lllllllll}
\varepsilon_{1}^{(\tau)} & \varepsilon_{2}^{(\tau)} & \gamma_{1}^{(\tau)} & \gamma_{2}^{(\tau)} & \gamma_{13}^{(\tau)} & \gamma_{23}^{(\tau)} & \omega_{13}^{(\tau)} & \omega_{23}^{(\tau)} & \varepsilon_{3}^{(\tau)}
\end{array}\right]^{T}
$$

The relation between three-dimensional strain components collected in $\varepsilon=\varepsilon\left(\alpha_{1}, \alpha_{2}, \zeta, t\right)$ and generalized strains (14) can be expressed as follows

$$
\mathcal{\varepsilon}=\sum_{\tau=0}^{N+1} \mathbf{Z}^{(\tau)} \boldsymbol{\varepsilon}^{(\tau)}
$$

where $\varepsilon$ is described as

$$
\varepsilon=\left[\begin{array}{llllll}
\varepsilon_{1} & \varepsilon_{2} & \gamma_{12} & \gamma_{1 n} & \gamma_{2 n} & \varepsilon_{n}
\end{array}\right]^{T}
$$

It should be specified that the subscript $n$ in (16) denotes those strain components that involve the direction perpendicular to the shell middle surface. The matrix $\mathbf{Z}^{(\tau)}$ is described, for each order of kinematic expansion $\tau$, as follows

$$
\mathbf{Z}^{(\tau)}=\left[\begin{array}{ccccccccc}
\frac{F_{\tau}}{H_{1}} & 0 & 0 & 0 & 0 & 0 & 0 & 0 & 0 \\
0 & \frac{F_{\tau}}{H_{2}} & 0 & 0 & 0 & 0 & 0 & 0 & 0 \\
0 & 0 & \frac{F_{\tau}}{H_{1}} & \frac{F_{\tau}}{H_{2}} & 0 & 0 & 0 & 0 & 0 \\
0 & 0 & 0 & 0 & \frac{F_{\tau}}{H_{1}} & 0 & \frac{\partial F_{\tau}}{\partial \zeta} & 0 & 0 \\
0 & 0 & 0 & 0 & 0 & \frac{F_{\tau}}{H_{2}} & 0 & \frac{\partial F_{\tau}}{\partial \zeta} & 0 \\
0 & 0 & 0 & 0 & 0 & 0 & 0 & 0 & \frac{\partial F_{\tau}}{\partial \zeta}
\end{array}\right]
$$

The stress results for each order $\tau$ of kinematic expansion can be calculated over the generalized strains (11) as

$$
\mathbf{S}^{(\tau)}=\sum_{\eta=0}^{N+1} \mathbf{A}^{(\tau \eta)} \boldsymbol{\varepsilon}^{(\eta)}
$$

where the algebraic vector $\mathbf{S}^{(\tau)}=\mathbf{S}^{(\tau)}\left(\alpha_{1}, \alpha_{2}, t\right)$ is taken as

$$
\mathbf{S}^{(\tau)}=\left[\begin{array}{lllllllll}
N_{1}^{(\tau)} & N_{2}^{(\tau)} & N_{12}^{(\tau)} & N_{21}^{(\tau)} & T_{1}^{(\tau)} & T_{2}^{(\tau)} & P_{1}^{(\tau)} & P_{2}^{(\tau)} & S_{3}^{(\tau)}
\end{array}\right]^{T}
$$

The constitutive operator $\mathbf{A}^{(\tau \eta)}$ is defined as follows

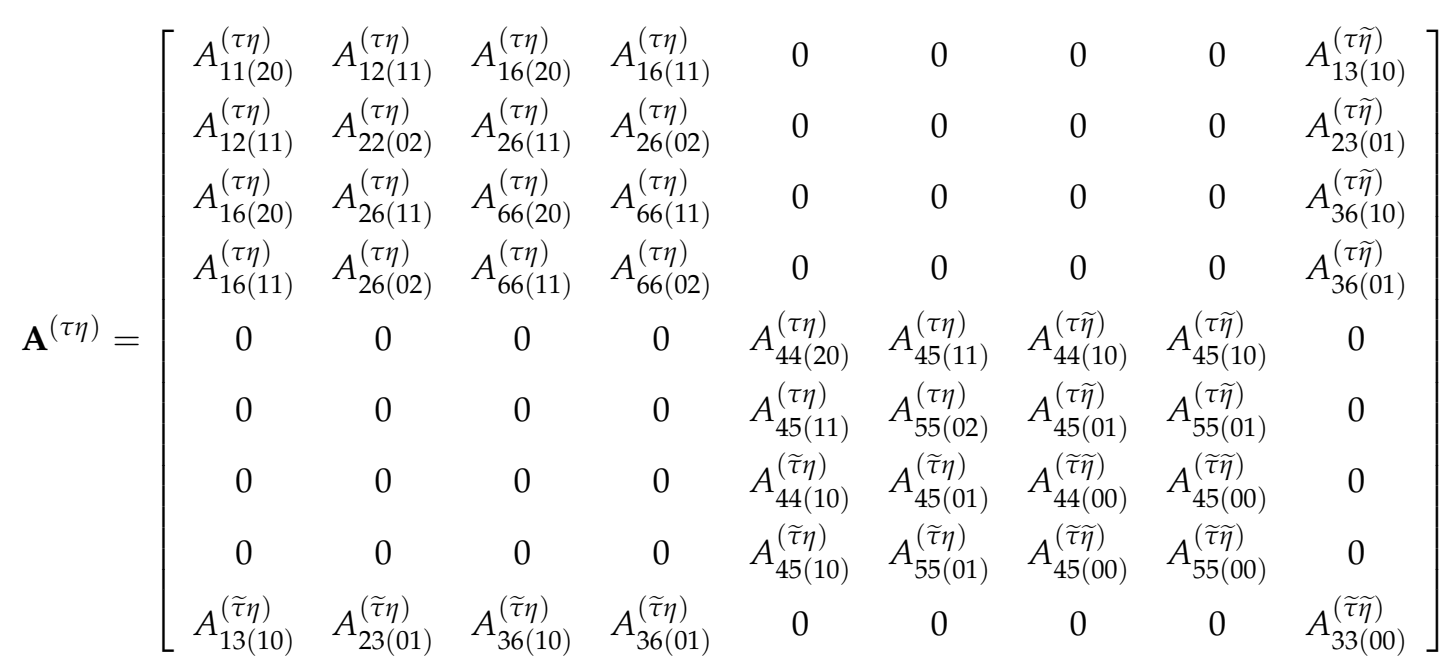


where the elastic constant in (20) can be evaluated according to the following expressions

$$
\begin{aligned}
& A_{n m(p q)}^{(\tau \eta)}=\sum_{k=1}^{l} \int_{\zeta_{k}}^{\zeta_{k+1}} \bar{B}_{n m}^{(k)} F_{\eta} F_{\tau} \frac{H_{1} H_{2}}{H_{1}^{p} H_{2}^{q}} d \zeta \\
& A_{n m(p q)}^{(\widetilde{\tau} \eta)}=\sum_{k=1}^{l} \int_{\zeta_{k}}^{\zeta_{k+1}} \bar{B}_{n m}^{(k)} F_{\eta} \frac{\partial F_{\tau}}{\partial \zeta} \frac{H_{1} H_{2}}{H_{1}^{p} H_{2}^{q}} d \zeta \\
& A_{n m(p q)}^{(\tau \widetilde{\eta})}=\sum_{k=1}^{l} \int_{\zeta_{k}}^{\zeta_{k+1}} \bar{B}_{n m}^{(k)} \frac{\partial F_{\eta}}{\partial \zeta} F_{\tau} \frac{H_{1} H_{2}}{H_{1}^{p} H_{2}^{q}} d \zeta \\
& A_{n m(p q)}^{(\widetilde{\tau} \widetilde{\eta})}=\sum_{k=1}^{l} \int_{\zeta_{k}}^{\zeta_{k+1}} \bar{B}_{n m}^{(k)} \frac{\partial F_{\eta}}{\partial \zeta} \frac{\partial F_{\tau}}{\partial \zeta} \frac{H_{1} H_{2}}{H_{1}^{p} H_{2}^{q}} d \zeta
\end{aligned}
$$

for $\tau, \eta=0,1,2, \ldots, N, N+1, n, m=1,2,3,4,5,6$, and $p, q=0,1,2$. The superscripts $\eta, \tau$ on the left-hand side of (21) denote the use of the corresponding thickness functions $F_{\eta}, F_{\tau}$, where the tilde denotes that the derivative of the corresponding thickness function with respect to $\zeta$ has been used. Due to the dependence of all the quantities $F_{\eta}, F_{\tau}, H_{1}, H_{2}$ in (21) on the thickness coordinate $\zeta$, the numerical method must be introduced to solve the problem. The notation $\bar{B}_{n m}^{(k)}$ is related to the elastic constants of the material $\bar{C}_{n m}^{(k)}$ as follows

$$
\begin{gathered}
\bar{B}_{n m}^{(k)}=\bar{C}_{n m}^{(k)} \quad \text { for } \quad n, m=1,2,3,6 \\
\bar{B}_{n m}^{(k)}=\kappa \bar{C}_{n m}^{(k)} \quad \text { for } \quad n, m=4,5
\end{gathered}
$$

where $\kappa$ is the shear correction factor, the value of which will be specified in the notation representative of the structural model through a proper superscript. This model assumes that each layer of the laminated composite is made of linearly elastic and homogenous materials. The plies are perfectly joined together, and both orthotropic and isotropic mediums can be taken into account. It should be recalled that the elastic constants $\bar{C}_{n m}^{(k)}$ are evaluated in the geometric reference system $O^{\prime} \alpha_{1} \alpha_{2} \zeta$ through proper transformations that take into account the orientation of the material $[46,99]$. If the $k$-th layer is orthotropic, the stress-strain relation is given as

$$
\left[\begin{array}{c}
\sigma_{1}^{(k)} \\
\sigma_{2}^{(k)} \\
\tau_{12}^{(k)} \\
\tau_{1 n}^{(k)} \\
\tau_{2 n}^{(k)} \\
\sigma_{n}^{(k)}
\end{array}\right]=\left[\begin{array}{cccccc}
\bar{C}_{11}^{(k)} & \bar{C}_{12}^{(k)} & \bar{C}_{16}^{(k)} & 0 & 0 & \bar{C}_{13}^{(k)} \\
\bar{C}_{12}^{(k)} & \bar{C}_{22}^{(k)} & \bar{C}_{26}^{(k)} & 0 & 0 & \bar{C}_{23}^{(k)} \\
\bar{C}_{16}^{(k)} & \bar{C}_{26}^{(k)} & \bar{C}_{66}^{(k)} & 0 & 0 & \bar{C}_{36}^{(k)} \\
0 & 0 & 0 & \bar{C}_{44}^{(k)} & \bar{C}_{45}^{(k)} & 0 \\
0 & 0 & 0 & \bar{C}_{45}^{(k)} & \bar{C}_{55}^{(k)} & 0 \\
\bar{C}_{13}^{(k)} & \bar{C}_{23}^{(k)} & \bar{C}_{36}^{(k)} & 0 & 0 & \bar{C}_{33}^{(k)}
\end{array}\right]\left[\begin{array}{c}
\varepsilon_{1}^{(k)} \\
\varepsilon_{2}^{(k)} \\
\gamma_{12}^{(k)} \\
\gamma_{1 n}^{(k)} \\
\gamma_{2 n}^{(k)} \\
\varepsilon_{n}^{(k)}
\end{array}\right]
$$

in which the elastic constants $\bar{C}_{n m}^{(k)}$ can be related to the nine independent engineering constants of the material- $E_{1}^{(k)}, E_{2}^{(k)}, E_{3}^{(k)}, G_{12}^{(k)}, G_{13}^{(k)}, G_{23}^{(k)}, v_{12}^{(k)}, v_{13}^{(k)}, v_{23}^{(k)}$-as specified in the book by Tornabene et al. [99]. It should be recalled that the hypothesis of plane stress is needed in lower-order theories, such as the Reissner-Mindlin theory or First-order Shear Deformation Theory (FSDT). When needed, the reduced elastic coefficients $\bar{Q}_{n m}^{(k)}$ are used. The meaning of these coefficients is explained in detail in [99].

On the other hand, the elastic foundation, studied in this paper, is approximated by applying uniformly distributed springs at the top and/or bottom surfaces of the shell (Figure 2). The stiffnesses 
of the springs are denoted by $k_{1 f}^{( \pm)}, k_{2 f}^{( \pm)}$, and $k_{3 f}^{( \pm)}$along the three coordinate directions $\alpha_{1}, \alpha_{2}$, and $\zeta$, respectively. Superscripts $(+)$ or $(-)$ denote that these springs are located on the top or the bottom surface of the shell, respectively. The elastic foundation is modeled according to the Winkler-Pasternak elastic foundation theory. In this paper, only the elastic foundations with the uniform thickness $h_{f}^{( \pm)}$ are considered. Further information about this theory can be found in the papers $[126-128,135]$ and in the book [99]. Forces produced by the springs along the three coordinate directions can be written in the form of generalized external load vector of the foundation $\mathbf{q}_{f}^{(\tau)}$ as

$$
\mathbf{q}_{f}^{(\tau)}=-\sum_{\eta=0}^{N+1} \mathbf{L}_{f}^{(\tau \eta)} \mathbf{u}^{(\eta)}-\sum_{\eta=0}^{N+1} \mathbf{M}_{f}^{(\tau \eta)} \ddot{\mathbf{u}}^{(\eta)}
$$

for $\tau=0,1,2, \ldots, N, N+1$, where the operators $\mathbf{L}_{f}^{(\tau \eta)}$ and $\mathbf{M}_{f}^{(\tau \eta)}$ are the stiffness matrix and inertia matrix, respectively, of the linear elastic foundation. Vector $\ddot{\mathbf{u}}^{(\tau)}=\ddot{\mathbf{u}}^{(\tau)}\left(\alpha_{1}, \alpha_{2}, t\right)$ collects the generalized acceleration components that correspond to the generalized displacements

$$
\ddot{\mathbf{u}}^{(\tau)}=\left[\begin{array}{lll}
\ddot{u}_{1}^{(\tau)} & \ddot{u}_{2}^{(\tau)} & \ddot{u}_{3}^{(\tau)}
\end{array}\right]^{T}
$$

The operator $\mathbf{L}_{f}^{(\tau \eta)}$ takes the following form

$$
\mathbf{L}_{f}^{(\tau \eta)}=\left[\begin{array}{ccc}
L_{f 1}^{(\tau \eta) \alpha_{1}} & 0 & 0 \\
0 & L_{f 2}^{(\tau \eta) \alpha_{2}} & 0 \\
0 & 0 & L_{f 3}^{(\tau \eta) \alpha_{3}}
\end{array}\right]
$$

with the quantities $L_{f 1}^{(\tau \eta) \alpha_{1}}, L_{f 2}^{(\tau \eta) \alpha_{2}}, L_{f 3}^{(\tau \eta) \alpha_{3}}$ defined as follows

$$
\begin{aligned}
& L_{f 1}^{(\tau \eta) \alpha_{1}}=k_{1 f}^{(-)} F_{\eta}^{\alpha_{1}(-)} F_{\tau}^{\alpha_{1}(-)} H_{1}^{(-)} H_{2}^{(-)}+k_{1 f}^{(+)} F_{\eta}^{\alpha_{1}(+)} F_{\tau}^{\alpha_{1}(+)} H_{1}^{(+)} H_{2}^{(+)} \\
& L_{f 2}^{(\tau \eta) \alpha_{2}}=k_{2 f}^{(-)} F_{\eta}^{\alpha_{2}(-)} F_{\tau}^{\alpha_{2}(-)} H_{1}^{(-)} H_{2}^{(-)}+k_{2 f}^{(+)} F_{\eta}^{\alpha_{2}(+)} F_{\tau}^{\alpha_{2}(+)} H_{1}^{(+)} H_{2}^{(+)} \\
& L_{f 3}^{(\tau \eta) \alpha_{3}}=\left(k_{3 f}^{(-)}-G_{f}^{(-)} \nabla_{(-)}^{2}\right) F_{\eta}^{\alpha_{3}(-)} F_{\tau}^{\alpha_{3}(-)} H_{1}^{(-)} H_{2}^{(-)}+\left(k_{3 f}^{(+)}-G_{f}^{(+)} \nabla_{(+)}^{2}\right) F_{\eta}^{\alpha_{3}(+)} F_{\tau}^{\alpha_{3}(+)} H_{1}^{(+)} H_{2}^{(+)}
\end{aligned}
$$

where $\nabla_{( \pm)}^{2}$ represents the Laplacian operator in curvilinear orthogonal coordinates applied at the top or the bottom surfaces of the shell defined below

$$
\begin{aligned}
& \nabla_{( \pm)}^{2}=\left(\frac{1}{A_{1}^{2}\left(H_{1}^{( \pm)}\right)^{2}} \frac{\partial^{2}}{\partial \alpha_{1}^{2}}+\frac{1}{A_{2}^{2}\left(H_{2}^{( \pm)}\right)^{2}} \frac{\partial^{2}}{\partial \alpha_{2}^{2}}+\left(\frac{1}{A_{1}^{2} A_{2}\left(H_{1}^{( \pm)}\right)^{2}} \frac{\partial A_{2}}{\partial \alpha_{1}}-\frac{h}{2 A_{1}^{2} R_{2}^{2}\left(H_{1}^{( \pm)}\right)^{2} H_{2}^{( \pm)}} \frac{\partial R_{2}}{\partial \alpha_{1}}+\right.\right. \\
& \left.-\frac{1}{A_{1}^{3}\left(H_{1}^{( \pm)}\right)^{2}} \frac{\partial A_{1}}{\partial \alpha_{1}}+\frac{h}{2 A_{1}^{2} R_{1}^{2}\left(H_{1}^{( \pm)}\right)^{3}} \frac{\partial R_{1}}{\partial \alpha_{1}}\right) \frac{\partial}{\partial \alpha_{1}}+\left(\frac{1}{A_{1} A_{2}^{2}\left(H_{2}^{( \pm)}\right)^{2}} \frac{\partial A_{1}}{\partial \alpha_{2}}-\frac{h}{2 A_{2}^{2} R_{1}^{2}\left(H_{2}^{( \pm)}\right)^{2} H_{1}^{( \pm)}} \frac{\partial R_{1}}{\partial \alpha_{2}}+\right. \\
& \left.\left.-\frac{1}{A_{2}^{3}\left(H_{2}^{( \pm)}\right)^{2}} \frac{\partial A_{2}}{\partial \alpha_{2}}+\frac{h}{2 A_{2}^{2} R_{2}^{2}\left(H_{2}^{( \pm)}\right)^{3}} \frac{\partial R_{2}}{\partial \alpha_{2}}\right) \frac{\partial}{\partial \alpha_{2}}\right)
\end{aligned}
$$

where

$$
H_{1}^{( \pm)}=1 \pm \frac{h}{2 R_{1}}, \quad H_{2}^{( \pm)}=1+\frac{h}{2 R_{2}}
$$


The quantity $G_{f}^{( \pm)}$is the shear modulus of the elastic foundation, according to the Pasternak model. On the other hand, the operator $\mathbf{M}_{f}^{(\tau \eta)}$ is defined as

$$
\mathbf{M}_{f}^{(\tau \eta)}=\left[\begin{array}{ccc}
I_{f 1}^{(\tau \eta) \alpha_{1}} & 0 & 0 \\
0 & I_{f 2}^{(\tau \eta) \alpha_{2}} & 0 \\
0 & 0 & I_{f 3}^{(\tau \eta) \alpha_{3}}
\end{array}\right]
$$

with the foundation inertial components $I_{f 1}^{(\tau \eta) \alpha_{1}}, I_{f 2}^{(\tau \eta) \alpha_{2}}, I_{f 3}^{(\tau \eta) \alpha_{3}}$ defined as follows

$$
\begin{aligned}
I_{f 1}^{(\tau \eta) \alpha_{1}} & =\frac{1}{3} \rho_{f}^{(-)} h_{f}^{(-)} F_{\eta}^{\alpha_{1}(-)} F_{\tau}^{\alpha_{1}(-)} H_{1}^{(-)} H_{2}^{(-)}+\frac{1}{3} \rho_{f}^{(+)} h_{f}^{(+)} F_{\eta}^{\alpha_{1}(+)} F_{\tau}^{\alpha_{1}(+)} H_{1}^{(+)} H_{2}^{(+)} \\
I_{f 2}^{(\tau \eta) \alpha_{2}} & =\frac{1}{3} \rho_{f}^{(-)} h_{f}^{(-)} F_{\eta}^{\alpha_{2}(-)} F_{\tau}^{\alpha_{2}(-)} H_{1}^{(-)} H_{2}^{(-)}+\frac{1}{3} \rho_{f}^{(+)} h_{f}^{(+)} F_{\eta}^{\alpha_{2}(+)} F_{\tau}^{\alpha_{2}(+)} H_{1}^{(+)} H_{2}^{(+)} \\
I_{f 3}^{(\tau \eta) \alpha_{3}} & =\frac{1}{3} \rho_{f}^{(-)} h_{f}^{(-)} F_{\eta}^{\alpha_{3}(-)} F_{\tau}^{\alpha_{3}(-)} H_{1}^{(-)} H_{2}^{(-)}+\frac{1}{3} \rho_{f}^{(+)} h_{f}^{(+)} F_{\eta}^{\alpha_{3}(+)} F_{\tau}^{\alpha_{3}(+)} H_{1}^{(+)} H_{2}^{(+)}
\end{aligned}
$$

where $\rho_{f}^{( \pm)}$is the density of the elastic foundation.

Finally, the equations of motion and the corresponding boundary conditions are deduced [99]. For each order $\tau$ of kinematic expansion, the three equations of motion can be written in matrix form as follows

$$
\mathbf{D}_{\Omega}^{*} \mathbf{S}^{(\tau)}+\mathbf{q}_{f}^{(\tau)}=\sum_{\eta=0}^{N+1} \mathbf{M}^{(\tau \eta)} \ddot{\mathbf{u}}^{(\eta)}
$$

in which $\mathbf{D}_{\Omega}^{*}$ represents the equilibrium differential operator defined as

$$
\mathbf{D}_{\Omega}^{*}=\left[\begin{array}{ccc}
\frac{1}{A_{1}} \frac{\partial}{\partial \alpha_{1}}+\frac{1}{A_{1} A_{2}} \frac{\partial A_{2}}{\partial \alpha_{1}} & -\frac{1}{A_{1} A_{2}} \frac{\partial A_{1}}{\partial \alpha_{2}} & -\frac{1}{R_{1}} \\
-\frac{1}{A_{1} A_{2}} \frac{\partial A_{2}}{\partial \alpha_{1}} & \frac{1}{A_{2}} \frac{\partial}{\partial \alpha_{2}}+\frac{1}{A_{1} A_{2}} \frac{\partial A_{1}}{\partial \alpha_{2}} & -\frac{1}{R_{2}} \\
\frac{1}{A_{1} A_{2}} \frac{\partial A_{1}}{\partial \alpha_{2}} & \frac{1}{A_{1}} \frac{\partial}{\partial \alpha_{1}}+\frac{1}{A_{1} A_{2}} \frac{\partial A_{2}}{\partial \alpha_{1}} & 0 \\
\frac{1}{A_{2}} \frac{\partial}{\partial \alpha_{2}}+\frac{1}{A_{1} A_{2}} \frac{\partial A_{1}}{\partial \alpha_{2}} & \frac{1}{A_{1} A_{2}} \frac{\partial A_{2}}{\partial \alpha_{1}} & 0 \\
\frac{1}{R_{1}} & 0 & \frac{1}{A_{1}} \frac{\partial}{\partial \alpha_{1}}+\frac{1}{A_{1} A_{2}} \frac{\partial A_{2}}{\partial \alpha_{1}} \\
0 & \frac{1}{R_{2}} & \frac{1}{A_{2}} \frac{\partial}{\partial \alpha_{2}}+\frac{1}{A_{1} A_{2}} \frac{\partial A_{1}}{\partial \alpha_{2}} \\
-1 & 0 & 0 \\
0 & -1 & -1
\end{array}\right]
$$

The inertia matrix $\mathbf{M}^{(\tau \eta)}$ is defined as follows, for $\tau, \eta=0,1,2, \ldots, N, N+1$

$$
\mathbf{M}^{(\tau \eta)}=\left[\begin{array}{ccc}
I^{(\tau \eta)} & 0 & 0 \\
0 & I^{(\tau \eta)} & 0 \\
0 & 0 & I^{(\tau \eta)}
\end{array}\right]
$$


where the inertia terms $I^{(\tau \eta)}$ are evaluated for $\tau, \eta=0,1,2, \ldots, N, N+1$ once the mass density $\rho^{(k)}$ of the $k$-th layer is introduced

$$
I^{(\tau \eta)}=\sum_{k=1}^{l} \int_{\zeta_{k}}^{\zeta_{k+1}} \rho^{(k)} F_{\tau} F_{\eta} H_{1} H_{2} d \zeta
$$

All the results are summarized in the fundamental system of equations with the size of $3 \times(N+2)$ equilibrium equations, in which, for each order $\tau=0,1,2, \ldots, N, N+1$ of kinematic expansion, the compact form is written as follows

$$
\sum_{\eta=0}^{N+1}\left(\mathbf{L}^{(\tau \eta)}-\mathbf{L}_{f}^{(\tau \eta)}\right) \mathbf{u}^{(\eta)}=\sum_{\eta=0}^{N+1}\left(\mathbf{M}^{(\tau \eta)}+\mathbf{M}_{f}^{(\tau \eta)}\right) \ddot{\mathbf{u}}^{(\eta)}
$$

where the fundamental operator $\mathbf{L}^{(\tau \eta)}=\mathbf{D}_{\Omega}^{*} \mathbf{A}^{(\tau \eta)} \mathbf{D}_{\Omega}$ is a $3 \times 3$ matrix defined as shown below

$$
\mathbf{L}^{(\tau \eta)}=\left[\begin{array}{ccc}
L_{11}^{(\tau \eta)} & L_{12}^{(\tau \eta)} & L_{13}^{(\tau \eta)} \\
L_{21}^{(\tau \eta)} & L_{22}^{(\tau \eta)} & L_{23}^{(\tau \eta)} \\
L_{31}^{(\tau \eta)} & L_{32}^{(\tau \eta)} & L_{33}^{(\tau \eta)}
\end{array}\right]
$$

The explicit definitions of the term $L_{f g}^{(\tau \eta)}$, for $f, g=1,2,3$ can be found in the book by Tornabene et al. [99]. To solve the elastic problem at hand, the proper boundary conditions must be enforced for each order of kinematic expansion $\tau=0,1,2, \ldots, N, N+1$. In this work, only the restrains of the whole edge are considered as completely clamped (C), simply-supported (S) or free (F). If the edge is identified by $\alpha_{1}=\alpha_{1}^{0}$ or $\alpha_{1}=\alpha_{1}^{1}$, for $\alpha_{2}^{0} \leq \alpha_{2} \leq \alpha_{2}^{1}$, one gets:

$$
\begin{aligned}
& \mathrm{C} \quad \rightarrow \quad u_{1}^{(\tau)}=u_{2}^{(\tau)}=u_{3}^{(\tau)}=0 \\
& \mathrm{~S} \quad \rightarrow \quad N_{1}^{(\tau)}=0, u_{2}^{(\tau)}=u_{3}^{(\tau)}=0 \\
& \mathrm{~F} \quad \rightarrow \quad N_{1}^{(\tau)}=N_{12}^{(\tau)}=T_{1}^{(\tau)}=0
\end{aligned}
$$

On the other hand, if the edge is characterized by $\alpha_{2}=\alpha_{2}^{0}$ or $\alpha_{2}=\alpha_{2}^{1}$, for $\alpha_{1}^{0} \leq \alpha_{1} \leq \alpha_{1}^{1}$, the following conditions are obtained

$$
\begin{aligned}
& \mathrm{C} \quad \rightarrow \quad u_{1}^{(\tau)}=u_{2}^{(\tau)}=u_{3}^{(\tau)}=0 \\
& \mathrm{~S} \quad \rightarrow \quad N_{2}^{(\tau)}=0, \quad u_{1}^{(\tau)}=u_{3}^{(\tau)}=0 \\
& \mathrm{~F} \quad \rightarrow \quad N_{21}^{(\tau)}=N_{2}^{(\tau)}=T_{2}^{(\tau)}=0
\end{aligned}
$$

To generalize the boundary conditions applied, the notation XXXX is introduced, where $\mathrm{X}$ is replaced either with $C$ (clamped), $\mathrm{S}$ (simply-supported) or $\mathrm{F}$ (free). The edges are referred in the sequence WSEN, where each edge is denoted by the following coordinates

$$
\begin{array}{lll}
\text { West edge }(\mathrm{W}) & \rightarrow & \alpha_{1}^{0} \leq \alpha_{1} \leq \alpha_{1}^{1}, \alpha_{2}=\alpha_{2}^{0} \\
\text { South edge (S) } & \rightarrow & \alpha_{1}=\alpha_{1}^{1}, \alpha_{2}^{0} \leq \alpha_{2} \leq \alpha_{2}^{1} \\
\text { East edge (E) } & \rightarrow & \alpha_{1}^{0} \leq \alpha_{1} \leq \alpha_{1}^{1}, \alpha_{2}=\alpha_{2}^{1} \\
\text { North edge (N) } & \rightarrow & \alpha_{1}=\alpha_{1}^{0}, \alpha_{2}^{0} \leq \alpha_{2} \leq \alpha_{2}^{1}
\end{array}
$$


So, the boundary conditions noted as CCFF mean that the West and the South edges are clamped and the last two edges are free.

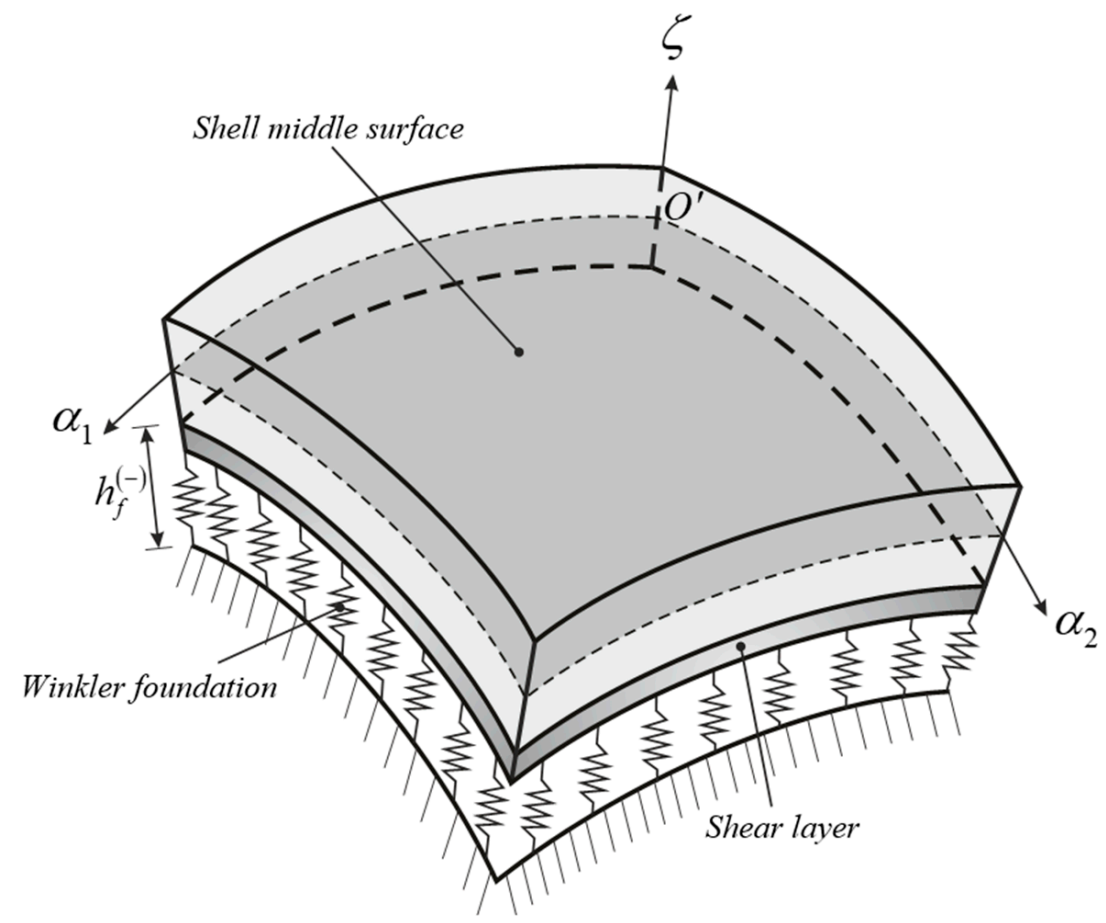

Figure 2. Doubly-curved panel representation and description.

\subsection{Functionally Graded Carbon Nanotube Reinforced Composite Structures}

The characteristic shape of CNTs is one of the main factors that causes the agglomeration of these particles when scattered in a polymer matrix [24-27,32]. Thus, in some regions of the Carbon Nanotube-reinforced ply, the concentration of CNTs is higher than the average volume fraction in the ply itself. According to the micromechanical model presented by Shi et al. [32], these areas can be assumed to be spherically shaped inclusions with different elastic properties from the surrounding matrix, as depicted in Figure 3a. Therefore, CNTs are contained both in the matrix and in the spherical inclusions. The overall volume of the lamina $W$ is given by the following relation

$$
W=W_{r}+W_{m}
$$

in which $W_{m}$ is the volume of the matrix. $W_{r}$ denotes the volume of CNTs embedded in the lamina, which can be further separated as

$$
W_{r}=W_{r}^{i n}+W_{r}^{m}
$$

where $W_{r}^{i n}$ and $W_{r}^{m}$ indicate the volume of CNTs scattered in the inclusions and in the matrix, respectively. The mass fraction of $\mathrm{CNTs}, w_{r}$, and of the matrix, $w_{m}$, can be expressed by the theory of mixture as

$$
w_{r}=\frac{M_{r}}{M_{r}+M_{m}}, \quad w_{m}=\frac{M_{m}}{M_{r}+M_{m}}
$$

Analogously, the volume fraction can be expressed as

$$
V_{r}=\frac{W_{r}}{W}, \quad V_{m}=\frac{W_{m}}{W}
$$

In which the relation $V_{r}+V_{m}=1$ must hold. In this paper, Functionally Graded Carbon Nanotube (FG-CNT)-reinforced composite is considered. This term specifies a structure with the reinforcing 
phase made of CNTs, which has a gradual distribution along the thickness direction. Further on, if the FG-CNT-reinforced composite is to be considered, the volume fraction of CNTs $V_{r}$ can be characterized by a continuous gradual variation from the bottom to the top surface of the lamina assuming

$$
V_{r}(\zeta)=V_{r}^{*} V_{C}(\zeta)
$$

where $V_{r}^{*}$ is the CNT volume fraction value and $V_{C}(\zeta)$ is through-the-thickness distribution. Depending on the CNT mass fraction $w_{r}$ and on the density of both CNT $\rho_{r}$ and the matrix $\rho_{m}$, CNT volume fraction value $V_{r}^{*}$ is given as

$$
V_{r}^{*}=\left(\frac{\rho_{r}}{w_{r} \rho_{m}}-\frac{\rho_{r}}{\rho_{m}}+1\right)^{-1}
$$

On the other hand, the function $V_{C}(\zeta)$ introduced in (45) can be defined by various distributions as described in $[75,83]$. The superscript $k$ will be introduced in the following to specify that the through-the-thickness distribution $V_{C}(\zeta)$ should be defined for each layer, when laminated configurations are analyzed. In other words, the quantity at hand will be indicated as $V_{C}^{(k)}(\zeta)$. In this paper, the five-parameter exponential law (5P), two-parameter exponential (2P-E) and two-parameter Weibull (2P-W) functions are considered. To describe through the thickness CNTs distribution the following notation has been used

$$
F G-C N T_{\text {bottom (distribution })\left(a^{(k)} / b^{(k)} / \ldots\right)}^{\text {top }}
$$

where superscript "top" indicates the material on the upper surface of the lamina, while the subscript "bottom" indicates the material on the lower surface of the lamina. The subscript "(distribution)" designates instead the through-the-thickness distribution used to describe the volume fraction $V_{C}^{(k)}(\zeta)$ as $(5 \mathrm{P}),(2 \mathrm{P}-\mathrm{E})$ or $(2 \mathrm{P}-\mathrm{W})$, if the distribution is, five parameter exponential law, two parameter exponential function or two parameter Weibull function, respectively. Finally, the expression " $\left(a^{(k)} / b^{(k)} / \ldots\right)$ " specifies the parameters that describe these distributions and control the volume fraction profile along the thickness $h_{k}$ of the $k$-th lamina. Depending on the material used on the top or bottom surfaces of the lamina, different expressions have to be used for all of the stated distributions. In particular, if the top material is CNTs and the bottom material is polymer matrix (PM), the through-the-thickness distributions $V_{C}^{(k)}(\zeta)$ can be written as follows

Five-parameter exponential law $F G-C N T_{P M(5 P)\left(a^{(k)} / b^{(k)} / c^{(k)} / d^{(k)} / p^{(k)}\right)}^{\mathrm{CNT}}$

$$
V_{C}^{(k)}(\zeta)=\left(d^{(k)}-a^{(k)}\left(\frac{\zeta_{k+1}-\zeta}{h_{k}}\right)+b^{(k)}\left(\frac{\zeta_{k+1}-\zeta}{h_{k}}\right)^{c^{(k)}}\right)^{p^{(k)}}
$$

Two-parameter exponential function $F G-C N T_{\mathrm{PM}(2 P-E)\left(a^{(k)} / b^{(k)}\right)}^{\mathrm{CNT}}$

$$
V_{C}^{(k)}(\zeta)=\left(\frac{\exp \left(a^{(k)}\left(\frac{\zeta-\zeta_{k}-h_{k} / 2}{h_{k}}+\frac{1}{2}\right)\right)-1}{\left(\exp \left(\frac{a^{(k)}}{2}\right)-1\right)\left(\exp \left(a^{(k)} \frac{\zeta-\zeta_{k}-h_{k} / 2}{h_{k}}\right)+1\right)}\right)^{b^{(k)}}
$$

Weibull function $F G-C N T_{\mathrm{PM}(2 P-W)\left(a^{(k)} / b^{(k)}\right)}^{\mathrm{CNT}}$

$$
V_{C}^{(k)}(\zeta)=1-\exp \left(-\left(\frac{1}{a^{(k)}} \frac{\zeta-\zeta_{k}}{h_{k}}\right)^{b^{(k)}}\right)
$$


Moreover, if top and bottom materials are reversed, the following distributions apply

Five-parameter exponential law $F G-C N T_{C N T(5 P)\left(a^{(k)} / b^{(k)} / c^{(k)} / d^{(k)} / p^{(k)}\right)}^{\mathrm{PM}}$

$$
V_{C}^{(k)}(\zeta)=\left(d^{(k)}-a^{(k)}\left(\frac{\zeta-\zeta_{k}}{h_{k}}\right)+b^{(k)}\left(\frac{\zeta-\zeta_{k}}{h_{k}}\right)^{c^{(k)}}\right)^{p^{(k)}}
$$

Two-parameter exponential function $F G-C N T_{\mathrm{CNT}(2 P-E)\left(a^{(k)} / b^{(k)}\right)}^{\mathrm{PM}}$

$$
V_{C}^{(k)}(\zeta)=1-\left(\frac{\exp \left(a^{(k)}\left(\frac{\zeta-\zeta_{k}-h_{k} / 2}{h_{k}}+\frac{1}{2}\right)\right)-1}{\left(\exp \left(\frac{a^{(k)}}{2}\right)-1\right)\left(\exp \left(a^{(k)} \frac{\zeta-\zeta_{k}-h_{k} / 2}{h_{k}}\right)+1\right)}\right)^{b^{(k)}}
$$

Weibull function $F G-C N T_{\mathrm{CNT}(2 P-W)\left(a^{(k)} / b^{(k)}\right)}^{\mathrm{PM}}$

$$
V_{C}^{(k)}(\zeta)=\exp \left(-\left(\frac{1}{a^{(k)}} \frac{\zeta-\zeta_{k}}{h_{k}}\right)^{b^{(k)}}\right)
$$

Further on, the total volume of the reinforcing phase $V_{r}$ is separated as follows

$$
V_{r}=V_{r}^{i n}+V_{r}^{m}
$$

where $V_{r}^{i n}$ is the volume of CNTs in the inclusions and $V_{r}^{m}$ is the volume of the nanoparticles scattered in the matrix. Two parameters that characterize the agglomeration of CNTs have to be introduced

$$
\mu_{1}=\frac{W_{i n}}{W}, \quad \mu_{2}=\frac{W_{r}^{i n}}{W_{r}}
$$

The parameter $\mu_{1}$ specifies the effective volume of the inclusions $W_{i n}$ with respect to the overall volume of the layer $W$. Therefore, if $\mu_{1}=1$, there is no agglomeration, and the CNTs are uniformly scattered in the polymer matrix. The second parameter $\mu_{2}$ defines the portion of CNT volume embedded in the inclusions $W_{r}^{i n}$ with respect to the total volume of CNTs $W_{r}$. Therefore, if $\mu_{2}=1$, all the nanoparticles are allocated in the spherical inclusions. To obtain the intermediate cases between the two limit cases, the following limitation must be introduced

$$
\mu_{2} \geq \mu_{1}
$$

It should be specified that it is possible to increase the CNT spatial heterogeneity for a generic value of $\mu_{1}<1$ if higher values of $\mu_{2}$ are taken, meeting the requirement defined in (56). By the use of the relations (44), (54) and (55), the following relations that correlate the agglomeration parameters can be obtained

$$
\begin{gathered}
\frac{W_{r}^{i n}}{W_{i n}}=\frac{V_{r} \mu_{2}}{\mu_{1}} \\
\frac{W_{r}^{m}}{W-W_{\text {in }}}=\frac{V_{r}\left(1-\mu_{2}\right)}{1-\mu_{1}}
\end{gathered}
$$

for $\mu_{2}>\mu_{1}$. After defining the micromechanics of the particle agglomeration, next step is to define properties of the CNT-reinforced composite layer. In order to do so, the mechanical properties of the polymer matrix and the hybrid inclusions have to be evaluated. For this purpose, in this paper, the Eshelby-Mori-Tanaka approach is considered. Readers can find more information about other methods in the work by Shi et al. [32]. This method assumes that CNTs are randomly oriented in the 
inclusions, and are made of a transversely isotropic material. The bulk modulus $K_{i n}$ and the shear modulus $G_{i n}$ of the spherical inclusions are given by

$$
\begin{aligned}
& K_{i n}(\zeta)=K_{m}+\frac{V_{r} \mu_{2}\left(\delta_{r}-3 K_{m} \alpha_{r}\right)}{3\left(\mu_{1}-V_{r} \mu_{2}+V_{r} \mu_{2} \alpha_{r}\right)} \\
& G_{i n}(\zeta)=G_{m}+\frac{V_{r} \mu_{2}\left(\eta_{r}-2 G_{m} \beta_{r}\right)}{2\left(\mu_{1}-V_{r} \mu_{2}+V_{r} \mu_{2} \beta_{r}\right)}
\end{aligned}
$$

The same moduli for the hybrid matrix are given by

$$
\begin{aligned}
& K_{\text {out }}(\zeta)=K_{m}+\frac{V_{r}\left(1-\mu_{2}\right)\left(\delta_{r}-3 K_{m} \alpha_{r}\right)}{3\left(1-\mu_{1}-V_{r}\left(1-\mu_{2}\right)+V_{r}\left(1-\mu_{2}\right) \alpha_{r}\right)} \\
& G_{\text {out }}(\zeta)=G_{m}+\frac{V_{r}\left(1-\mu_{2}\right)\left(\eta_{r}-2 G_{m} \beta_{r}\right)}{2\left(1-\mu_{1}-V_{r}\left(1-\mu_{2}\right)+V_{r}\left(1-\mu_{2}\right) \beta_{r}\right)}
\end{aligned}
$$

where $K_{m}$ and $G_{m}$ denote the bulk modulus and the shear modulus of the isotropic matrix. It should be mentioned that the subscripts "in" and "out" are associated with the mechanical properties of the inclusions and of the matrix enriched with scattered CNTs, respectively. From the theory of elasticity, it is known that

$$
K_{m}=\frac{E_{m}}{3\left(1-2 v_{m}\right)}, \quad G_{m}=\frac{E_{m}}{2\left(1+v_{m}\right)}
$$

where $E_{m}$ is the elastic modulus and $v_{m}$ the Poisson's ratio. The rest of the unknown quantities from (58) and (59) are defined as

$$
\begin{aligned}
\alpha_{r} & =\frac{3\left(K_{m}+G_{m}\right)+k_{r}+l_{r}}{3\left(G_{m}+k_{r}\right)} \\
\beta_{r} & =\frac{1}{5}\left(\frac{4 G_{m}+2 k_{r}+l_{r}}{3\left(G_{m}+k_{r}\right)}+\frac{4 G_{m}}{G_{m}+p_{r}}+\frac{2\left(G_{m}\left(3 K_{m}+G_{m}\right)+G_{m}\left(3 K_{m}+7 G_{m}\right)\right)}{G_{m}\left(3 K_{m}+G_{m}\right)+m_{r}\left(3 K_{m}+7 G_{m}\right)}\right) \\
\delta_{r} & =\frac{1}{3}\left(n_{r}+2 l_{r}+\frac{\left(2 k_{r}+l_{r}\right)\left(3 K_{m}+G_{m}-l_{r}\right)}{G_{m}+k_{r}}\right) \\
\eta_{r} & =\frac{1}{5}\left(\frac{2}{3}\left(n_{r}-l_{r}\right)+\frac{8 G_{m} p_{r}}{G_{m}+p_{r}}+\frac{2\left(k_{r}-l_{r}\right)\left(2 G_{m}+l_{r}\right)}{3\left(G_{m}+k_{r}\right)}+\frac{8 m_{r} G_{m}\left(3 K_{m}+4 G_{m}\right)}{3 K_{m}\left(m_{r}+G_{m}\right)+G_{m}\left(7 m_{r}+G_{m}\right)}\right)
\end{aligned}
$$

where $k_{r}, l_{r}, m_{r}, n_{r}, p_{r}$ are the Hill's elastic moduli of the nanoparticles. The reader can find further descriptions of these quantities in [27]. In brief, the mechanical characterization of a single CNT is given by the so-called Hill's elastic moduli, since it is assumed to be an equivalent continuum cylindrical shell, as shown in Figure 3b [7]. Values for these quantities are given for different Single-Walled Carbon Nanotubes (SWCNTs) for various chiral indices that can be found in literature. In this paper, only armchair-type SWCNTs are considered, as shown in Table 1 with the notation $\operatorname{SWCNT}(\Delta, \Delta)$, where $\Delta$ stands for the chiral index. After obtaining values from (58) and (59), the Mori-Tanaka method gives the effective bulk and shear modulus of the CNT-reinforced layer as

$$
\begin{aligned}
& K(\zeta)=K_{\text {out }}\left(1+\frac{\mu\left(\frac{K_{\text {in }}}{K_{\text {out }}}-1\right)}{1+(1-\mu)\left(\frac{K_{\text {in }}}{K_{\text {out }}}-1\right) \frac{1+v_{\text {out }}}{3-3 v_{\text {out }}}}\right) \\
& G(\zeta)=G_{\text {out }}\left(1+\frac{\mu\left(\frac{G_{\text {in }}}{G_{\text {out }}}-1\right)}{1+(1-\mu)\left(\frac{G_{\text {in }}}{G_{\text {out }}}-1\right) \frac{8-10 v_{\text {out }}}{15-15 v_{\text {out }}}}\right)
\end{aligned}
$$

where $v_{\text {out }}$ is the Poisson's ratio of the hybrid matrix defined as

$$
v_{\text {out }}(\zeta)=\frac{3 K_{\text {out }}-2 G_{\text {out }}}{6 K_{\text {out }}+2 G_{\text {out }}}
$$


The resulting reinforced layer, as specified in the works [24], is isotropic. Therefore, the Young modulus $E(\zeta)$ and the Poisson's ratio $v(\zeta)$ are evaluated through the following expressions

$$
E(\zeta)=\frac{9 K G}{3 K+G}, \quad v(\zeta)=\frac{3 K-2 G}{6 K+2 G}
$$

At the end, density $\rho(\zeta)$ of the reinforced layer is evaluated by Mixture theory as

$$
\rho(\zeta)=\left(\rho_{r}-\rho_{m}\right) V_{r}+\rho_{m}
$$

where $\rho_{r}$ is the density of the CNTs and $\rho_{m}$ density of the polymer matrix. Further details concerning the present approach are illustrated in depth in the works by Tornabene et al. [24-27].

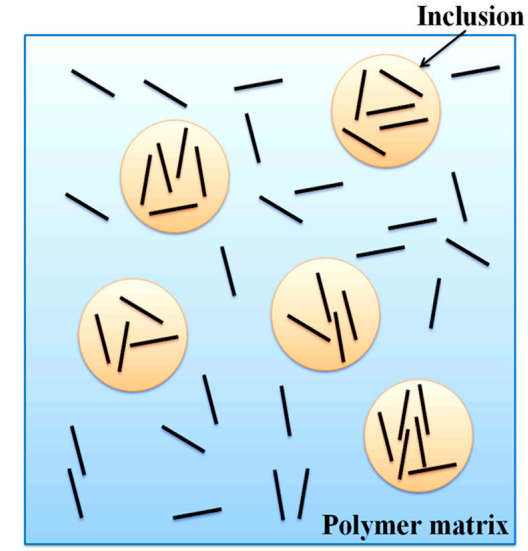

a)

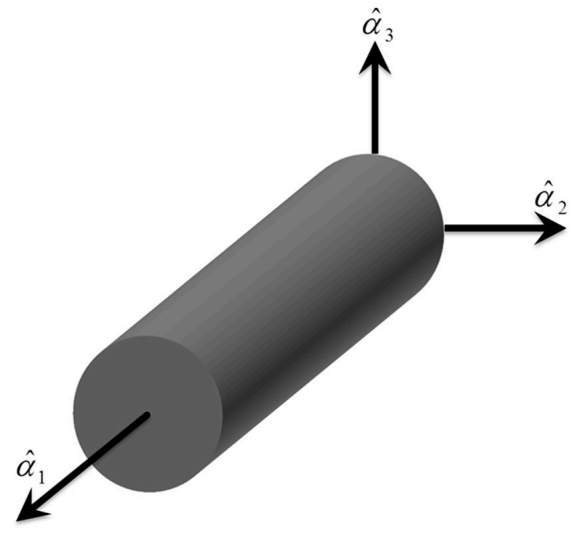

b)

Figure 3. CNT reinforced composite layer: (a) shell element with inclusion model of CNT agglomeration; (b) effective CNT fiber and local co-ordinate system representation.

Table 1. Hill's elastic moduli for several Single-Walled Carbon Nanotubes.

\begin{tabular}{ccccccc}
\hline Carbon Nanotubes & $\boldsymbol{k}_{\boldsymbol{r}}[\mathbf{G P a}]$ & $\boldsymbol{l}_{\boldsymbol{r}}[\mathbf{G P a}]$ & $\boldsymbol{m}_{\boldsymbol{r}}[\mathbf{G P a}]$ & $\boldsymbol{n}_{\boldsymbol{r}}[\mathbf{G P a}]$ & $\boldsymbol{p}_{\boldsymbol{r}}[\mathbf{G P a}]$ & $\mathbf{R e f s .}$ \\
\hline SWCNT $(5,5)$ & 536 & 184 & 132 & 2143 & 791 & {$[9,12]$} \\
SWCNT $(6,6)$ & 9.9 & 8.4 & 4.4 & 457.6 & 27 & {$[8]$} \\
SWCNT $(10,10)$ & 271 & 88 & 17 & 1089 & 442 & {$[9]$} \\
SWCNT $(15,15)$ & 181 & 58 & 5 & 726 & 301 & {$[9]$} \\
SWCNT $(20,20)$ & 136 & 43 & 2 & 545 & 227 & {$[9,12]$} \\
SWCNT $(50,50)$ & 55 & 17 & 0.1 & 218 & 92 & {$[9,12]$} \\
\hline
\end{tabular}

\section{Numerical Scheme}

After the fundamental system of Equation (36), along with the proper boundary conditions of (38)-(40), is set, a numerical scheme has to be implemented in order to obtain the solution. In this paper, the fundamental system of equations is solved by the Generalized Differential Quadrature (GDQ) method. Although, only fundamental aspects of this techniques are presented in the current paper, the reader can find further information about this method in [137]. Using this approach, the $n$-th derivative at a generic point $x_{i}$ of a sufficiently smooth one-dimensional function $f(x)$ is obtained as a weighted linear sum of the function values at some chosen grid points

$$
\left.\frac{d^{n} f(x)}{d x^{n}}\right|_{x=x_{i}} \cong \sum_{j=1}^{I_{N}} s_{i j}^{(n)} f\left(x_{j}\right)
$$


for $i=1,2, \ldots, I_{N}$, where quantities $\varsigma_{i j}^{(n)}$ represent the weighting coefficients of the sum. To obtain the solution, weighting coefficients $\varsigma_{i j}^{(n)}$ have to be evaluated at each grid point, as highlighted in the review paper by Tornabene et al. [137]. Additionally, if adequate solutions are to be acquired, proper grid distribution is needed. In this paper, Chebyshev-Gauss-Lobatto grid distribution has been chosen to discretize the domain under consideration. If Expression (66) is extended on a two-dimensional problem, the points of the shell middle surface are placed according to the following Expressions along the principal co-ordinates $\alpha_{1}, \alpha_{2}$

$$
\alpha_{1 i}=\left(1-\cos \left(\frac{i-1}{I_{N}-1} \pi\right)\right) \frac{\left(\alpha_{1}^{1}-\alpha_{1}^{0}\right)}{2}+\alpha_{1}^{0}
$$

for $i=1,2, \ldots, I_{N}$ with $\alpha_{1} \in\left[\alpha_{1}^{0}, \alpha_{1}^{1}\right]$, and

$$
\alpha_{2 j}=\left(1-\cos \left(\frac{j-1}{I_{M}-1} \pi\right)\right) \frac{\left(\alpha_{2}^{1}-\alpha_{2}^{0}\right)}{2}+\alpha_{2}^{0}
$$

for $j=1,2, \ldots, I_{M}$ with $\alpha_{2} \in\left[\alpha_{2}^{0}, \alpha_{2}^{1}\right]$, in which $I_{N}, I_{M}$ are the total number of nodes along $\alpha_{1}, \alpha_{2}$, respectively. To solve the fundamental system of equations the separation of variables is to be used. The generalized displacements can be expressed as

$$
\mathbf{u}^{(\tau)}\left(\alpha_{1}, \alpha_{2}, t\right)=\mathbf{U}^{(\tau)}\left(\alpha_{1}, \alpha_{2}\right) \mathrm{e}^{\mathrm{i} \omega t}
$$

where $\mathbf{U}^{(\tau)}=\left[\begin{array}{lll}U_{1}^{(\tau)}\left(\alpha_{1}, \alpha_{2}\right) & U_{2}^{(\tau)}\left(\alpha_{1}, \alpha_{2}\right) & U_{3}^{(\tau)}\left(\alpha_{1}, \alpha_{2}\right)\end{array}\right]^{T}$ denotes the mode shape vector, whose components are the amplitude of the modes at issue, whereas $\omega$ is the circular frequency of the system, which allows the natural frequency to be defined as $f=\omega / 2 \pi$. If Expression (69) and its second-order temporal derivative are substituted in (36), the fundamental system of Equation (36) becomes

$$
\sum_{\eta=0}^{N+1}\left(\mathbf{L}^{(\tau \eta)}-\mathbf{L}_{f}^{(\tau \eta)}\right) \mathbf{U}^{(\eta)}+\omega^{2} \sum_{\eta=0}^{N+1}\left(\mathbf{M}^{(\tau \eta)}+\mathbf{M}_{f}^{(\tau \eta)}\right) \mathbf{U}^{(\eta)}=\mathbf{0}
$$

for $\tau=0,1,2, \ldots, N, N+1$. Once the GDQ method is applied, the following discrete form of Equation (70) is obtained

$$
\mathbf{K} \delta=\omega^{2} \mathbf{M} \delta
$$

in which $\mathbf{K}$ is the discrete global stiffness matrix, $\mathbf{M}$ is the discrete inertia matrix, $\delta$ the discrete mode shape vector. It should be mentioned that $\mathbf{K}, \mathbf{M}$ include the effect of the elastic foundation, too.

Finally, the numerical problem can be simplified by isolating the components related to the boundary nodes $(b)$ from the inner ones $(d)$. Through the kinematic condensation of non-domain degrees of freedom, System (71) can be rewritten as

$$
\left(\mathbf{K}_{d d}-\mathbf{K}_{d b}\left(\mathbf{K}_{b b}\right)^{-1} \mathbf{K}_{b d}\right) \boldsymbol{\delta}_{d}=\omega^{2} \mathbf{M}_{d d} \boldsymbol{\delta}_{d}
$$

According to this approach, numerical instabilities and ill-conditioned matrices can be avoided. It is well known that Expression (72) represents a set of linear eigenvalue problem that allow the solution of the dynamic problem under consideration to be obtained in terms of natural frequencies.

\section{Applications}

In the current Section, a few applications are presented regarding the free vibration problem of laminated doubly-curved shells and plates reinforced by Carbon Nanotubes resting on elastic foundations. All of the results were obtained by MATLAB code [141]. This Section is subdivided into four Subsections. Due to a lack of papers regarding this subject, in the first Subsection, a comparison 
with the FEM solution is provided. All the remaining Subsections deal with the parametric studies for free vibration presented as follows. The first parametric studies aim to present the effect of CNT volume fraction distribution, the second ones show the effect of the elastic foundation, and the last ones show the effect of CNT agglomeration parameters. In all the following applications, a Single-Walled Carbon Nanotube (SWCNT) with chiral index $\Delta=10$ is assumed, for which values can be found in Table 1 ; the density of the CNTs is taken to be $\rho_{r}=1400 \mathrm{~kg} / \mathrm{m}^{3}$. Additionally, the matrix material has the same values in all applications: $E_{m}=2.1 \mathrm{GPa}, \rho_{m}=1150 \mathrm{~kg} / \mathrm{m}^{3}$ and $v_{m}=0.34$. Figure 4 depicts the structures that have been considered (square plate (Figure 4a), cylindrical surface (Figure $4 \mathrm{~b}$ ) and helicoidal surface (Figure $4 \mathrm{c})$ ) along with the geometric parameters and position vectors $\mathbf{r}\left(\alpha_{1}, \alpha_{2}\right)$ needed for the description of the reference surfaces of such structures. In all the applications, FG-CNT material was used, the parameters and lamination schemes of which are depicted in Figure 5.
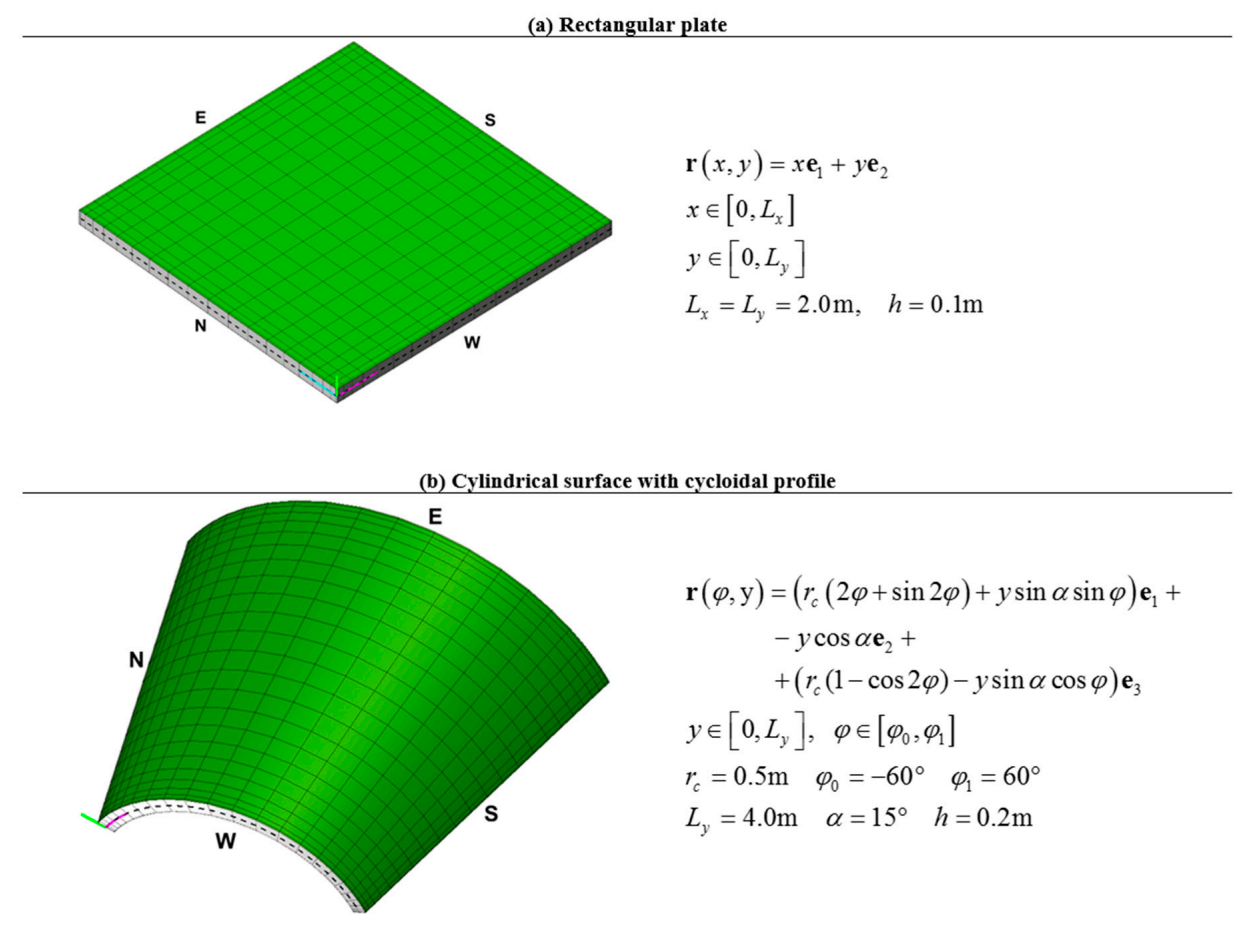

(c) Helicoid

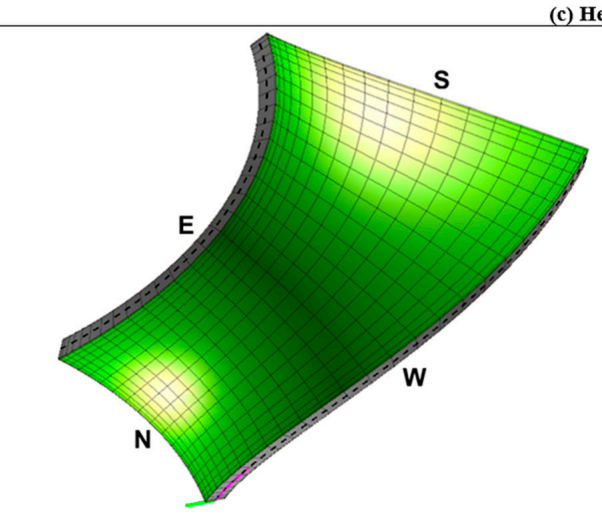

$$
\begin{aligned}
& \mathbf{r}\left(\alpha_{1}, \alpha_{2}\right)=-a \cos \left(\alpha_{1}+\alpha_{2}\right) \sinh \left(\alpha_{1}-\alpha_{2}\right) \mathbf{e}_{1}+ \\
& -a \sin \left(\alpha_{1}+\alpha_{2}\right) \sinh \left(\alpha_{1}-\alpha_{2}\right) \mathbf{e}_{2}+ \\
& +a\left(\alpha_{1}-\alpha_{2}\right) \mathbf{e}_{3} \\
& \alpha_{1} \in\left[\alpha_{1}^{0}, \alpha_{1}^{1}\right], \quad \alpha_{2} \in\left[\alpha_{2}^{0}, \alpha_{2}^{1}\right] \\
& \alpha_{1}^{0}=0 \quad \alpha_{1}^{1}=\pi / 2 \quad \alpha_{2}^{0}=0 \quad \alpha_{2}^{1}=\pi / 4 \\
& a=2.5 \mathrm{~m} \quad h=0.3 \mathrm{~m}
\end{aligned}
$$

Figure 4. Three panel structures with GDQ discretization and local co-ordinate system representation. For each structure, the position vector $\mathbf{r}\left(\alpha_{1}, \alpha_{2}\right)$ is shown, along with the geometric parameters that describe the reference surface of the three structures under consideration: (a) rectangular plate; (b) cylindrical surface; (c) helicoid. 


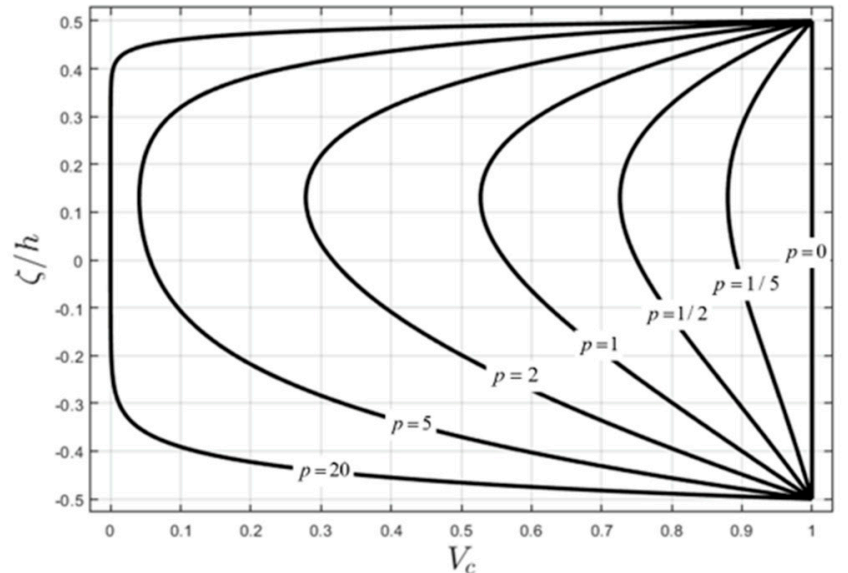

(a)

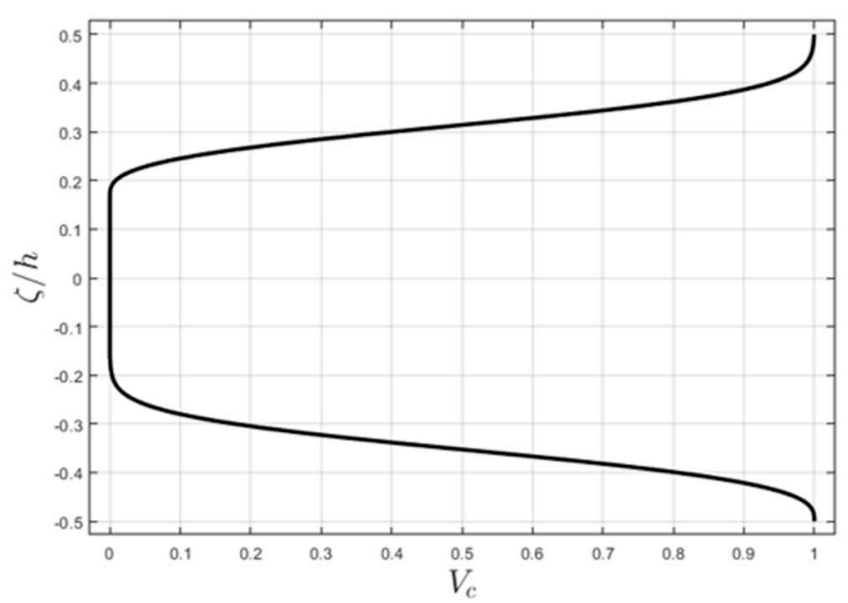

(b)

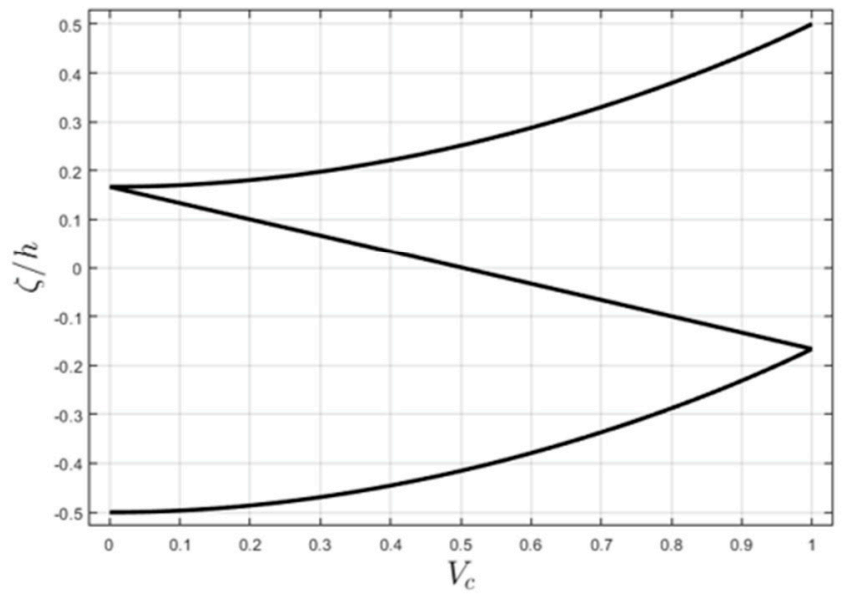

(c)

$$
\begin{aligned}
& F G-C N T_{\mathrm{CNI}(5 P)\left(a^{(1)}=1 / b^{(1)}=1 / c^{(1)}=4 / d^{(1)}=1 / p^{(1)}\right)}^{\mathrm{PM}} \\
& a^{(1)}=1 \quad b^{(1)}=1 \quad c^{(1)}=4 \quad d^{(1)}=1 \\
& p^{(1)}-\text { variable } \\
& \text { top = polymer matrix, bottom }=\mathrm{CNTs} \\
& \mu_{1}=1, \quad \mu_{2}=1, \quad w_{r}=0.05, \quad h=0.1 \mathrm{~m}
\end{aligned}
$$

layer 1: $F G-C N T_{\mathrm{CNI}(2 P-W)\left(a^{(1)}=0.5 / b^{(1)}=3\right)}^{\mathrm{PM}}$

$a^{(1)}=0.5 \quad b^{(1)}=3$

top $=$ polymer matrix bottom $=\mathrm{CNTs}$

$\mu_{1}=0.5 \quad \mu_{2}=0.75 \quad w_{r}=0.25 \quad h=0.05 \mathrm{~m}$

layer 2: polymer matrix $h=0.1 \mathrm{~m}$

layer 3: $F G-C N T_{\mathrm{PM}(2 P-W)\left(a^{(3)}=0.5 / b^{(3)}=3\right)}^{\mathrm{CNT}}$

$a^{(3)}=0.5 \quad b^{(3)}=3$

top $=$ CNTs bottom $=$ polymer matrix

$\mu_{1}=0.5 \quad \mu_{2}=0.75 \quad w_{r}=0.25 \quad h=0.05 \mathrm{~m}$

layer 1: FG-CNT $T_{\mathrm{PM}(2 P-E)\left(\mathrm{a}^{(1)}=1 / \mathrm{b}^{(1)}=0.5\right)}^{\mathrm{CNT}}$

$a^{(1)}=1 \quad b^{(1)}=0.5 \quad h=0.1 \mathrm{~m}$

top $=$ CNTs bottom $=$ polymer matrix

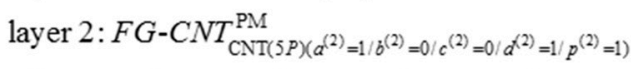

$a^{(2)}=1 \quad b^{(2)}=0 \quad c^{(2)}=0 \quad d^{(2)}=1 \quad p^{(2)}=1$

top $=$ polymer matrix bottom $=\mathrm{CNTs}$

$h=0.1 \mathrm{~m}$

layer 3: $F G-C N T_{\mathrm{PM}(2 P-E)\left(\mathrm{a}^{(3)}=1 / \mathrm{b}^{(3)}=0.5\right)}^{\mathrm{CNT}}$

$a^{(3)}=1 \quad b^{(3)}=0.5 \quad h=0.1 \mathrm{~m}$

top $=$ CNTs bottom $=$ polymer matrix

Figure 5. Distributions of the CNT-reinforcing phase along the thickness. For each layer, the parameters for the distribution itself are shown: (a) (5P); (b) (2P-W); (c) (2P-E).

\subsection{Comparison with FEM}

The aim of this application is to validate the present approach by means of a comparison with results obtained through a commercial FEM code. Two examples are conducted in this Subsection: a CNT-reinforced fully clamped square plate (Figure 4a) made of single-ply of constant thickness 
( $h=0.1 \mathrm{~m})$; and the same square plate with 3 layers $(\mathrm{CNT} /$ matrix/CNT) of various thickness $(0.02 \mathrm{~m} / 0.06 \mathrm{~m} / 0.02 \mathrm{~m})$. The agglomeration parameters and mass fraction value of the CNTs are given in Tables 2 and 3. All the phases were considered to be isotropic. The 3D FEM solution was obtained by the commercial software Strand7. Several kinematic models were considered with reference to the GDQ solution. In particular, in the first example, the following theories were used: $\mathrm{FSDT}_{R S}^{\kappa=5 / 6}$, $\mathrm{ED}^{\kappa=5 / 6}$ and ED3; and in the second example, the following theories: $\mathrm{FSDTZ}_{\mathrm{RS}}^{\kappa=1}, \mathrm{FSDTZ}_{\mathrm{RS}}^{\kappa=5 / 6}$, $\mathrm{EDZ2}^{\kappa=1}, \mathrm{EDZ2}^{\kappa=5 / 6}$ and EDZ3. The notation RS means that reduced stiffness is used (hypothesis of plane stress). Analogously, $\kappa$ stands for the shear correction factor. It should be noted that the zig-zag theories up to the second order of kinematic expansion are taken with and without the shear correction factor. Further details concerning this choice can be found in the following papers [101-110]. The results of the comparison can be observed in Tables 2 and 3, showing good agreement between GDQ solutions and FEM ones. It should be recalled that, in the second circumstance, only zig-zag theories were used, since the structure has a soft-core. As highlighted in [109], sandwich structures with soft inner cores require the Murakami's function to be well analyzed.

Table 2. Comparison between the first ten natural frequency variations of a CCCC square plate made of a single CNT-reinforced lamina of constant thickness $h=0.1 \mathrm{~m}$ given by GDQ method and FEM. The 3D FEM solution was obtained by commercial software Strand7.

\begin{tabular}{ccccc}
\hline \multicolumn{5}{c}{ Uniform CNT Reinforcement Distribution } \\
\hline$f[\mathbf{H z}]$ & FSDT $_{\boldsymbol{R S}}^{\boldsymbol{\kappa}=5 / 6}$ & ED2 $^{\boldsymbol{\kappa}=5 / 6}$ & ED3 & 3D FEM \\
\hline 1 & 120.787 & 120.982 & 121.091 & 121.155 \\
2 & 241.448 & 241.821 & 242.199 & 242.324 \\
3 & 241.448 & 241.821 & 242.199 & 242.324 \\
4 & 349.728 & 350.238 & 350.992 & 351.162 \\
5 & 421.114 & 421.732 & 422.774 & 422.987 \\
6 & 423.751 & 424.381 & 425.403 & 425.619 \\
7 & 520.239 & 520.961 & 522.499 & 522.739 \\
8 & 520.239 & 520.961 & 522.499 & 522.739 \\
9 & 652.917 & 653.821 & 656.100 & 656.432 \\
10 & 652.917 & 653.821 & 656.100 & 656.432 \\
\hline
\end{tabular}

Table 3. Comparison between the first ten natural frequency variations of a CCCC square plate made of a 3-layered material (CNT/matrix/CNT) with various thickness $h=0.02 \mathrm{~m} / 0.06 \mathrm{~m} / 0.02 \mathrm{~m}$ given by GDQ method and FEM. The 3D FEM solution was obtained by commercial software Strand7.

\begin{tabular}{|c|c|c|c|c|c|c|}
\hline \multicolumn{7}{|c|}{ Lamination Scheme: } \\
\hline \multicolumn{7}{|c|}{$F G-C N T_{C N T(5 P)\left(a^{(1)}=1 / b^{(1)}=0 / c^{(1)}=0 / d^{(1)}=1 / p^{(1)}=0\right)}^{P M} / P M / F G-C N T_{C N T(5 P)\left(a^{(3)}=1 / b^{(3)}=0 / c^{(3)}=0 / d^{(3)}=1 / p^{(3)}=0\right)}^{P M}$} \\
\hline$f[\mathrm{~Hz}]$ & FSDTZ $_{R S}^{\kappa=1}$ & FSDTZ $_{R S}^{\kappa=5 / 6}$ & $\mathrm{EDZ2}^{\kappa=1}$ & $\mathrm{EDZ2}^{\kappa=5 / 6}$ & EDZ3 & 3D FEM \\
\hline 1 & 105.243 & 103.892 & 105.559 & 104.188 & 105.498 & 105.482 \\
\hline 2 & 204.169 & 200.091 & 204.815 & 200.691 & 204.637 & 204.608 \\
\hline 3 & 204.169 & 200.091 & 204.815 & 200.691 & 204.637 & 204.608 \\
\hline 4 & 289.471 & 282.386 & 290.400 & 283.241 & 290.096 & 290.038 \\
\hline 5 & 343.586 & 334.061 & 344.730 & 335.112 & 344.322 & 344.246 \\
\hline 6 & 346.354 & 336.858 & 347.512 & 337.923 & 347.104 & 347.037 \\
\hline 7 & 418.461 & 405.747 & 419.848 & 407.016 & 419.308 & 419.190 \\
\hline 8 & 418.461 & 405.747 & 419.848 & 407.016 & 419.308 & 419.190 \\
\hline 9 & 514.520 & 496.736 & 516.310 & 498.371 & 515.554 & 515.393 \\
\hline 10 & 514.520 & 496.736 & 516.310 & 498.371 & 515.554 & 515.393 \\
\hline
\end{tabular}

\subsection{Effect of Through-the-Thickness Distribution of CNTs}

The following examples show the variation of the natural frequencies as a function of the volume fraction distribution along the thickness of the lamina by varying the parameter $p^{(1)}$ of a five-parameter 
exponential law. A functionally graded CNT-reinforced fully clamped square plate (Figure 4a) made of a single ply of constant thickness $(h=0.1 \mathrm{~m})$ is assumed. The agglomeration parameters and mass fraction value of the CNTs are given in Tables 4 and 5. Material was described with the five-parameter exponential law defined in Figure 5a. At the bottom of the plate, elastic foundations were applied, the parameters of which can be found in Tables 4 and 5 .

Table 4. First ten natural frequency variations of a CCCC square plate (Figure 4a) made of one lamina of constant thickness $h=0.1 \mathrm{~m}$ reinforced by CNTs distributed as in Figure $5 \mathrm{a}$ for the different parameters $p^{(1)}=p$. The mass fraction was $w_{r}=0.05$ and agglomeration parameters $\mu_{1}=\mu_{2}=1$. The Chebyshev-Gauss-Lobatto grid distribution was employed, with $I_{N}=I_{M}=21$.

\begin{tabular}{|c|c|c|c|c|c|c|c|c|c|}
\hline \multicolumn{10}{|c|}{ Elastic Foundation: $\rho^{(-)}=1800 \mathrm{~kg} / \mathrm{m}^{3}$} \\
\hline$f[\mathrm{~Hz}]$ & $p=0$ & $p=1 / 5$ & $p=1 / 2$ & $p=1$ & $p=2$ & $p=5$ & $p=10$ & $p=15$ & $p=20$ \\
\hline \multicolumn{10}{|c|}{$\mathrm{FSDT}_{R S}^{\kappa=5 / 6}$} \\
\hline 1 & 341.557 & 341.153 & 340.590 & 339.761 & 338.431 & 336.089 & 334.456 & 333.695 & 333.244 \\
\hline 2 & 379.719 & 378.036 & 375.701 & 372.262 & 366.774 & 357.249 & 350.783 & 347.791 & 345.955 \\
\hline 3 & 379.719 & 378.036 & 375.701 & 372.262 & 366.774 & 357.249 & 350.783 & 347.791 & 345.955 \\
\hline 4 & 430.007 & 426.774 & 422.278 & 415.633 & 404.978 & 386.395 & 373.862 & 368.213 & 361.622 \\
\hline 5 & 469.071 & 464.709 & 458.633 & 449.631 & 435.144 & 409.749 & 392.584 & 372.274 & 361.622 \\
\hline 6 & 470.711 & 466.315 & 460.190 & 451.114 & 436.502 & 410.867 & 392.772 & 372.274 & 364.919 \\
\hline 7 & 528.685 & 522.691 & 514.326 & 501.897 & 481.810 & 446.124 & 392.772 & 384.850 & 380.340 \\
\hline 8 & 528.685 & 522.691 & 514.326 & 501.897 & 481.810 & 446.124 & 393.522 & 385.704 & 381.145 \\
\hline 9 & 615.397 & 607.148 & 595.607 & 578.371 & 545.185 & 448.132 & 422.311 & 411.447 & 405.105 \\
\hline 10 & 615.397 & 607.148 & 595.607 & 578.371 & 545.185 & 448.132 & 422.311 & 411.447 & 405.105 \\
\hline \multicolumn{10}{|c|}{$\mathrm{ED} 2^{\kappa=5 / 6}$} \\
\hline 1 & 341.102 & 340.694 & 340.125 & 339.286 & 337.937 & 335.534 & 333.785 & 332.923 & 332.394 \\
\hline 2 & 379.134 & 377.436 & 375.080 & 371.609 & 366.065 & 356.412 & 349.675 & 346.337 & 344.127 \\
\hline 3 & 379.134 & 377.436 & 375.080 & 371.609 & 366.065 & 356.412 & 349.675 & 346.337 & 344.127 \\
\hline 4 & 429.582 & 426.313 & 421.765 & 415.040 & 404.257 & 385.503 & 372.865 & 367.085 & 363.664 \\
\hline 5 & 468.880 & 464.461 & 458.301 & 449.169 & 434.470 & 408.804 & 391.565 & 374.142 & 363.701 \\
\hline 6 & 470.552 & 466.098 & 459.891 & 450.687 & 435.867 & 409.972 & 392.572 & 374.142 & 363.701 \\
\hline 7 & 528.912 & 522.822 & 514.318 & 501.673 & 481.227 & 445.156 & 394.458 & 383.731 & 379.103 \\
\hline 8 & 528.912 & 522.822 & 514.318 & 501.673 & 481.227 & 445.156 & 394.458 & 384.670 & 380.006 \\
\hline 9 & 616.397 & 607.989 & 596.217 & 578.621 & 545.954 & 449.492 & 421.306 & 410.411 & 403.988 \\
\hline 10 & 616.397 & 607.989 & 596.217 & 578.621 & 545.954 & 449.492 & 421.306 & 410.411 & 403.988 \\
\hline \multicolumn{10}{|c|}{ ED3 } \\
\hline 1 & 341.119 & 340.703 & 340.124 & 339.266 & 337.883 & 335.425 & 333.690 & 332.852 & 332.339 \\
\hline 2 & 379.252 & 377.510 & 375.088 & 371.506 & 365.765 & 355.852 & 349.266 & 346.071 & 343.938 \\
\hline 3 & 379.252 & 377.510 & 375.088 & 371.506 & 365.765 & 355.852 & 349.266 & 346.071 & 343.938 \\
\hline 4 & 429.893 & 426.514 & 421.800 & 414.804 & 403.531 & 384.143 & 371.918 & 366.529 & 363.321 \\
\hline 5 & 469.350 & 464.763 & 458.350 & 448.800 & 433.342 & 406.672 & 390.077 & 373.876 & 363.523 \\
\hline 6 & 471.009 & 466.390 & 459.933 & 450.315 & 434.743 & 407.854 & 391.096 & 373.876 & 363.523 \\
\hline 7 & 529.659 & 523.308 & 514.408 & 501.107 & 479.468 & 441.878 & 394.095 & 382.864 & 378.578 \\
\hline 8 & 529.659 & 523.308 & 514.408 & 501.107 & 479.468 & 441.878 & 394.095 & 383.811 & 379.486 \\
\hline 9 & 617.534 & 608.718 & 596.322 & 577.690 & 545.058 & 449.114 & 418.954 & 409.047 & 403.174 \\
\hline 10 & 617.534 & 608.718 & 596.322 & 577.690 & 545.058 & 449.114 & 418.954 & 409.047 & 403.174 \\
\hline
\end{tabular}

In this example, the following theories were used: $\mathrm{FSDT}_{R S}^{\kappa=5 / 6}, \mathrm{ED}^{\kappa=5 / 6}$ and ED3. Since the lamination scheme is characterized by only one layer, the Murakami's function was not needed. Tables 4 and 5 show the first ten natural frequencies for each theory for different values of the parameter $p^{(1)}$ with two different parameters of elastic foundations. The overall behavior of the through-the-thickness distribution variation can be observed more easily from the graphs depicted in Figures 6 and 7 . 
Table 5. First ten natural frequency variations of a CCCC square plate (Figure 4a) made of one lamina of constant thickness $h=0.1 \mathrm{~m}$ reinforced by CNTs distributed as in Figure $5 \mathrm{a}$ for the different parameters $p^{(1)}=p$. The mass fraction was $w_{r}=0.05$ and the agglomeration parameters $\mu_{1}=\mu_{2}=1$. The Chebyshev-Gauss-Lobatto grid distribution was employed, with $I_{N}=I_{M}=21$.

\begin{tabular}{|c|c|c|c|c|c|c|c|c|c|}
\hline \multicolumn{4}{|c|}{ Elastic Foundation: $\rho^{(-)}=1800 \mathrm{~kg} / \mathrm{m}^{3}$} & \multicolumn{6}{|c|}{$h_{f}^{(-)}=0.1 m, \quad k_{3 f}^{(-)}=75 \times 10^{7} \mathrm{~N} / \mathrm{m}^{3}, \quad G_{f}^{(-)}=35 \times 10^{7} \mathrm{~N} / \mathrm{m}$} \\
\hline$f[\mathrm{~Hz}]$ & $p=0$ & $p=1 / 5$ & $p=1 / 2$ & $p=1$ & $p=2$ & $p=5$ & $p=10$ & $p=15$ & $p=20$ \\
\hline \multicolumn{10}{|c|}{$\mathrm{FSDT}_{R S}^{\kappa=5 / 6}$} \\
\hline 1 & 612.245 & 611.801 & 611.176 & 607.409 & 545.860 & 447.819 & 392.661 & 372.062 & 361.264 \\
\hline 2 & 694.928 & 674.844 & 647.287 & 607.409 & 545.860 & 447.819 & 392.661 & 372.062 & 361.264 \\
\hline 3 & 694.928 & 674.844 & 647.287 & 610.241 & 608.718 & 533.861 & 465.074 & 439.250 & 425.671 \\
\hline 4 & 841.143 & 816.155 & 781.879 & 732.290 & 655.761 & 606.022 & 571.512 & 541.063 & 525.069 \\
\hline 5 & 882.978 & 881.931 & 880.480 & 878.335 & 796.786 & 652.772 & 604.140 & 603.198 & 592.152 \\
\hline 6 & 882.978 & 881.931 & 880.480 & 878.335 & 874.733 & 737.097 & 645.461 & 611.039 & 592.152 \\
\hline 7 & 1014.165 & 985.285 & 945.251 & 886.992 & 874.733 & 742.231 & 646.908 & 611.039 & 592.949 \\
\hline 8 & 1091.717 & 1089.519 & 1065.496 & 1000.323 & 899.095 & 742.231 & 646.908 & 611.050 & 602.574 \\
\hline 9 & 1141.685 & 1110.007 & 1085.265 & 1016.790 & 911.249 & 843.117 & 741.232 & 703.178 & 683.275 \\
\hline 10 & 1167.091 & 1132.591 & 1085.265 & 1016.790 & 911.249 & 868.882 & 782.404 & 740.408 & 718.273 \\
\hline \multicolumn{10}{|c|}{$\mathrm{ED} 2^{\kappa=5 / 6}$} \\
\hline 1 & 609.884 & 609.437 & 608.802 & 607.835 & 547.042 & 449.412 & 394.399 & & 362.913 \\
\hline 2 & 695.503 & 675.522 & 648.089 & 608.367 & 547.042 & 449.412 & 394.399 & 373.763 & 362.913 \\
\hline 3 & 695.503 & 675.522 & 648.089 & 608.367 & 606.200 & 534.043 & 465.263 & 439.426 & 425.831 \\
\hline 4 & 840.697 & 815.811 & 781.659 & 732.214 & 655.840 & 602.962 & 573.416 & 542.922 & 526.852 \\
\hline 5 & 877.187 & 876.030 & 874.415 & 871.974 & 797.669 & 654.451 & 600.059 & 598.222 & 592.267 \\
\hline 6 & 877.187 & 876.030 & 874.415 & 871.974 & 867.465 & 739.181 & 647.091 & 611.198 & 592.267 \\
\hline 7 & 1011.509 & 983.749 & 944.615 & 887.136 & 867.465 & 742.301 & 647.091 & 611.198 & 595.047 \\
\hline 8 & 1083.926 & 1080.617 & 1063.945 & 1000.169 & 900.119 & 742.301 & 647.765 & 613.263 & 596.846 \\
\hline 9 & 1135.880 & 1106.652 & 1077.028 & 1016.506 & 911.740 & 844.974 & 744.339 & 706.795 & 687.261 \\
\hline 10 & 1165.706 & 1131.497 & 1084.530 & 1016.506 & 911.740 & 859.755 & 784.023 & 742.118 & 719.888 \\
\hline \multicolumn{10}{|c|}{ ED3 } \\
\hline 1 & 610.023 & 609.540 & 608.848 & 607.782 & 547.049 & 449.104 & 394.016 & 373.474 & 362.709 \\
\hline 2 & 695.772 & 675.763 & 648.289 & 608.502 & 547.049 & 449.104 & 394.016 & 373.474 & 362.709 \\
\hline 3 & 695.772 & 675.763 & 648.289 & 608.502 & 605.958 & 534.106 & 465.302 & 439.471 & 425.888 \\
\hline 4 & 841.121 & 816.194 & 781.989 & 732.474 & 656.005 & 602.386 & 573.017 & 542.643 & 526.687 \\
\hline 5 & 877.414 & 876.191 & 874.471 & 871.845 & 797.862 & 654.157 & 599.484 & 597.759 & 592.395 \\
\hline 6 & 877.414 & 876.191 & 874.471 & 871.845 & 866.972 & 738.858 & 647.157 & 611.288 & 592.395 \\
\hline 7 & 1012.318 & 984.477 & 945.231 & 887.590 & 866.972 & 742.434 & 647.157 & 611.288 & 594.908 \\
\hline 8 & 1084.191 & 1080.794 & 1064.835 & 1000.830 & 900.416 & 742.434 & 647.332 & 612.983 & 596.474 \\
\hline 9 & 1137.009 & 1107.694 & 1077.065 & 1017.204 & 912.174 & 844.270 & 743.433 & 706.190 & 686.930 \\
\hline 10 & 1166.848 & 1132.530 & 1085.420 & 1017.204 & 912.174 & 858.515 & 783.568 & 741.866 & 719.822 \\
\hline
\end{tabular}




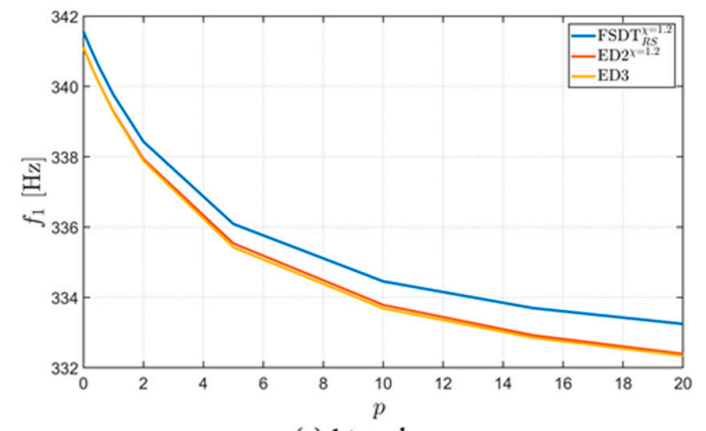

(a) $1^{\text {st }}$ mode

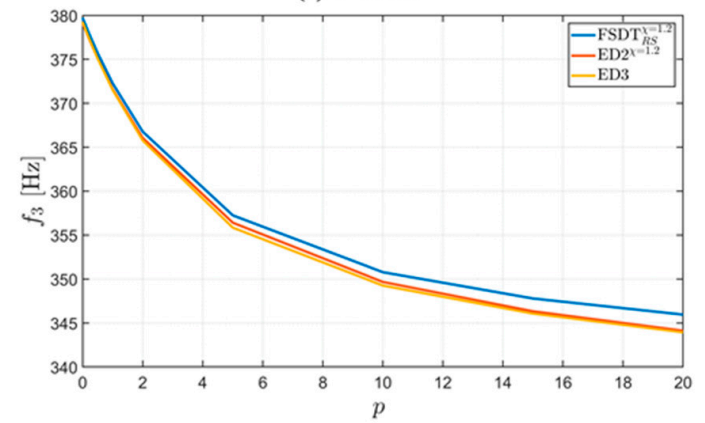

(c) $3^{\text {rd }}$ mode

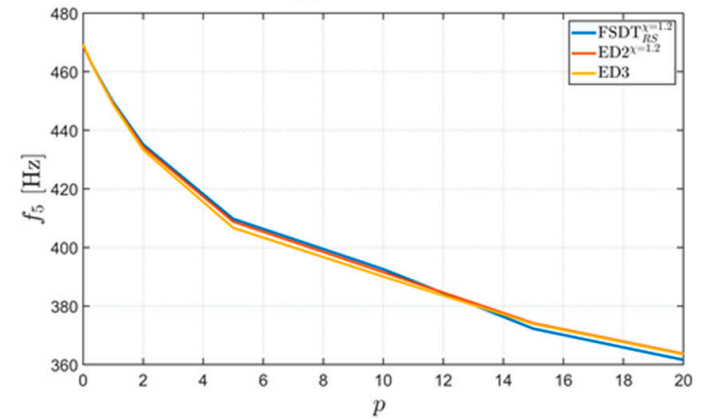

(e) $5^{\text {th }}$ mode

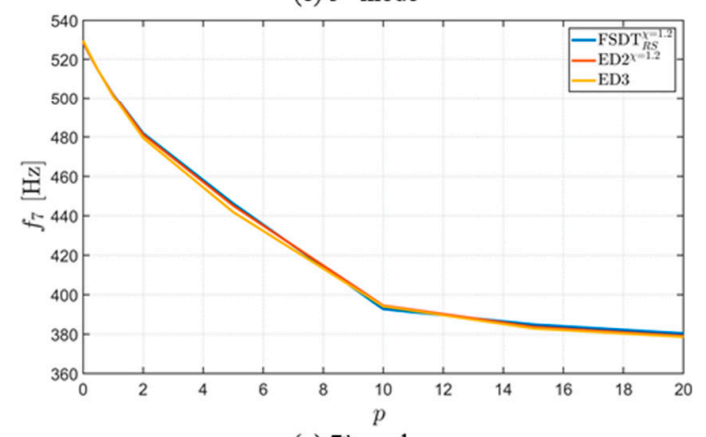

(g) $7^{\text {th }}$ mode

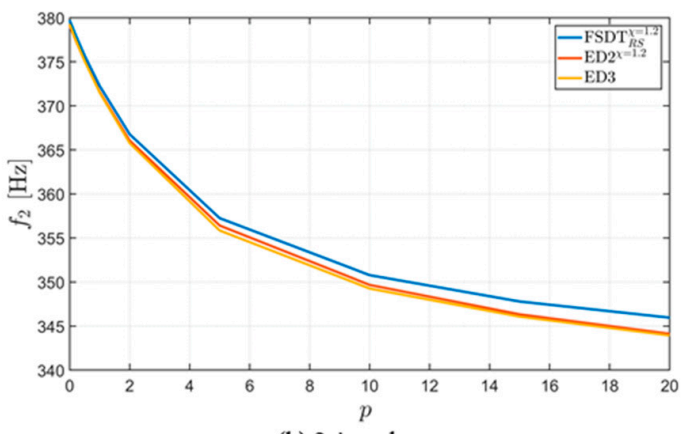

(b) $2^{\text {nd }}$ mode

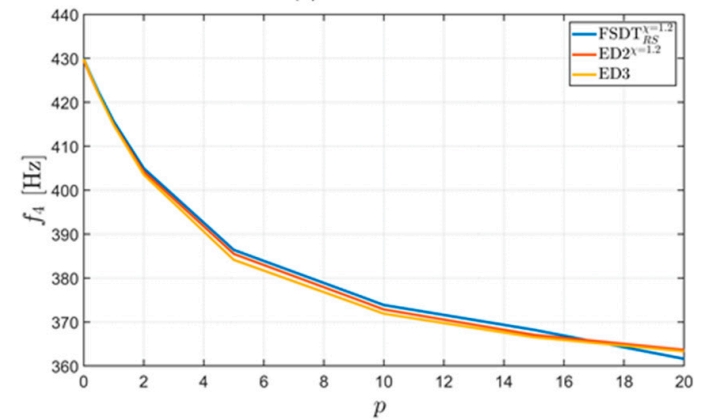

(d) $4^{\text {th }}$ mode

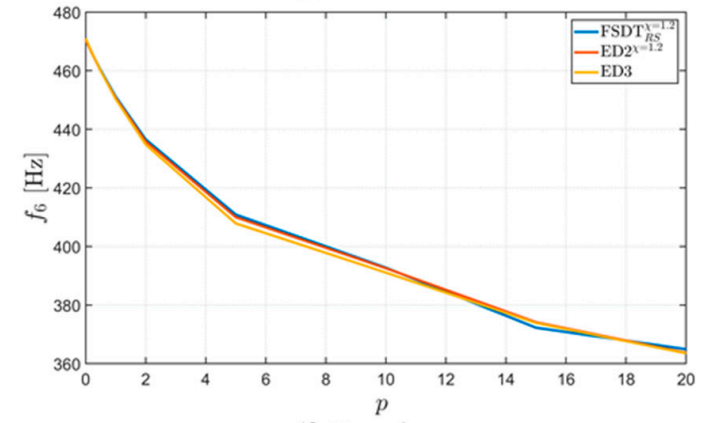

(f) $6^{\text {th }}$ mode

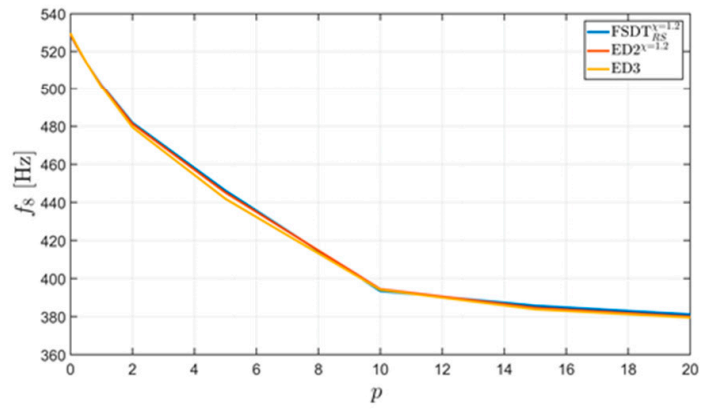

(h) $8^{\text {th }}$ mode

Figure 6. Frequency variations of a CCCC square plate (Figure 3a) made of one lamina of constant thickness $h=0.1 \mathrm{~m}$; reinforced by CNTs distributed as in Figure $5 \mathrm{a}$ for the different parameters $p^{(k)}$. The mass fraction was $w_{r}=0.05$, and the agglomeration parameters $\mu_{1}=\mu_{2}=1$. The Chebyshev-Gauss-Lobatto grid distribution was employed, with $I_{N}=I_{M}=21$. The following mode shapes are considered: (a) 1st mode; (b) 2nd mode; (c) 3rd mode; (d) 4th mode; (e) 5th mode; (f) 6th mode; (g) 7th mode; (h) 8th mode. 


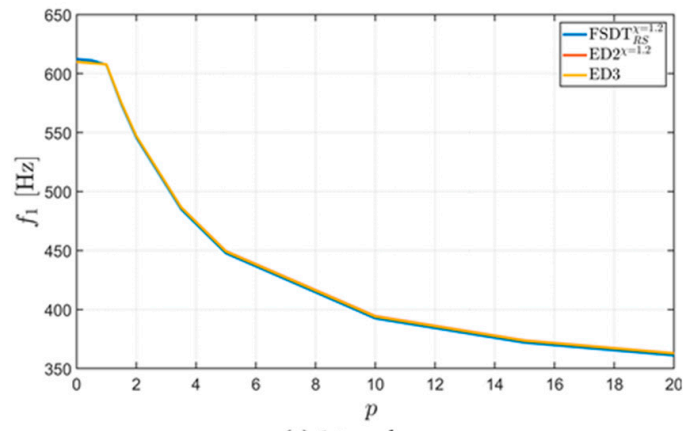

(a) $1^{\text {st }}$ mode

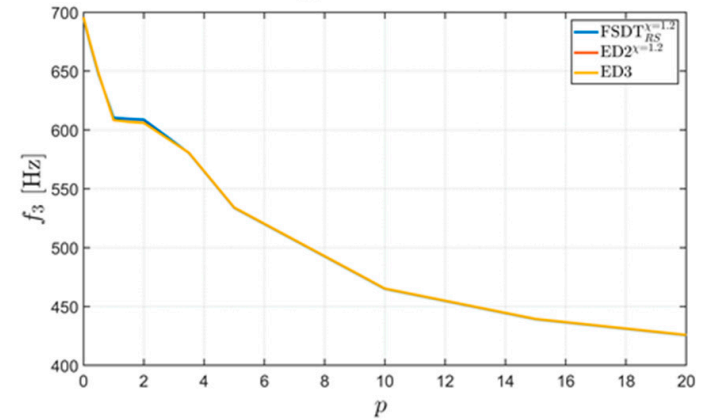

(c) $3^{\text {rd }}$ mode

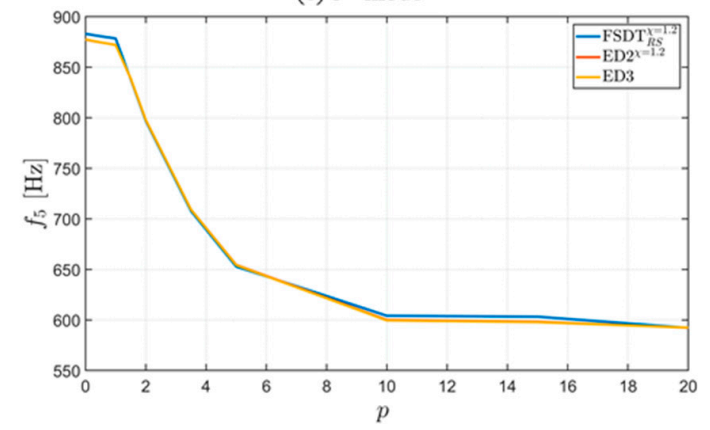

(e) $5^{\text {th }}$ mode

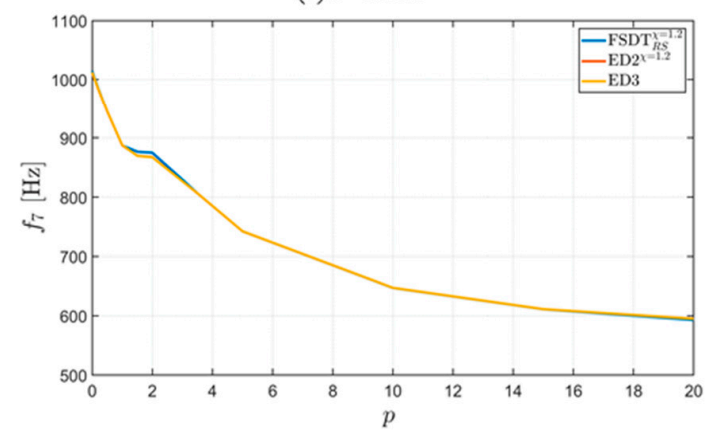

(g) $7^{\text {th }}$ mode

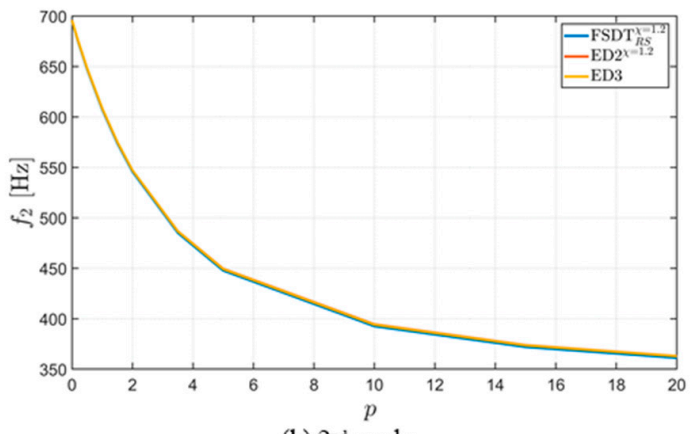

(b) $2^{\text {nd }}$ mode

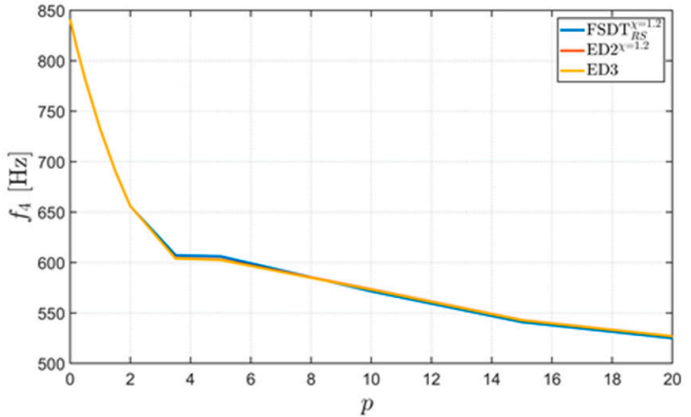

(d) $4^{\text {th }}$ mode

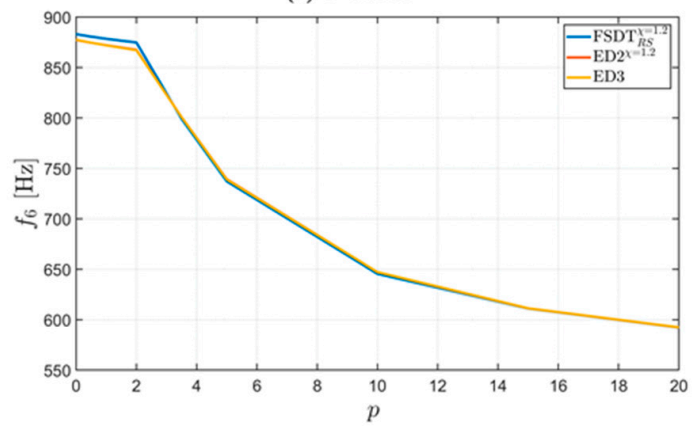

(f) $6^{\text {th }}$ mode

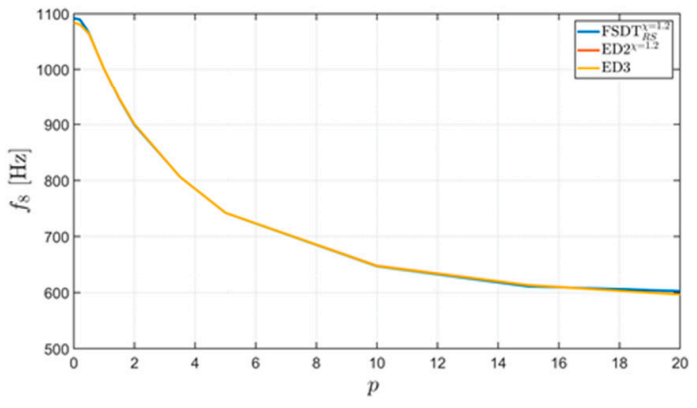

(h) $8^{\text {th }}$ mode

Figure 7. Frequency variations of a CCCC square plate (Figure 3a) made of one lamina of constant thickness $h=0.1 \mathrm{~m}$ reinforced by CNTs distributed as in Figure $5 \mathrm{a}$ for the different parameters $p^{(k)}$. The mass fraction was $w_{r}=0.05$, and the agglomeration parameters $\mu_{1}=\mu_{2}=1$. The Chebyshev-Gauss-Lobatto grid distribution was employed, with $I_{N}=I_{M}=21$. The following mode shapes are considered: (a) 1st mode; (b) 2nd mode; (c) 3rd mode; (d) 4th mode; (e) 5th mode; (f) 6th mode; (g) 7th mode; (h) 8th mode.

\subsection{Effect of Elastic Foundation}

Following example show the variation of the natural frequencies as a function of the parameters that define elastic foundations. A cylindrical surface with cycloidal profile, as shown in Figure $4 \mathrm{~b}$, is assumed, with the boundary conditions CFCF. The agglomeration parameters and the mass fraction 
value of the CNTs are given in Tables 6 and 7. The applied layer schemes are shown in Figure $5 \mathrm{~b}$. In this example, the following theories were used: $\mathrm{FSDT}_{R S}^{\kappa=5 / 6}, \mathrm{FSDTZ}_{R S}^{\kappa=1}, \mathrm{FSDTZ}_{R S}^{\kappa=5 / 6}, \mathrm{ED}^{\kappa=5 / 6}$, $\mathrm{EDZ2}^{\kappa=1}, \mathrm{EDZ2}^{\kappa=5 / 6}$ and ED3. Tables 6 and 7 show the first seven natural frequencies for each theory for different values of the parameters of elastic foundation $k_{3 f}^{(-)}, G_{f}^{(-)}$, respectively. The overall behavior of the variation of these elastic foundation parameters can be observed from the graphs depicted in Figures 8-11. In particular, Figures 8 and 10 show the variation of the first eight natural frequencies as a function of the foundation parameters $k_{3 f}^{(-)}$and $G_{f}^{(-)}$, respectively. In each graph, all the aforementioned theories have been considered. On the other hand, Figures 9 and 11 present seven different graphs (one for each structural theory), in which the variation of the first four natural frequencies are presented in terms of the foundation parameters $k_{3 f}^{(-)}$and $G_{f}^{(-)}$, respectively. Interesting behaviors can be observed. With reference to Figure 9, it can be noted that, initially, $f_{1}$ and $f_{2}$-as well as $f_{3}$ and $f_{4}$-are overlapped. Nevertheless, this feature changes when increasing the value of $k_{3 f}^{(-)}$. Then, a bifurcation point appears, and the frequencies $f_{1}$ and $f_{4}$ are not overlapped anymore; on the other hand, the curve related to $f_{2}$ corresponds with that representing $f_{3}$. Similar observations can be made with reference to Figure 11. In particular, $f_{1}$ and $f_{2}$ exhibit an intermediate behavior in which they are overlapped. Then, the bifurcation point occurs, following which $f_{3}$ and $f_{4}$ turn out to be overlapped. In general, all these frequencies seem to follow specific paths due to the regularity of the corresponding curves. 
Table 6. First seven natural frequency variations of a CFCF cylindrical surface (Figure $4 \mathrm{~b}$ ) reinforced by CNTs distributed as in Figure $5 \mathrm{~b}$ for the different theories. The mass fraction was $w_{r}=0.25$, and the agglomeration parameters $\mu_{1}=0.5$ and $\mu_{2}=0.75$. The Chebyshev-Gauss-Lobatto grid distribution was employed, with $I_{N}=I_{M}=25$.

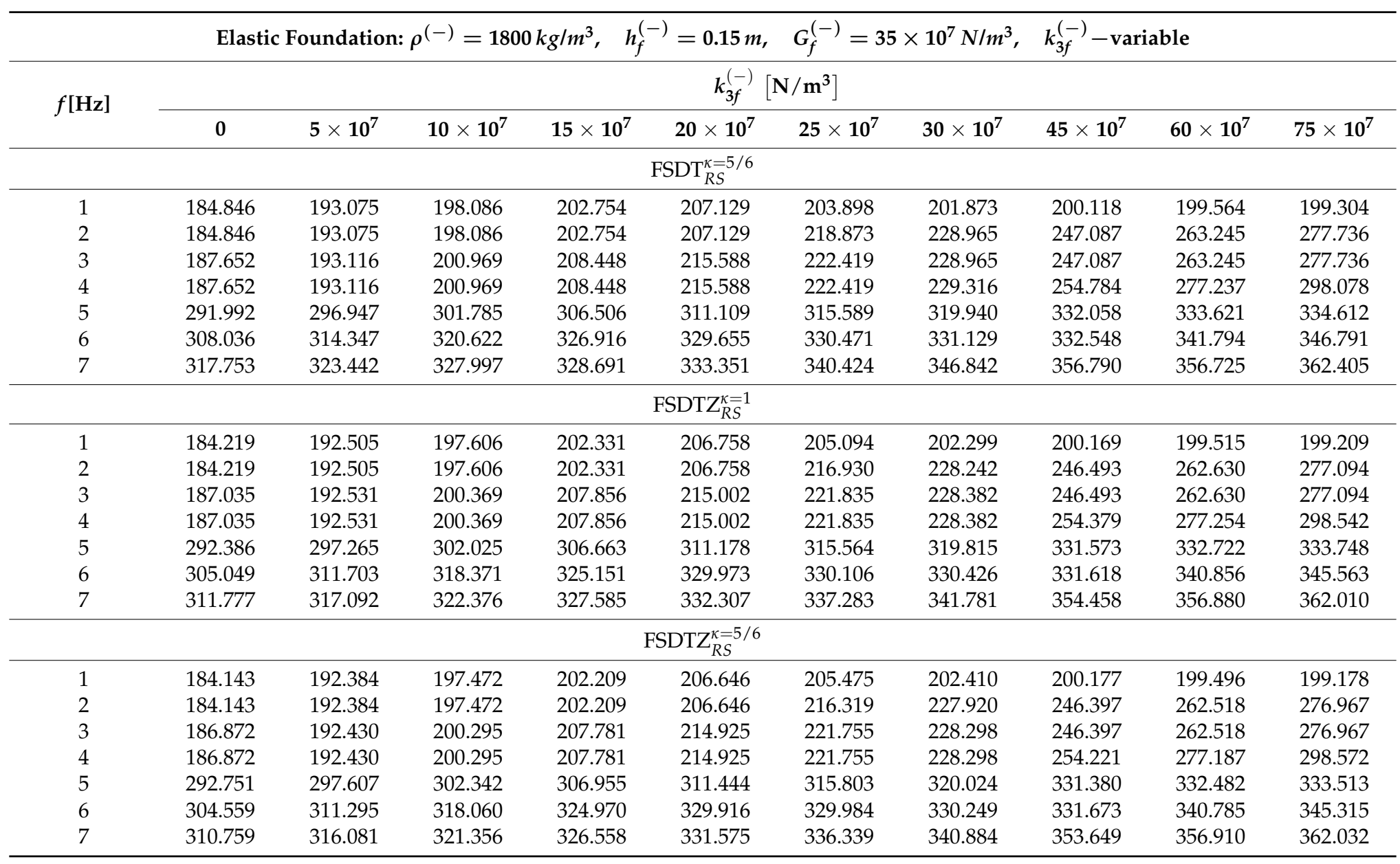


Table 6. Cont

\begin{tabular}{|c|c|c|c|c|c|c|c|c|c|c|}
\hline \multirow{3}{*}{$f[\mathrm{~Hz}]$} & \multicolumn{7}{|c|}{ Elastic Foundation: $\rho^{(-)}=1800 \mathrm{~kg} / \mathrm{m}^{3}, \quad h_{f}^{(-)}=0.15 \mathrm{~m}, \quad G_{f}^{(-)}=35 \times 10^{7} \mathrm{~N} / \mathrm{m}^{3}$, } & \multicolumn{3}{|c|}{$k_{3 f}^{(-)}-$variable } \\
\hline & \multicolumn{10}{|c|}{$k_{3 f}^{(-)}\left[\mathbf{N} / \mathbf{m}^{3}\right]$} \\
\hline & 0 & $5 \times 10^{7}$ & $10 \times 10^{7}$ & $15 \times 10^{7}$ & $20 \times 10^{7}$ & $25 \times 10^{7}$ & $30 \times 10^{7}$ & $45 \times 10^{7}$ & $60 \times 10^{7}$ & $75 \times 10^{7}$ \\
\hline \multicolumn{11}{|c|}{$\mathrm{ED}^{\kappa=5 / 6}$} \\
\hline 1 & 186.687 & 194.391 & 199.212 & 203.714 & 207.942 & 205.231 & 202.692 & 200.560 & 199.876 & 199.550 \\
\hline 2 & 186.687 & 194.391 & 199.212 & 203.714 & 207.942 & 218.856 & 229.420 & 247.064 & 262.813 & 276.946 \\
\hline 5 & 290.128 & 295.022 & 299.799 & 304.461 & 309.005 & 313.429 & 317.727 & 329.757 & 335.300 & 336.145 \\
\hline 6 & 316.760 & 323.854 & 328.821 & 333.100 & 333.255 & 333.455 & 333.689 & 334.478 & 339.860 & 346.176 \\
\hline 7 & 319.144 & 324.040 & 328.821 & 333.474 & 337.991 & 342.370 & 346.620 & 358.671 & 361.209 & 363.034 \\
\hline \multicolumn{11}{|c|}{$\mathrm{EDZ2}^{\kappa=1}$} \\
\hline 1 & 180.565 & 188.140 & 193.540 & 197.799 & 201.800 & 205.576 & 209.157 & 201.174 & 200.003 & 199.511 \\
\hline 6 & 297.762 & 303.773 & 309.834 & 316.050 & 322.668 & 327.295 & 331.515 & 332.455 & 334.959 & 343.487 \\
\hline 7 & 304.543 & 309.302 & 313.956 & 318.507 & 322.956 & 327.295 & 331.515 & 343.413 & 354.283 & 363.689 \\
\hline \multicolumn{11}{|c|}{$\mathrm{EDZ2}^{\kappa=5 / 6}$} \\
\hline 1 & 179.922 & 187.463 & 192.989 & 197.232 & 201.218 & 204.980 & 208.546 & 201.278 & 200.014 & 199.492 \\
\hline 2 & 179.922 & 187.463 & 192.989 & 197.232 & 201.218 & 204.980 & 208.546 & 236.706 & 252.078 & 265.484 \\
\hline 3 & 182.707 & 188.447 & 194.651 & 201.516 & 208.084 & 214.377 & 220.413 & 237.145 & 252.078 & 265.484 \\
\hline 4 & 184.399 & 188.447 & 194.651 & 201.516 & 208.084 & 214.377 & 220.413 & 237.145 & 257.315 & 275.870 \\
\hline 5 & 283.169 & 288.047 & 292.818 & 297.481 & 302.038 & 306.486 & 310.826 & 323.154 & 333.056 & 333.840 \\
\hline 6 & 295.135 & 301.128 & 307.161 & 313.323 & 319.812 & 324.824 & 329.049 & 332.330 & 334.212 & 343.052 \\
\hline 7 & 302.090 & 306.851 & 311.501 & 316.046 & 320.488 & 324.824 & 329.049 & 341.003 & 351.930 & 361.448 \\
\hline
\end{tabular}


Table 6. Cont

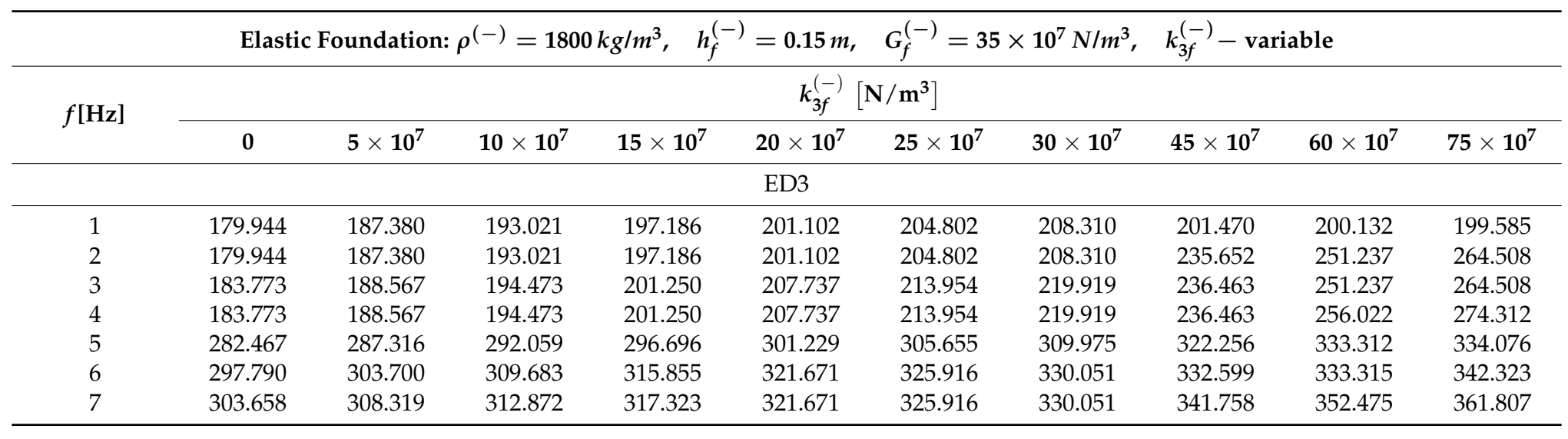

Table 7. First seven natural frequency variations of a CFCF cylindrical surface (Figure $4 b$ ) reinforced by CNTs distributed as in Figure $5 b$ for the different theories. The mass fraction was $w_{r}=0.25$, and the agglomeration parameters $\mu_{1}=0.5$ and $\mu_{2}=0.75$. The Chebyshev-Gauss-Lobatto grid distribution was employed, with $I_{N}=I_{M}=25$.

\begin{tabular}{|c|c|c|c|c|c|c|c|c|c|c|}
\hline \multirow{3}{*}{$f[\mathbf{H z}]$} & \multicolumn{4}{|c|}{ Elastic Foundation: $\mathfrak{x}^{(-)}=1800 \mathrm{~kg} / \mathrm{m}^{3}$} & \multirow{2}{*}{\multicolumn{2}{|c|}{$\frac{\boldsymbol{k}_{3 f}^{(-)}}{[\mathbf{N} / \mathbf{m}]}=$}} & \multicolumn{3}{|c|}{$G_{f}^{(-)}-$variable } & \multirow[b]{3}{*}{$50 \times 10^{7}$} \\
\hline & \multirow[b]{2}{*}{0} & \multirow[b]{2}{*}{$2.5 \times 10^{7}$} & \multirow[b]{2}{*}{$5 \times 10^{7}$} & \multirow[b]{2}{*}{$10 \times 10^{7}$} & & & \multirow[b]{2}{*}{$25 \times 10^{7}$} & \multirow[b]{2}{*}{$30 \times 10^{7}$} & \multirow[b]{2}{*}{$40 \times 10^{7}$} & \\
\hline & & & & & \multirow{2}{*}{$\frac{\mathbf{1 5} \times \mathbf{1 0}^{\mathbf{7}}}{\mathrm{SDT}_{R S}^{\kappa=5 / 6}}$} & \multirow[t]{2}{*}{$20 \times 10^{7}$} & & & & \\
\hline & & & & & & & & & & \\
\hline 1 & 168.599 & 173.281 & 178.405 & 191.003 & 199.948 & 205.025 & 202.136 & 201.329 & 200.784 & 200.568 \\
\hline 2 & 168.830 & 174.502 & 180.563 & 194.562 & 199.948 & 205.025 & 217.847 & 228.065 & 242.029 & 254.510 \\
\hline 3 & 179.422 & 186.012 & 191.354 & 194.562 & 203.783 & 212.375 & 220.454 & 228.065 & 242.029 & 254.510 \\
\hline 4 & 196.850 & 197.574 & 197.383 & 198.293 & 203.783 & 212.375 & 220.454 & 228.422 & 247.988 & 266.838 \\
\hline 5 & 209.081 & 220.508 & 231.570 & 251.683 & 269.487 & 285.418 & 299.759 & 312.664 & 332.575 & 333.808 \\
\hline 6 & 217.985 & 229.196 & 239.947 & 260.269 & 279.357 & 297.576 & 315.303 & 329.404 & 333.975 & 345.403 \\
\hline 7 & 221.416 & 231.995 & 242.131 & 261.435 & 279.879 & 297.945 & 316.271 & 333.309 & 357.922 & 362.186 \\
\hline
\end{tabular}


Table 7. Cont

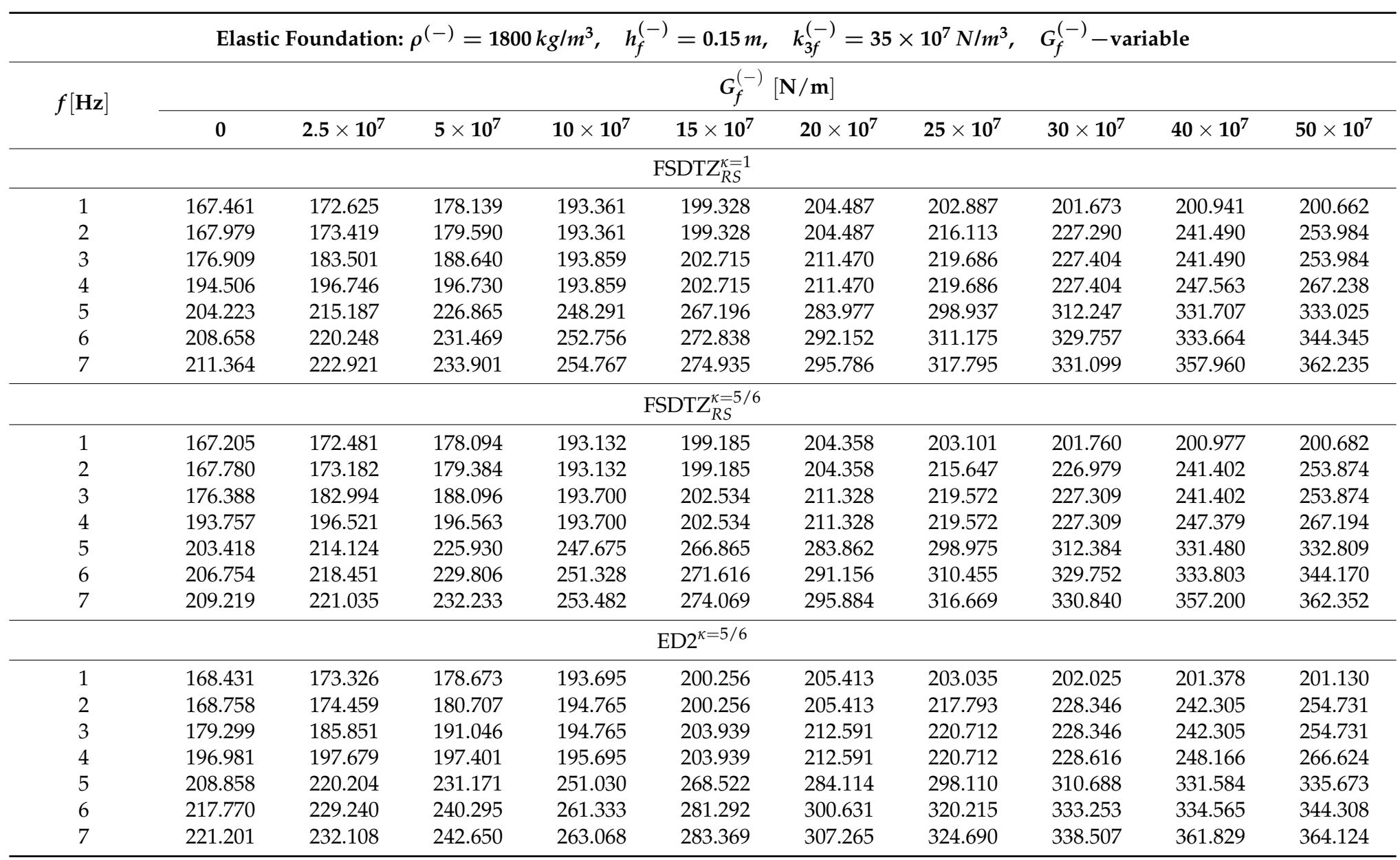


Table 7. Cont

\begin{tabular}{|c|c|c|c|c|c|c|c|c|c|c|}
\hline \multirow{3}{*}{$f[\mathbf{H z}]$} & \multicolumn{9}{|c|}{ Elastic Foundation: $\rho^{(-)}=1800 \mathrm{~kg} / \mathrm{m}^{3}, \quad h_{f}^{(-)}=0.15 \mathrm{~m}, \quad k_{3 f}^{(-)}=35 \times 10^{7} \mathrm{~N} / \mathrm{m}^{3}, G_{f}^{(-)}$-variable } & \\
\hline & \multicolumn{10}{|c|}{$G_{f}^{(-)}[\mathbf{N} / \mathbf{m}]$} \\
\hline & 0 & $2.5 \times 10^{7}$ & $5 \times 10^{7}$ & $10 \times 10^{7}$ & $15 \times 10^{7}$ & $20 \times 10^{7}$ & $25 \times 10^{7}$ & $30 \times 10^{7}$ & $40 \times 10^{7}$ & $50 \times 10^{7}$ \\
\hline \multicolumn{11}{|c|}{$\mathrm{EDZ2}^{\kappa=1}$} \\
\hline 1 & 167.236 & 172.472 & 178.124 & 192.146 & 197.888 & 202.183 & 206.026 & 205.652 & 202.944 & 202.326 \\
\hline 2 & 167.833 & 173.074 & 179.034 & 192.146 & 197.888 & 202.183 & 206.026 & 213.362 & 228.492 & 239.412 \\
\hline 3 & 176.814 & 183.084 & 187.585 & 193.078 & 200.557 & 208.161 & 215.056 & 221.326 & 232.261 & 241.442 \\
\hline 4 & 194.584 & 196.747 & 196.648 & 193.078 & 200.557 & 208.161 & 215.056 & 221.326 & 232.261 & 241.442 \\
\hline 5 & 204.112 & 214.709 & 225.898 & 246.080 & 263.541 & 278.882 & 292.555 & 304.866 & 326.035 & 333.636 \\
\hline 6 & 208.625 & 220.225 & 231.364 & 252.173 & 271.301 & 289.110 & 306.087 & 323.596 & 332.584 & 342.169 \\
\hline 7 & 211.286 & 222.873 & 233.855 & 254.761 & 275.619 & 298.544 & 312.422 & 324.837 & 344.900 & 360.170 \\
\hline \multicolumn{11}{|c|}{$\mathrm{EDZ}^{\kappa}=5 / 6$} \\
\hline 1 & 166.980 & 172.326 & 178.114 & 191.798 & 197.625 & 201.857 & 205.617 & 207.691 & 203.273 & 202.552 \\
\hline 2 & 167.631 & 172.827 & 178.800 & 191.798 & 197.625 & 201.857 & 205.617 & 210.240 & 226.537 & 236.924 \\
\hline 3 & 176.294 & 182.547 & 186.920 & 192.855 & 200.153 & 207.674 & 214.466 & 220.620 & 231.306 & 240.237 \\
\hline 4 & 193.813 & 196.497 & 196.455 & 192.855 & 200.153 & 207.674 & 214.466 & 220.620 & 231.306 & 240.237 \\
\hline 5 & 203.317 & 213.613 & 224.859 & 245.162 & 262.660 & 277.984 & 291.624 & 303.911 & 325.148 & 333.478 \\
\hline 6 & 206.723 & 218.389 & 229.604 & 250.495 & 269.621 & 287.349 & 304.151 & 321.276 & 332.459 & 341.815 \\
\hline 7 & 209.133 & 220.933 & 232.078 & 253.265 & 274.647 & 296.656 & 310.380 & 322.564 & 342.275 & 357.154 \\
\hline \multicolumn{11}{|c|}{ ED3 } \\
\hline 1 & 167.259 & 172.489 & 178.170 & 192.009 & 197.704 & 201.876 & 205.559 & 208.802 & 203.701 & 202.970 \\
\hline 2 & 167.856 & 173.068 & 178.993 & 192.009 & 197.704 & 201.876 & 205.559 & 208.802 & 225.123 & 234.634 \\
\hline 3 & 176.871 & 183.085 & 187.476 & 192.984 & 200.265 & 207.662 & 214.302 & 220.272 & 230.507 & 238.906 \\
\hline 4 & 194.680 & 196.763 & 196.639 & 192.984 & 200.265 & 207.662 & 214.302 & 220.272 & 230.507 & 238.906 \\
\hline 5 & 204.223 & 214.827 & 225.954 & 245.940 & 263.121 & 278.119 & 291.422 & 303.369 & 323.983 & 333.744 \\
\hline 6 & 208.851 & 220.422 & 231.538 & 252.312 & 271.396 & 289.125 & 305.978 & 323.453 & 332.735 & 340.344 \\
\hline 7 & 211.554 & 223.103 & 234.067 & 255.009 & 276.214 & 298.269 & 311.825 & 323.781 & 342.863 & 357.017 \\
\hline
\end{tabular}




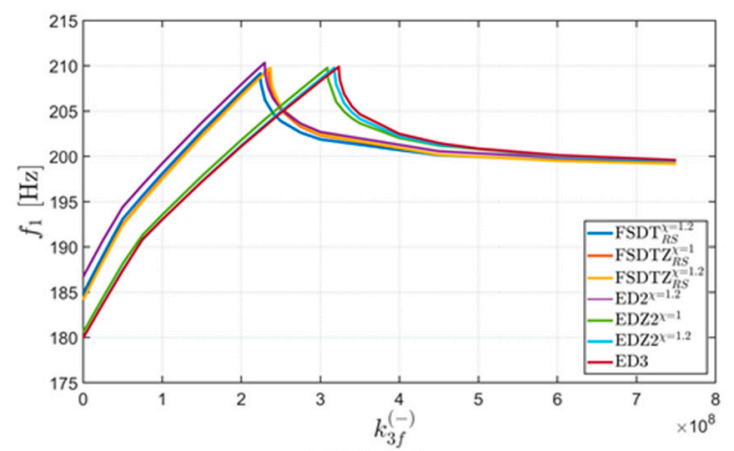

(a) $1^{\text {st }}$ mode

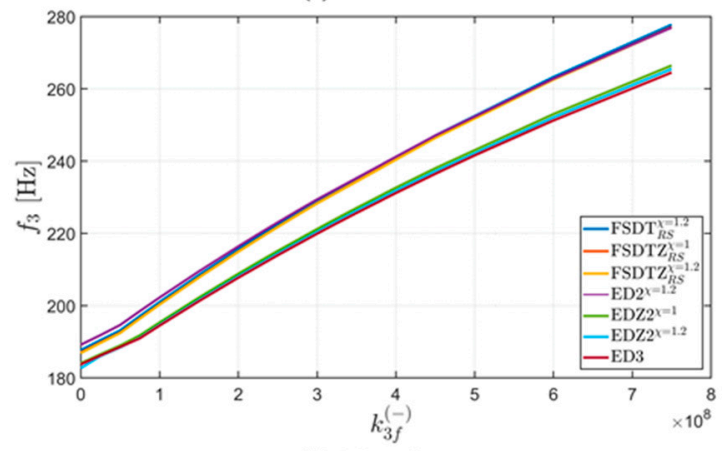

(c) $3^{\text {rd }}$ mode

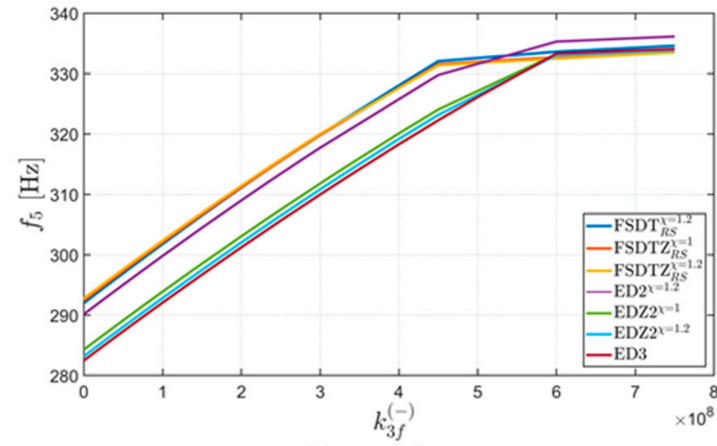

(e) $5^{\text {th }}$ mode

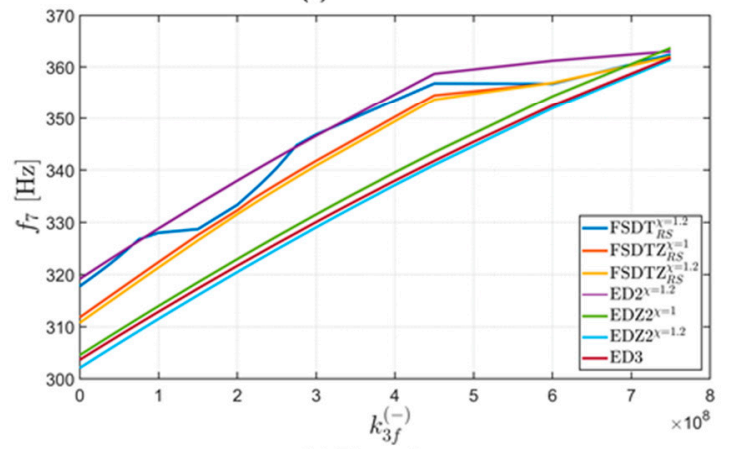

(g) $7^{\text {th }}$ mode

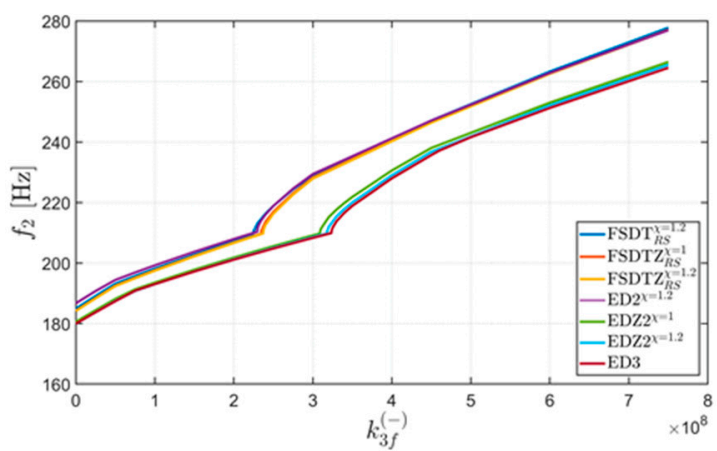

(b) $2^{\text {nd }}$ mode

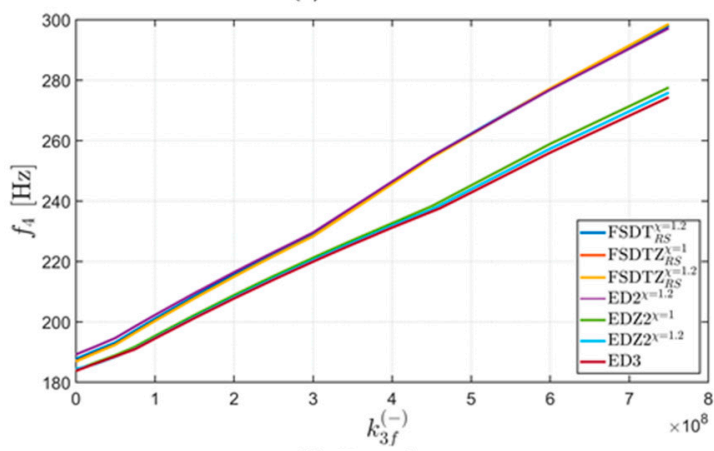

(d) $4^{\text {th }}$ mode

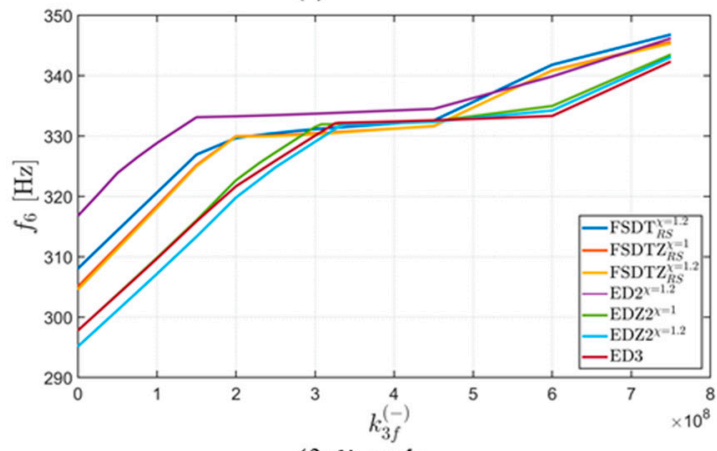

(f) $6^{\text {th }}$ mode

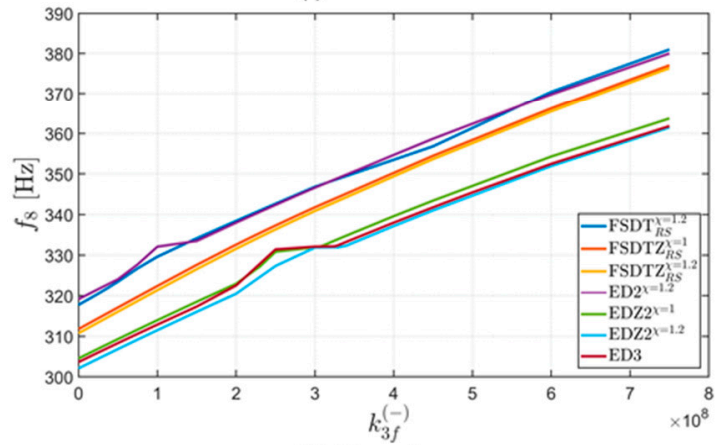

(h) $8^{\text {th }}$ mode

Figure 8. Frequency variations of a CFCF cylindrical surface (Figure $4 \mathrm{~b}$ ) reinforced by CNTs distributed as in Figure $5 \mathrm{~b}$. The mass fraction is $w_{r}=0.25$, and the agglomeration parameters $\mu_{1}=0.5$ and $\mu_{2}=0.75$. The Chebyshev-Gauss-Lobatto grid distribution was employed, with $I_{N}=I_{M}=25$. The following mode shapes are considered: (a) 1st mode; (b) 2nd mode; (c) 3rd mode; (d) 4th mode; (e) 5th mode; (f) 6th mode; (g) 7th mode; (h) 8th mode. 


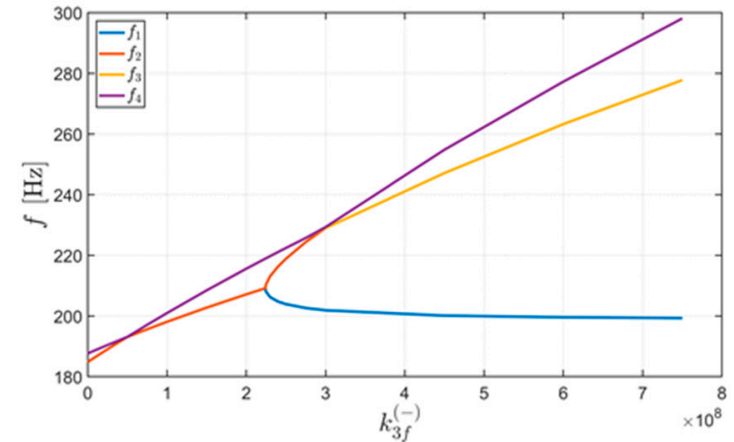

(a) $\mathrm{FSDT}_{R S}^{x-5 / 6}$

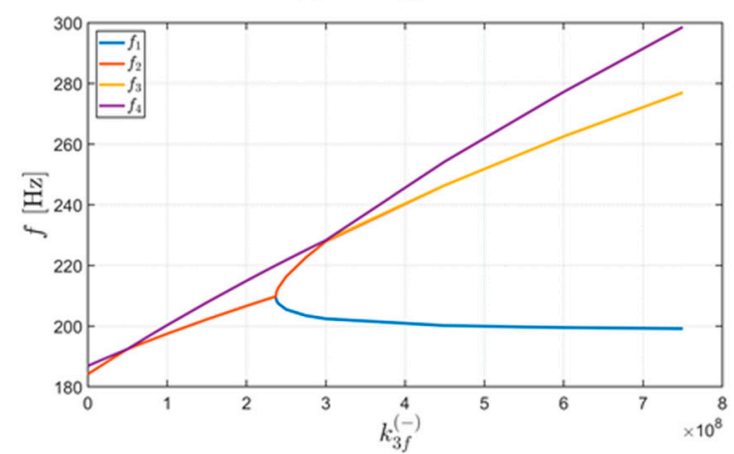

(c) FSDT Z

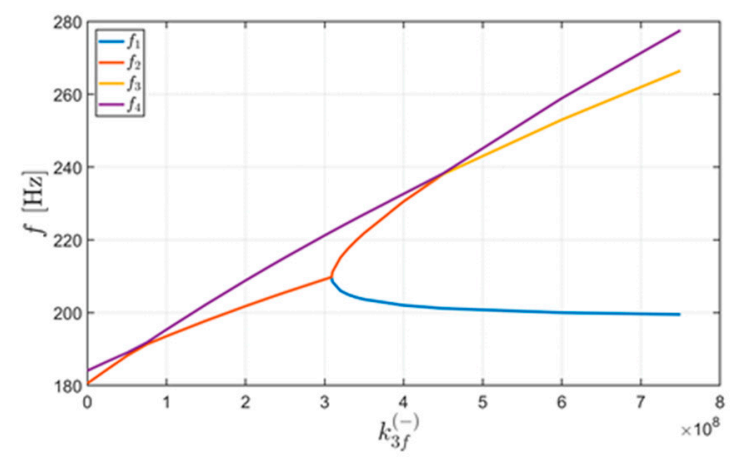

(e) $\mathrm{EDZ}^{x-1}$

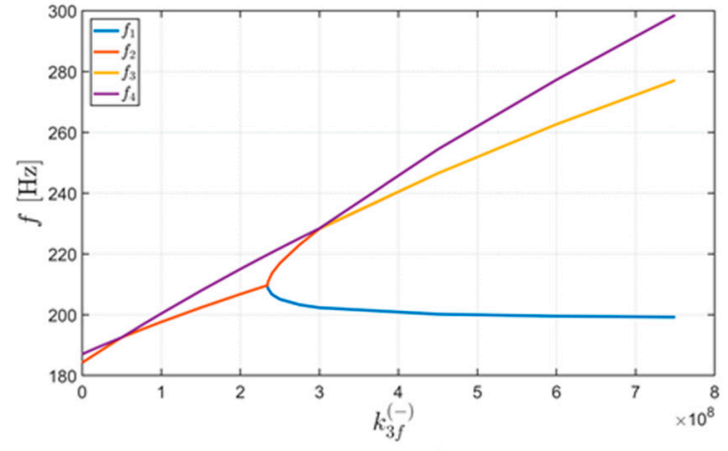

(b) FSDT Z $Z_{R S}^{K-1}$

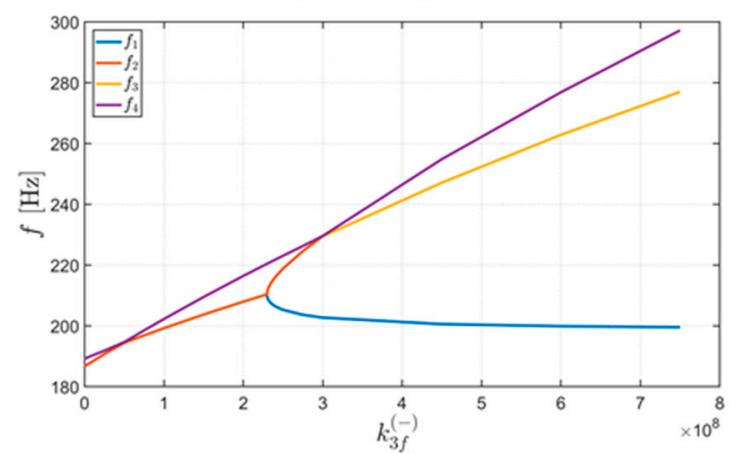

(d) $\mathrm{ED}^{\mathrm{r}-536}$

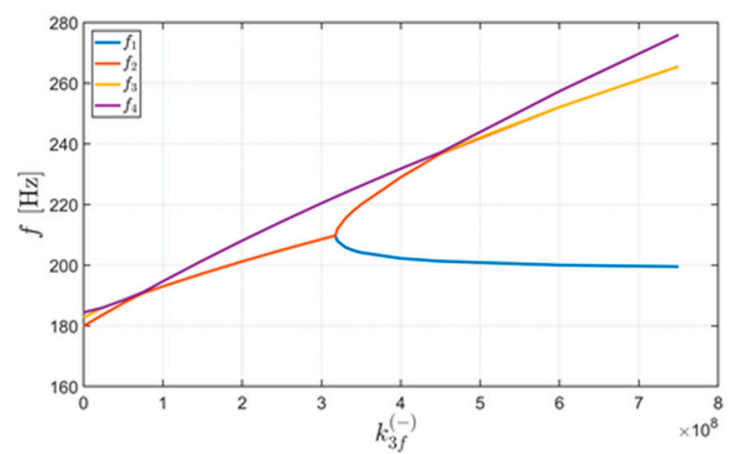

(f) $\mathrm{EDZ2}^{\mathrm{x}-5 / 5}$

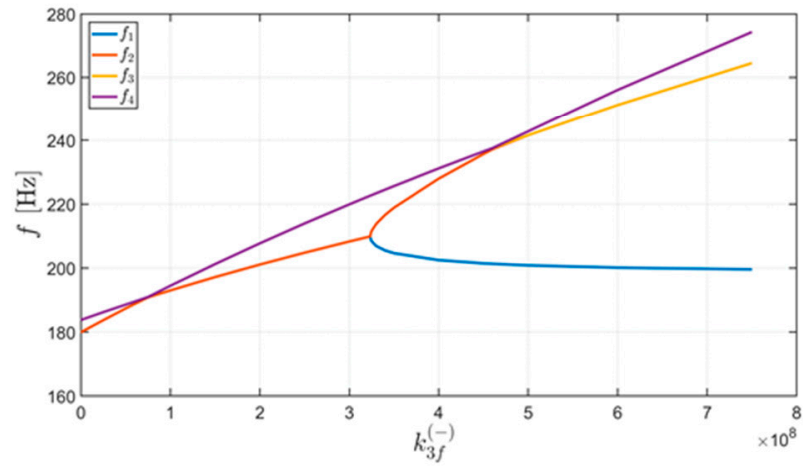

(g) ED3

Figure 9. First four frequency modes of a CFCF cylindrical surface (Figure $4 \mathrm{~b}$ ) reinforced by CNTs distributed as in Figure $5 \mathrm{~b}$ for the different theories: (a) $\mathrm{FSDT}_{R S}^{\kappa=5 / 6}$; (b) $\mathrm{FSDTZ}_{R S}^{\kappa=1}$; (c) $\mathrm{FSDTZ}_{R S}^{\kappa=5 / 6}$; (d) $\mathrm{ED}^{\kappa=5 / 6} ;$ (e) $\mathrm{EDZ}^{\kappa=1}$; (f) $\mathrm{EDZ2}^{\kappa=5 / 6}$; (g) ED3. The mass fraction was $w_{r}=0.25$, and the agglomeration parameters $\mu_{1}=0.5$ and $\mu_{2}=0.75$. The Chebyshev-Gauss-Lobatto grid distribution was employed, with $I_{N}=I_{M}=25$. 


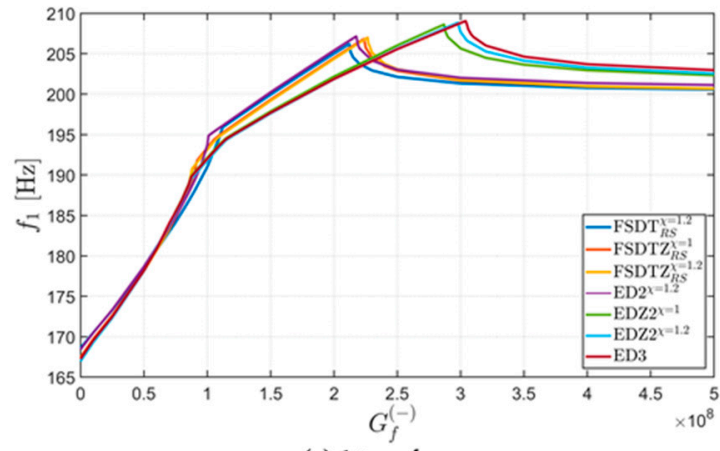

(a) $1^{\text {st }}$ mode

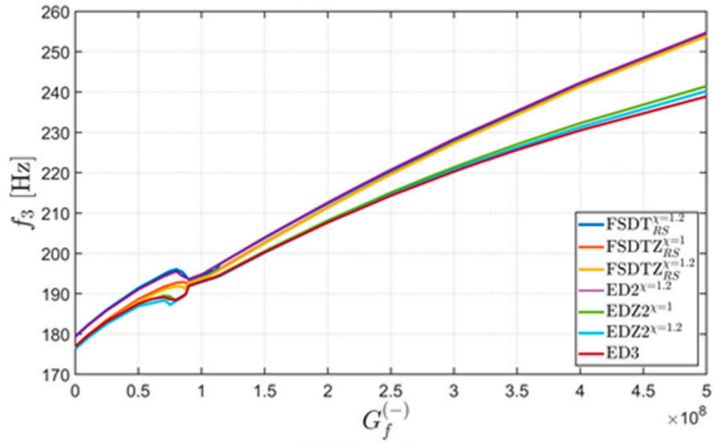

(c) $3^{\text {rd }}$ mode

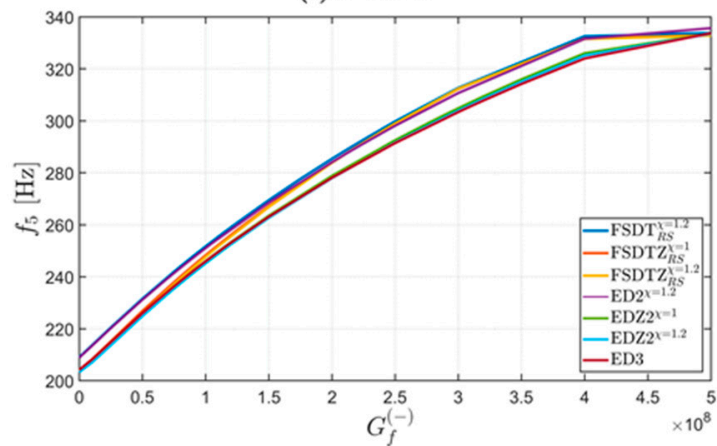

(e) $5^{\text {th }}$ mode

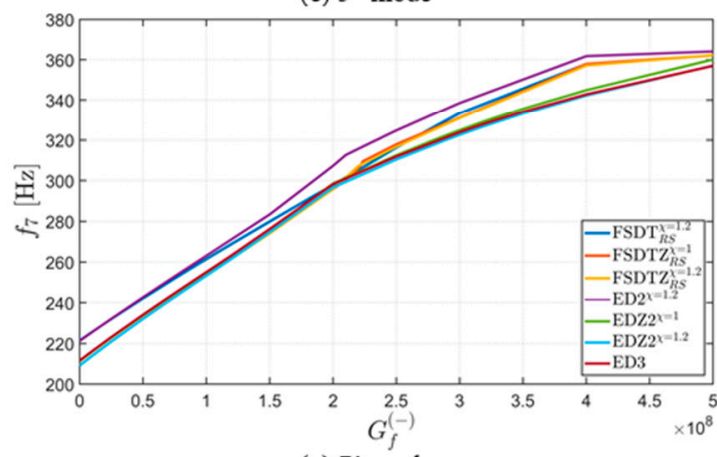

(g) $7^{\text {th }}$ mode

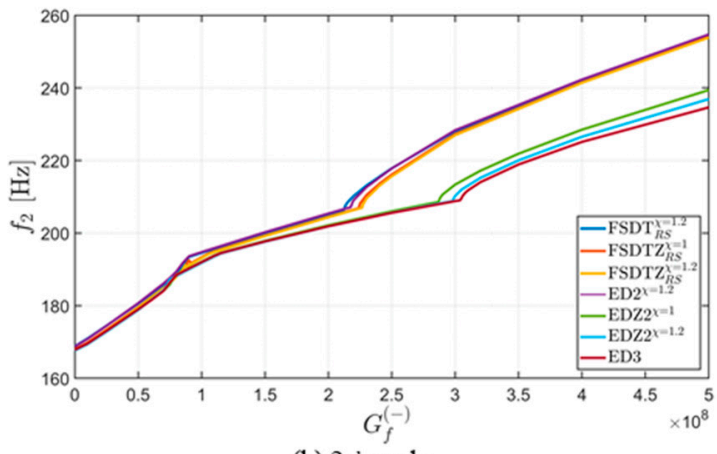

(b) $2^{\text {nd }}$ mode

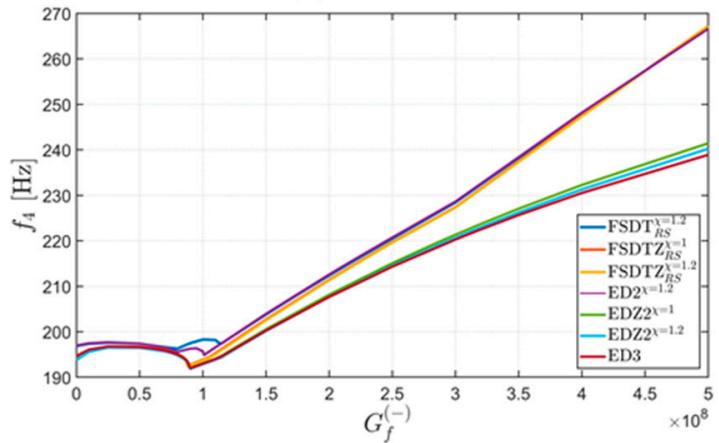

(d) $4^{\text {th }}$ mode

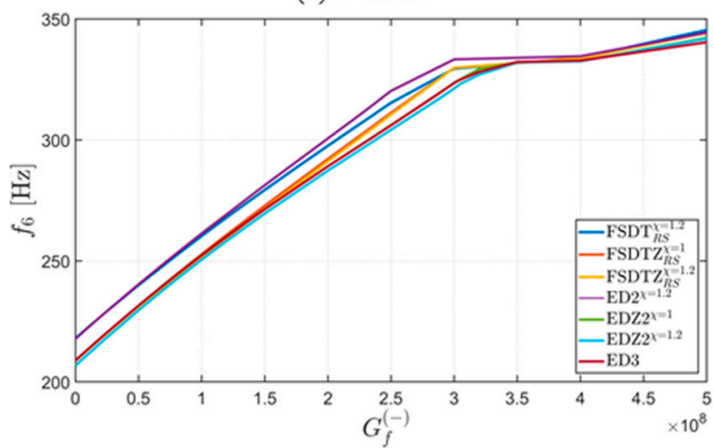

(f) $6^{\text {th }}$ mode

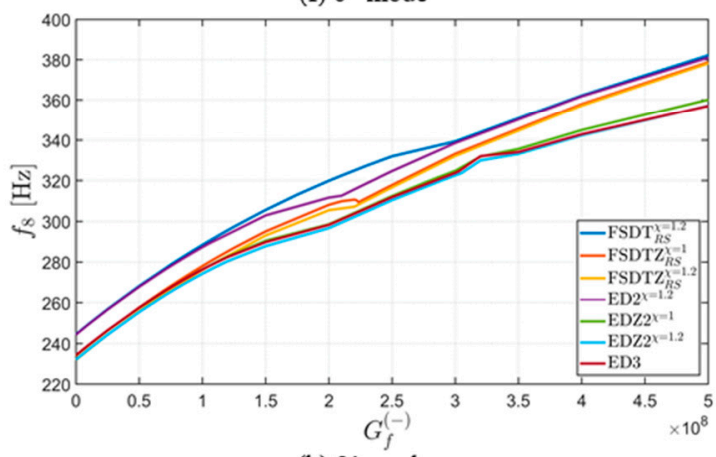

(h) $8^{\text {th }}$ mode

Figure 10. Frequency variations of a CFCF cylindrical surface (Figure $4 \mathrm{~b}$ ) reinforced by CNTs distributed as in Figure $5 \mathrm{~b}$. The mass fraction was $w_{r}=0.25$, and the agglomeration parameters $\mu_{1}=0.5$ and $\mu_{2}=0.75$. The Chebyshev-Gauss-Lobatto grid distribution was employed, with $I_{N}=I_{M}=25$. The following mode shapes are considered: (a) 1st mode; (b) 2nd mode; (c) 3rd mode; (d) 4 th mode; (e) 5th mode; (f) 6th mode; (g) 7th mode; (h) 8 th mode. 


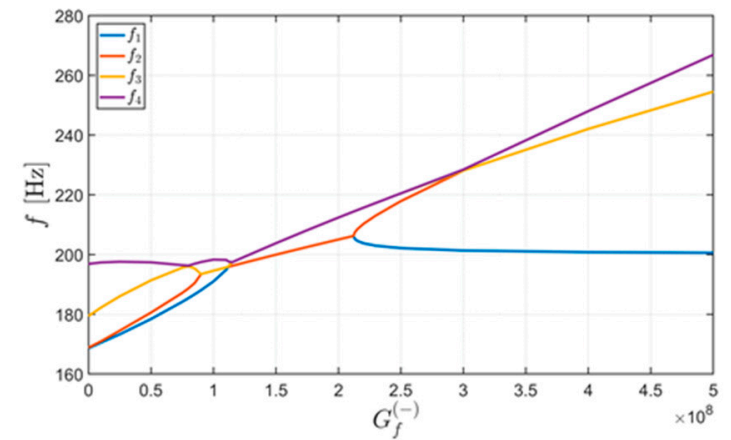

(a) $\operatorname{FSDT}_{R S}^{x-5 / 6}$

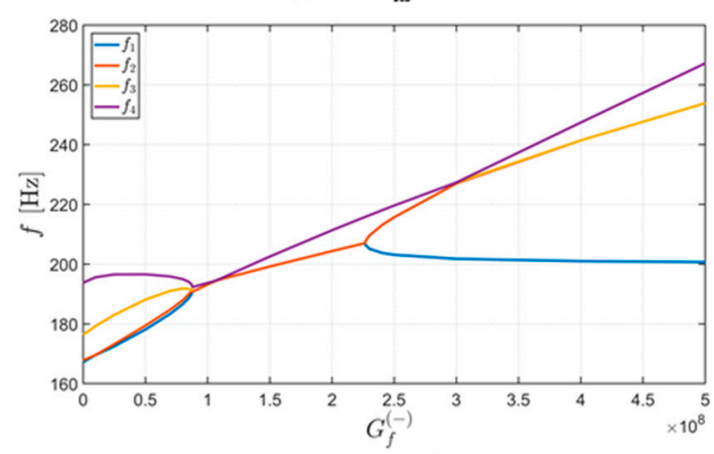

(c) FSDT Z $Z_{R S}^{K-5 / 6}$

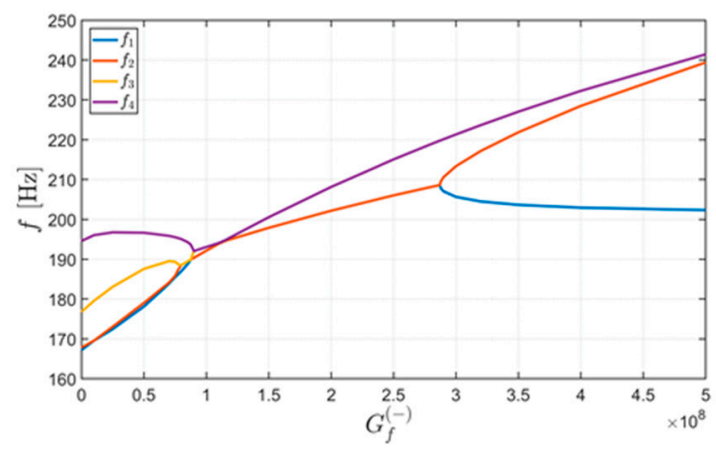

(e) $\mathrm{EDZ2}^{\mathrm{x}-1}$

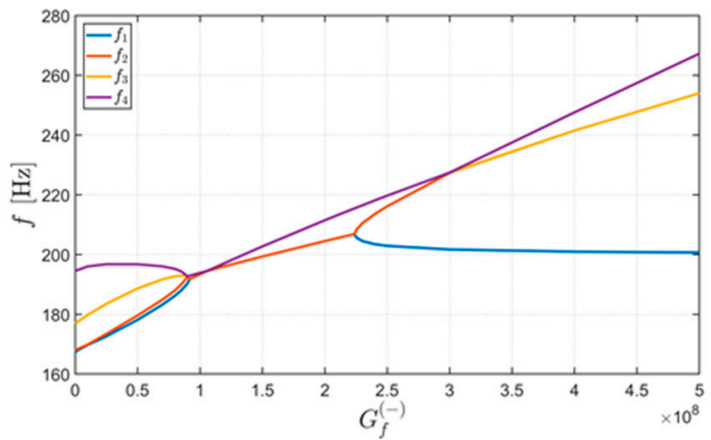

(b) FSDT Z $Z_{R S}^{K-1}$

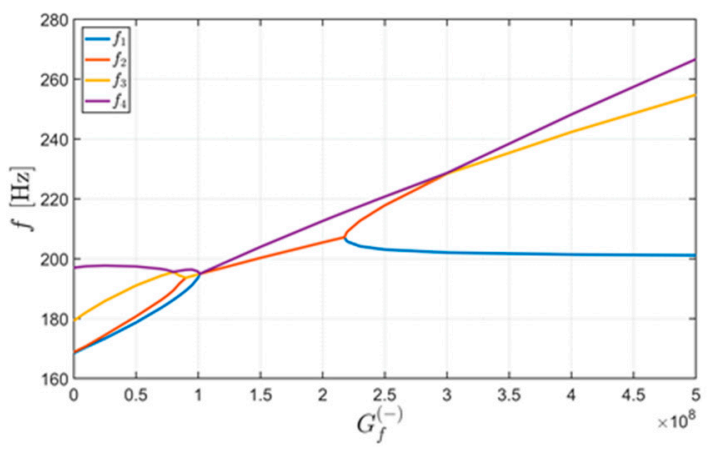

(d) $\mathrm{ED}^{\mathrm{x}-5 / 6}$

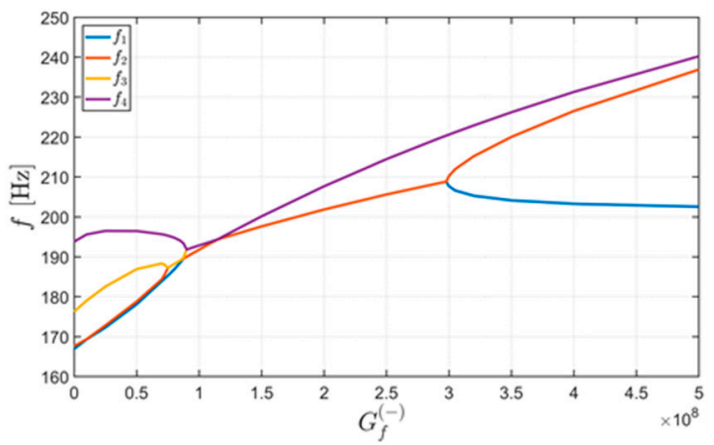

(f) $\mathrm{EDZ}^{\mathrm{x}-5 / 6}$

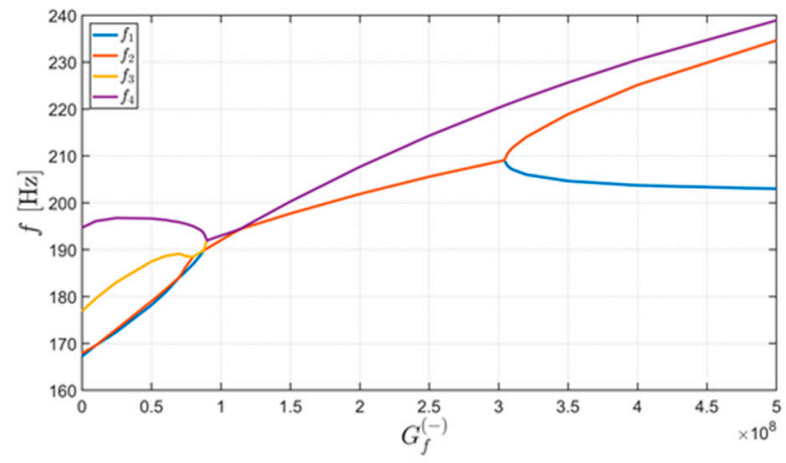

(g) ED3

Figure 11. First four frequency modes of a CFCF cylindrical surface (Figure $4 b$ ) reinforced by CNTs distributed as in Figure 5b for the different theories: (a) $\mathrm{FSDT}_{R S}^{\mathcal{K}=5 / 6}$; (b) $\mathrm{FSDTZ}_{R S}^{\kappa=1}$; (c) $\mathrm{FSDTZ}_{R S}^{\kappa=5 / 6}$; (d) $\mathrm{ED}^{\kappa=5 / 6}$; (e) $\mathrm{EDZ2}^{\kappa=1}$; (f) $\mathrm{EDZ}^{\kappa=5 / 6}$; (g) ED3. The mass fraction was $w_{r}=0.25$, and the agglomeration parameters $\mu_{1}=0.5$ and $\mu_{2}=0.75$. The Chebyshev-Gauss-Lobatto grid distribution was employed, with $I_{N}=I_{M}=25$. 


\subsection{Effect of CNT Agglomeration}

The last example shows the variation of the natural frequencies as a function of the CNT agglomeration parameters. The helicoidal surface, shown in Figure 4c, is considered, with the boundary conditions CCFF. The agglomeration parameters and the mass fraction value of the CNTs are given in Tables 8-21. The applied layer schemes are shown in Figure 5c. In this example, the following theories have been used: $\mathrm{FSDT}_{R S}^{\kappa=5 / 6}, \mathrm{FSDTZ}_{R S}^{\kappa=1}, \mathrm{FSDTZ}_{R S}^{\kappa=5 / 6}, \mathrm{ED2}^{\kappa=5 / 6}, \mathrm{EDZ2}^{\kappa=1}, \mathrm{EDZ}^{\kappa=5 / 6}$ and ED3. Tables 8-14 show the first ten natural frequencies for the corresponding theories for different values of the mass fraction and agglomeration parameter $\mu_{1}$. Tables 15-21 show the first ten natural frequencies for the corresponding theories for different values of the mass fraction and agglomeration parameter $\mu_{2}$. The overall behavior of the agglomeration parameter variation can be observed from the graphs depicted in Figures 12 and 13. These graphs prove again what has been shown in the previous paper by Tornabene et al. [24] and by Shi et al. [32].

Table 8. First ten natural frequency variations for $\mathrm{FSDT}_{R S}^{\kappa=5 / 6}$ theory of a CCFF helicoidal surface (Figure 4c) reinforced by CNTs distributed as in Figure $5 \mathrm{c}$ for different mass fractions $w_{r}$ when varying the parameter of agglomeration $\mu_{1}$ with $\mu_{2}=1$. The Chebyshev-Gauss-Lobatto grid distribution was employed, with $I_{N}=31, I_{M}=21$.

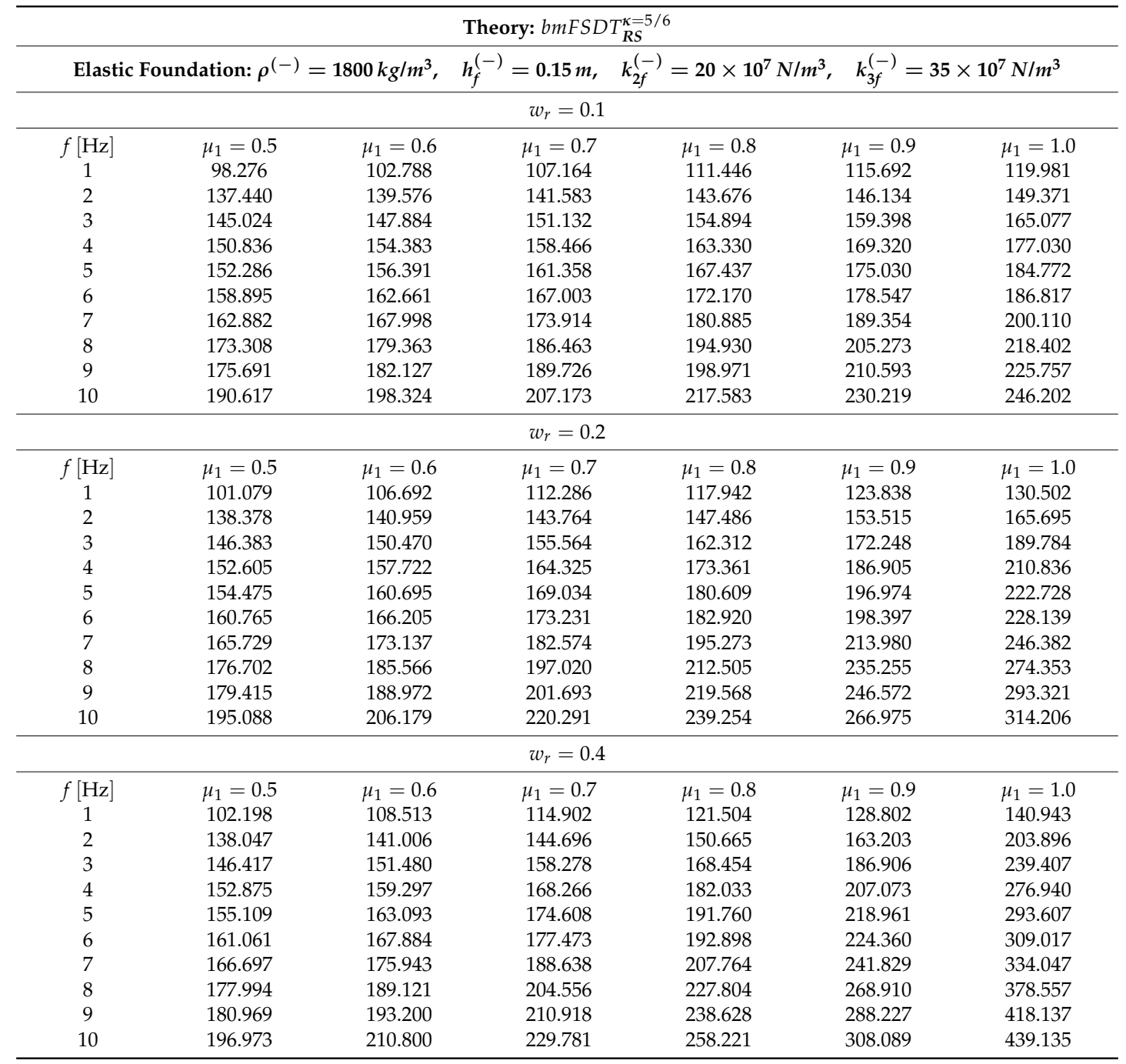


Table 9. First ten natural frequency variations for $\mathrm{FSDTZ}_{R S}^{\kappa=1}$ theory of a CCFF helicoidal surface (Figure $4 \mathrm{c}$ ) reinforced by CNTs distributed as in Figure $5 \mathrm{c}$ for different mass fractions $w_{r}$ when varying the parameter of agglomeration $\mu_{1}$ with $\mu_{2}=1$. The Chebyshev-Gauss-Lobatto grid distribution was employed, with $I_{N}=31, I_{M}=21$.

\begin{tabular}{|c|c|c|c|c|c|c|}
\hline \multicolumn{7}{|c|}{ Theory: FSDTZ $Z_{R S}^{\kappa=1}$} \\
\hline \multicolumn{2}{|c|}{$\rho^{(-)}=1800 \mathrm{~kg} / \mathrm{m}^{3}$} & \multirow{2}{*}{$h_{f}^{(-)}=0.15 m$} & \multicolumn{2}{|c|}{$k_{2 f}^{(-)}=20$} & \multicolumn{2}{|c|}{$k_{3 f}^{(-)}=35 \times 10^{7} \mathrm{~N} / \mathrm{m}^{3}$} \\
\hline \multicolumn{6}{|c|}{$w_{r}=0.1$} & \\
\hline$f[\mathrm{~Hz}]$ & $\mu_{1}=0.5$ & $\mu_{1}=0.6$ & $\mu_{1}=0.7$ & $\mu_{1}=0.8$ & $\mu_{1}=0.9$ & $\mu_{1}=1.0$ \\
\hline 1 & 98.298 & 102.811 & 107.187 & 111.469 & 115.713 & 119.996 \\
\hline 2 & 137.451 & 139.584 & 141.591 & 143.685 & 146.142 & 149.379 \\
\hline 3 & 145.054 & 147.911 & 151.155 & 154.912 & 159.410 & 165.078 \\
\hline 4 & 150.895 & 154.437 & 158.517 & 163.375 & 169.355 & 177.044 \\
\hline 5 & 152.340 & 156.449 & 161.416 & 167.491 & 175.072 & 184.794 \\
\hline 6 & 158.975 & 162.741 & 167.079 & 172.237 & 178.595 & 186.833 \\
\hline 7 & 162.962 & 168.086 & 174.004 & 180.966 & 189.414 & 200.125 \\
\hline 8 & 173.457 & 179.516 & 186.619 & 195.077 & 205.387 & 218.445 \\
\hline 9 & 175.786 & 182.215 & 189.798 & 199.022 & 210.623 & 225.766 \\
\hline 10 & 190.891 & 198.599 & 207.435 & 217.814 & 230.391 & 246.273 \\
\hline \multicolumn{7}{|c|}{$w_{r}=0.2$} \\
\hline$f[\mathrm{~Hz}]$ & $\mu_{1}=0.5$ & $\mu_{1}=0.6$ & $\mu_{1}=0.7$ & $\mu_{1}=0.8$ & $\mu_{1}=0.9$ & $\mu_{1}=1.0$ \\
\hline 1 & 101.103 & 106.718 & 112.314 & 117.970 & 123.860 & 130.511 \\
\hline 2 & 138.388 & 140.969 & 143.776 & 147.502 & 153.533 & 165.698 \\
\hline 3 & 146.418 & 150.503 & 155.595 & 162.338 & 172.263 & 189.771 \\
\hline 4 & 152.671 & 157.789 & 164.394 & 173.427 & 186.953 & 210.818 \\
\hline 5 & 154.542 & 160.769 & 169.109 & 180.679 & 197.030 & 222.701 \\
\hline 6 & 160.863 & 166.308 & 173.337 & 183.020 & 198.462 & 228.129 \\
\hline 7 & 165.836 & 173.262 & 182.709 & 195.403 & 214.068 & 246.329 \\
\hline 8 & 176.891 & 185.781 & 197.257 & 212.735 & 235.416 & 274.285 \\
\hline 9 & 179.521 & 189.065 & 201.763 & 219.618 & 246.601 & 293.314 \\
\hline 10 & 195.423 & 206.534 & 220.649 & 239.582 & 267.204 & 314.140 \\
\hline \multicolumn{7}{|c|}{$w_{r}=0.4$} \\
\hline$f[\mathrm{~Hz}]$ & $\mu_{1}=0.5$ & $\mu_{1}=0.6$ & $\mu_{1}=0.7$ & $\mu_{1}=0.8$ & $\mu_{1}=0.9$ & $\mu_{1}=1.0$ \\
\hline 1 & 102.225 & 108.544 & 114.936 & 121.538 & 128.828 & 140.942 \\
\hline 2 & 138.058 & 141.018 & 144.714 & 150.693 & 163.240 & 203.866 \\
\hline 3 & 146.456 & 151.521 & 158.320 & 168.495 & 186.938 & 239.360 \\
\hline 4 & 152.949 & 159.379 & 168.359 & 182.133 & 207.159 & 276.830 \\
\hline 5 & 155.186 & 163.180 & 174.703 & 191.870 & 219.073 & 293.470 \\
\hline 6 & 161.176 & 168.014 & 177.619 & 193.040 & 224.456 & 308.923 \\
\hline 7 & 166.828 & 176.106 & 188.829 & 207.969 & 241.997 & 333.815 \\
\hline 8 & 178.222 & 189.403 & 204.888 & 228.156 & 269.192 & 378.214 \\
\hline 9 & 181.083 & 193.297 & 210.996 & 238.692 & 288.273 & 418.095 \\
\hline 10 & 197.364 & 211.239 & 230.258 & 258.706 & 308.475 & 438.735 \\
\hline
\end{tabular}


Table 10. First ten natural frequency variations for $\mathrm{FSDTZ}_{R S}^{\kappa=5 / 6}$ theory of a CCFF helicoidal surface (Figure $4 \mathrm{c}$ ) reinforced by CNTs distributed as in Figure $5 \mathrm{c}$ for different mass fractions $w_{r}$ when varying the parameter of agglomeration $\mu_{1}$ with $\mu_{2}=1$. The Chebyshev-Gauss-Lobatto grid distribution was employed, with $I_{N}=31, I_{M}=21$.

\begin{tabular}{|c|c|c|c|c|c|c|}
\hline \multicolumn{7}{|c|}{ Theory: $F S D T Z_{R S}^{\kappa=5 / 6}$} \\
\hline \multicolumn{3}{|c|}{ Elastic Foundation: $\rho^{(-)}=1800 \mathrm{~kg} / \mathrm{m}^{3}$, } & \multirow{2}{*}{$\begin{array}{r}h_{f}^{(-)}=\mathbf{0 . 1 5 m}, \\
w_{r}=0.1\end{array}$} & \multicolumn{3}{|c|}{$k_{2 f}^{(-)}=20 \times 10^{7} \mathrm{~N} / \mathrm{m}^{3}, \quad k_{3 f}^{(-)}=35 \times 10^{7} \mathrm{~N} / \mathrm{m}^{3}$} \\
\hline & & & & & & \\
\hline$f[\mathrm{~Hz}]$ & $\mu_{1}=0.5$ & $\mu_{1}=0.6$ & $\mu_{1}=0.7$ & $\mu_{1}=0.8$ & $\mu_{1}=0.9$ & $\mu_{1}=1.0$ \\
\hline 1 & 98.258 & 102.763 & 107.129 & 111.399 & 115.630 & 119.900 \\
\hline 2 & 137.423 & 139.559 & 141.565 & 143.651 & 146.095 & 149.306 \\
\hline 3 & 144.961 & 147.806 & 151.038 & 154.781 & 159.261 & 164.908 \\
\hline 4 & 150.722 & 154.248 & 158.302 & 163.122 & 169.052 & 176.676 \\
\hline 5 & 152.192 & 156.267 & 161.202 & 167.242 & 174.783 & 184.461 \\
\hline 6 & 158.713 & 162.436 & 166.724 & 171.823 & 178.108 & 186.246 \\
\hline 7 & 162.674 & 167.720 & 173.550 & 180.412 & 188.742 & 199.310 \\
\hline 8 & 172.955 & 178.916 & 185.883 & 194.170 & 204.279 & 217.108 \\
\hline 9 & 175.487 & 181.897 & 189.485 & 198.730 & 210.350 & 225.500 \\
\hline 10 & 189.997 & 197.568 & 206.251 & 216.455 & 228.826 & 244.456 \\
\hline \multicolumn{7}{|c|}{$w_{r}=0.2$} \\
\hline$f[\mathrm{~Hz}]$ & $\mu_{1}=0.5$ & $\mu_{1}=0.6$ & $\mu_{1}=0.7$ & $\mu_{1}=0.8$ & $\mu_{1}=0.9$ & $\mu_{1}=1.0$ \\
\hline 1 & 101.058 & 106.661 & 112.241 & 117.881 & 123.755 & 130.393 \\
\hline 2 & 138.363 & 140.943 & 143.740 & 147.441 & 153.421 & 165.480 \\
\hline 3 & 146.318 & 150.387 & 155.461 & 162.179 & 172.065 & 189.504 \\
\hline 4 & 152.491 & 157.578 & 164.133 & 173.093 & 186.507 & 210.178 \\
\hline 5 & 154.374 & 160.560 & 168.856 & 180.372 & 196.491 & 221.839 \\
\hline 6 & 160.575 & 165.960 & 172.908 & 182.477 & 197.904 & 227.479 \\
\hline 7 & 165.499 & 172.819 & 182.135 & 194.662 & 213.093 & 244.971 \\
\hline 8 & 176.324 & 185.050 & 196.302 & 211.504 & 233.824 & 272.136 \\
\hline 9 & 179.221 & 188.769 & 201.492 & 219.361 & 246.331 & 292.986 \\
\hline 10 & 194.446 & 205.368 & 219.252 & 237.885 & 265.088 & 311.348 \\
\hline \multicolumn{7}{|c|}{$w_{r}=0.4$} \\
\hline$f[\mathrm{~Hz}]$ & $\mu_{1}=0.5$ & $\mu_{1}=0.6$ & $\mu_{1}=0.7$ & $\mu_{1}=0.8$ & $\mu_{1}=0.9$ & $\mu_{1}=1.0$ \\
\hline 1 & 102.177 & 108.481 & 114.854 & 121.439 & 128.715 & 140.784 \\
\hline 2 & 138.034 & 140.989 & 144.665 & 150.596 & 163.036 & 203.369 \\
\hline 3 & 146.352 & 151.398 & 158.173 & 168.310 & 186.680 & 238.914 \\
\hline 4 & 152.764 & 159.151 & 168.062 & 181.727 & 206.558 & 275.716 \\
\hline 5 & 155.007 & 162.957 & 174.425 & 191.415 & 218.244 & 292.008 \\
\hline 6 & 160.873 & 167.636 & 177.132 & 192.481 & 223.841 & 307.863 \\
\hline 7 & 166.463 & 175.613 & 188.170 & 207.075 & 240.709 & 331.549 \\
\hline 8 & 177.609 & 188.579 & 203.785 & 226.685 & 267.137 & 374.759 \\
\hline 9 & 180.793 & 193.025 & 210.746 & 238.435 & 287.960 & 417.583 \\
\hline 10 & 196.341 & 209.988 & 228.709 & 256.731 & 305.792 & 434.336 \\
\hline
\end{tabular}


Table 11. First ten natural frequency variations for ED $2^{\kappa=5 / 6}$ theory of a CCFF helicoidal surface (Figure $4 \mathrm{c}$ ) reinforced by CNTs distributed as in Figure $5 \mathrm{c}$ for different mass fractions $w_{r}$ when varying the parameter of agglomeration $\mu_{1}$ with $\mu_{2}=1$. The Chebyshev-Gauss-Lobatto grid distribution was employed, with $I_{N}=31, I_{M}=21$.

\begin{tabular}{|c|c|c|c|c|c|c|}
\hline \multicolumn{7}{|c|}{ Theory: $E D 2^{\kappa=5 / 6}$} \\
\hline \multicolumn{3}{|c|}{ Elastic Foundation: $\rho^{(-)}=1800 \mathrm{~kg} / \mathrm{m}^{3}$, } & \multirow{2}{*}{$\begin{array}{r}h_{f}^{(-)}=0.15 m, \\
w_{r}=0.1\end{array}$} & \multicolumn{3}{|c|}{$k_{2 f}^{(-)}=20 \times 10^{7} \mathrm{~N} / \mathrm{m}^{3}, \quad k_{3 f}^{(-)}=35 \times 10^{7} \mathrm{~N} / \mathrm{m}^{3}$} \\
\hline & & & & & & \\
\hline$f[\mathrm{~Hz}]$ & $\mu_{1}=0.5$ & $\mu_{1}=0.6$ & $\mu_{1}=0.7$ & $\mu_{1}=0.8$ & $\mu_{1}=0.9$ & $\mu_{1}=1.0$ \\
\hline 1 & 97.894 & 102.446 & 106.868 & 111.200 & 115.498 & 119.837 \\
\hline 2 & 136.937 & 139.191 & 141.300 & 143.475 & 145.999 & 149.295 \\
\hline 3 & 144.467 & 147.289 & 150.551 & 154.371 & 158.961 & 164.738 \\
\hline 4 & 150.691 & 154.330 & 158.473 & 163.375 & 169.394 & 177.129 \\
\hline 5 & 152.660 & 156.839 & 161.849 & 167.948 & 175.543 & 185.272 \\
\hline 6 & 158.439 & 162.211 & 166.579 & 171.782 & 178.201 & 186.528 \\
\hline 7 & 162.193 & 167.428 & 173.440 & 180.496 & 189.047 & 199.881 \\
\hline 8 & 172.779 & 178.909 & 186.051 & 194.552 & 204.945 & 218.150 \\
\hline 9 & 176.008 & 182.493 & 190.143 & 199.416 & 211.023 & 226.131 \\
\hline 10 & 189.979 & 197.824 & 206.789 & 217.298 & 230.016 & 246.067 \\
\hline \multicolumn{7}{|c|}{$w_{r}=0.2$} \\
\hline$f[\mathrm{~Hz}]$ & $\mu_{1}=0.5$ & $\mu_{1}=0.6$ & $\mu_{1}=0.7$ & $\mu_{1}=0.8$ & $\mu_{1}=0.9$ & $\mu_{1}=1.0$ \\
\hline 1 & 100.723 & 106.395 & 112.057 & 117.784 & 123.743 & 130.460 \\
\hline 2 & 137.960 & 140.675 & 143.586 & 147.394 & 153.498 & 165.745 \\
\hline 3 & 145.793 & 149.886 & 155.061 & 161.931 & 172.000 & 189.671 \\
\hline 4 & 152.528 & 157.729 & 164.384 & 173.465 & 187.053 & 211.021 \\
\hline 5 & 154.917 & 161.207 & 169.577 & 181.163 & 197.005 & 222.707 \\
\hline 6 & 160.320 & 165.790 & 172.867 & 182.615 & 198.682 & 228.543 \\
\hline 7 & 165.122 & 172.660 & 182.216 & 195.032 & 213.851 & 246.355 \\
\hline 8 & 176.218 & 185.146 & 196.662 & 212.247 & 235.133 & 274.376 \\
\hline 9 & 179.796 & 189.426 & 202.176 & 220.004 & 246.891 & 293.478 \\
\hline 10 & 194.567 & 205.823 & 220.077 & 239.158 & 266.969 & 314.238 \\
\hline \multicolumn{7}{|c|}{$w_{r}=0.4$} \\
\hline$f[\mathrm{~Hz}]$ & $\mu_{1}=0.5$ & $\mu_{1}=0.6$ & $\mu_{1}=0.7$ & $\mu_{1}=0.8$ & $\mu_{1}=0.9$ & $\mu_{1}=1.0$ \\
\hline 1 & 101.864 & 108.252 & 114.722 & 121.404 & 128.766 & 140.951 \\
\hline 2 & 137.683 & 140.779 & 144.578 & 150.639 & 163.267 & 204.024 \\
\hline 3 & 145.819 & 150.929 & 157.852 & 168.182 & 186.792 & 239.451 \\
\hline 4 & 152.830 & 159.330 & 168.359 & 182.191 & 207.303 & 277.206 \\
\hline 5 & 155.588 & 163.638 & 175.184 & 191.874 & 218.971 & 293.756 \\
\hline 6 & 160.629 & 167.501 & 177.156 & 193.146 & 224.836 & 309.455 \\
\hline 7 & 166.135 & 175.527 & 188.366 & 207.644 & 241.865 & 334.180 \\
\hline 8 & 177.526 & 188.725 & 204.271 & 227.692 & 269.018 & 378.841 \\
\hline 9 & 181.399 & 193.701 & 211.408 & 239.014 & 288.443 & 418.095 \\
\hline 10 & 196.528 & 210.541 & 229.689 & 258.280 & 308.268 & 439.244 \\
\hline
\end{tabular}


Table 12. First ten natural frequency variations for $\mathrm{EDZ}^{\kappa=1}$ theory of a CCFF helicoidal surface (Figure $4 \mathrm{c}$ ) reinforced by CNTs distributed as in Figure $5 \mathrm{c}$ for different mass fractions $w_{r}$ when varying the parameter of agglomeration $\mu_{1}$ with $\mu_{2}=1$. The Chebyshev-Gauss-Lobatto grid distribution was employed, with $I_{N}=31, I_{M}=21$.

\begin{tabular}{|c|c|c|c|c|c|c|}
\hline \multicolumn{7}{|c|}{ Theory: $E D Z 2^{\kappa=1}$} \\
\hline \multicolumn{3}{|c|}{ Elastic Foundation: $\rho^{(-)}=1800 \mathrm{~kg} / \mathrm{m}^{3}$} & \multirow{2}{*}{$\begin{array}{r}h_{f}^{(-)}=\mathbf{0 . 1 5} \boldsymbol{m} \\
w_{r}=0.1\end{array}$} & \multicolumn{3}{|c|}{$k_{2 f}^{(-)}=20 \times 10^{7} \mathrm{~N} / \mathrm{m}^{3}, \quad k_{3 f}^{(-)}=35 \times 10^{7} \mathrm{~N} / \mathrm{m}^{3}$} \\
\hline & & & & & & \\
\hline$f[\mathrm{~Hz}]$ & $\mu_{1}=0.5$ & $\mu_{1}=0.6$ & $\mu_{1}=0.7$ & $\mu_{1}=0.8$ & $\mu_{1}=0.9$ & $\mu_{1}=1.0$ \\
\hline 1 & 97.929 & 102.482 & 106.906 & 111.238 & 115.534 & 119.867 \\
\hline 2 & 136.950 & 139.200 & 141.307 & 143.481 & 146.006 & 149.300 \\
\hline 3 & 144.509 & 147.330 & 150.589 & 154.405 & 158.988 & 164.754 \\
\hline 4 & 150.770 & 154.404 & 158.543 & 163.437 & 169.442 & 177.151 \\
\hline 5 & 152.733 & 156.916 & 161.926 & 168.019 & 175.601 & 185.303 \\
\hline 6 & 158.543 & 162.319 & 166.686 & 171.882 & 178.284 & 186.574 \\
\hline 7 & 162.309 & 167.555 & 173.571 & 180.620 & 189.145 & 199.925 \\
\hline 8 & 173.013 & 179.150 & 186.294 & 194.784 & 205.141 & 218.262 \\
\hline 9 & 176.110 & 182.593 & 190.232 & 199.487 & 211.072 & 226.155 \\
\hline 10 & 190.373 & 198.233 & 207.198 & 217.684 & 230.345 & 246.283 \\
\hline \multicolumn{7}{|c|}{$w_{r}=0.2$} \\
\hline$f[\mathrm{~Hz}]$ & $\mu_{1}=0.5$ & $\mu_{1}=0.6$ & $\mu_{1}=0.7$ & $\mu_{1}=0.8$ & $\mu_{1}=0.9$ & $\mu_{1}=1.0$ \\
\hline 1 & 100.761 & 106.436 & 112.101 & 117.828 & 123.783 & 130.485 \\
\hline 2 & 137.972 & 140.685 & 143.597 & 147.408 & 153.514 & 165.743 \\
\hline 3 & 145.840 & 149.935 & 155.110 & 161.977 & 172.037 & 189.677 \\
\hline 4 & 152.615 & 157.817 & 164.474 & 173.550 & 187.116 & 210.997 \\
\hline 5 & 155.004 & 161.301 & 169.673 & 181.251 & 197.102 & 222.702 \\
\hline 6 & 160.445 & 165.927 & 173.012 & 182.761 & 198.767 & 228.535 \\
\hline 7 & 165.268 & 172.831 & 182.402 & 195.216 & 213.991 & 246.317 \\
\hline 8 & 176.498 & 185.457 & 197.000 & 212.586 & 235.403 & 274.373 \\
\hline 9 & 179.911 & 189.536 & 202.270 & 220.078 & 246.941 & 293.483 \\
\hline 10 & 195.033 & 206.330 & 220.609 & 239.682 & 267.404 & 314.329 \\
\hline \multicolumn{7}{|c|}{$w_{r}=0.4$} \\
\hline$f[\mathrm{~Hz}]$ & $\mu_{1}=0.5$ & $\mu_{1}=0.6$ & $\mu_{1}=0.7$ & $\mu_{1}=0.8$ & $\mu_{1}=0.9$ & $\mu_{1}=1.0$ \\
\hline 1 & 101.905 & 108.297 & 114.773 & 121.456 & 128.812 & 140.966 \\
\hline 2 & 137.694 & 140.791 & 144.595 & 150.667 & 163.304 & 203.979 \\
\hline 3 & 145.872 & 150.986 & 157.914 & 168.247 & 186.854 & 239.424 \\
\hline 4 & 152.926 & 159.435 & 168.475 & 182.314 & 207.407 & 277.054 \\
\hline 5 & 155.685 & 163.747 & 175.301 & 192.048 & 219.143 & 293.615 \\
\hline 6 & 160.772 & 167.667 & 177.348 & 193.306 & 224.958 & 309.332 \\
\hline 7 & 166.309 & 175.740 & 188.617 & 207.919 & 242.106 & 333.912 \\
\hline 8 & 177.849 & 189.109 & 204.718 & 228.181 & 269.452 & 378.513 \\
\hline 9 & 181.523 & 193.819 & 211.512 & 239.105 & 288.515 & 418.060 \\
\hline 10 & 197.055 & 211.143 & 230.364 & 259.003 & 308.927 & 438.971 \\
\hline
\end{tabular}


Table 13. First ten natural frequency variations for $E D Z 2^{\kappa=5 / 6}$ theory of a CCFF helicoidal surface (Figure $4 \mathrm{c}$ ) reinforced by CNTs distributed as in Figure $5 \mathrm{c}$ for different mass fractions $w_{r}$ when varying the parameter of agglomeration $\mu_{1}$ with $\mu_{2}=1$. The Chebyshev-Gauss-Lobatto grid distribution was employed, with $I_{N}=31, I_{M}=21$.

\begin{tabular}{|c|c|c|c|c|c|c|}
\hline \multicolumn{7}{|c|}{ Theory: $E D Z 2^{\kappa=5 / 6}$} \\
\hline \multicolumn{3}{|c|}{ Elastic Foundation: $\rho^{(-)}=1800 \mathrm{~kg} / \mathrm{m}^{3}$, } & \multirow{2}{*}{$\begin{array}{r}h_{f}^{(-)}=\mathbf{0 . 1 5} \boldsymbol{m} \\
w_{r}=0.1\end{array}$} & \multicolumn{3}{|c|}{$k_{2 f}^{(-)}=20 \times 10^{7} \mathrm{~N} / \mathrm{m}^{3}, \quad k_{3 f}^{(-)}=35 \times 10^{7} \mathrm{~N} / \mathrm{m}^{3}$} \\
\hline & & & & & & \\
\hline$f[\mathrm{~Hz}]$ & $\mu_{1}=0.5$ & $\mu_{1}=0.6$ & $\mu_{1}=0.7$ & $\mu_{1}=0.8$ & $\mu_{1}=0.9$ & $\mu_{1}=1.0$ \\
\hline 1 & 97.885 & 102.430 & 106.843 & 111.165 & 115.447 & 119.768 \\
\hline 2 & 136.918 & 139.173 & 141.279 & 143.447 & 145.957 & 149.225 \\
\hline 3 & 144.416 & 147.224 & 150.469 & 154.270 & 158.835 & 164.578 \\
\hline 4 & 150.582 & 154.198 & 158.310 & 163.168 & 169.123 & 176.767 \\
\hline 5 & 152.576 & 156.728 & 161.705 & 167.761 & 175.301 & 184.961 \\
\hline 6 & 158.287 & 162.018 & 166.332 & 171.466 & 177.789 & 185.970 \\
\hline 7 & 162.001 & 167.168 & 173.097 & 180.044 & 188.451 & 199.084 \\
\hline 8 & 172.434 & 178.474 & 185.493 & 193.826 & 203.991 & 216.881 \\
\hline 9 & 175.865 & 182.324 & 189.953 & 199.208 & 210.798 & 225.880 \\
\hline 10 & 189.471 & 197.189 & 205.994 & 216.298 & 228.744 & 244.417 \\
\hline \multicolumn{7}{|c|}{$w_{r}=0.2$} \\
\hline$f[\mathrm{~Hz}]$ & $\mu_{1}=0.5$ & $\mu_{1}=0.6$ & $\mu_{1}=0.7$ & $\mu_{1}=0.8$ & $\mu_{1}=0.9$ & $\mu_{1}=1.0$ \\
\hline 1 & 100.712 & 106.375 & 112.025 & 117.736 & 123.675 & 130.364 \\
\hline 2 & 137.944 & 140.657 & 143.559 & 147.345 & 153.399 & 165.519 \\
\hline 3 & 145.740 & 149.816 & 154.972 & 161.812 & 171.831 & 189.398 \\
\hline 4 & 152.419 & 157.589 & 164.197 & 173.201 & 186.653 & 210.336 \\
\hline 5 & 154.827 & 161.085 & 169.410 & 180.934 & 196.482 & 221.801 \\
\hline 6 & 160.162 & 165.580 & 172.581 & 182.207 & 198.259 & 227.876 \\
\hline 7 & 164.913 & 172.368 & 181.809 & 194.452 & 212.987 & 244.915 \\
\hline 8 & 175.859 & 184.667 & 196.003 & 211.317 & 233.767 & 272.154 \\
\hline 9 & 179.657 & 189.267 & 202.004 & 219.814 & 246.660 & 293.144 \\
\hline 10 & 194.046 & 205.148 & 219.187 & 237.949 & 265.234 & 311.452 \\
\hline \multicolumn{7}{|c|}{$w_{r}=0.4$} \\
\hline$f[\mathrm{~Hz}]$ & $\mu_{1}=0.5$ & $\mu_{1}=0.6$ & $\mu_{1}=0.7$ & $\mu_{1}=0.8$ & $\mu_{1}=0.9$ & $\mu_{1}=1.0$ \\
\hline 1 & 101.852 & 108.230 & 114.687 & 121.353 & 128.696 & 140.804 \\
\hline 2 & 137.668 & 140.760 & 144.544 & 150.567 & 163.094 & 203.466 \\
\hline 3 & 145.767 & 150.861 & 157.762 & 168.056 & 186.586 & 238.956 \\
\hline 4 & 152.724 & 159.191 & 168.163 & 181.893 & 206.788 & 275.907 \\
\hline 5 & 155.498 & 163.514 & 175.011 & 191.488 & 218.278 & 292.100 \\
\hline 6 & 160.473 & 167.289 & 176.856 & 192.825 & 224.335 & 308.240 \\
\hline 7 & 165.925 & 175.229 & 187.938 & 207.001 & 240.783 & 331.572 \\
\hline 8 & 177.170 & 188.238 & 203.580 & 226.671 & 267.343 & 374.944 \\
\hline 9 & 181.270 & 193.560 & 211.257 & 238.838 & 288.194 & 417.537 \\
\hline 10 & 196.020 & 209.874 & 228.786 & 256.984 & 306.175 & 434.423 \\
\hline
\end{tabular}


Table 14. First ten natural frequency variations for ED3 theory of a CCFF helicoidal surface (Figure 4c) reinforced by CNTs distributed as in Figure $5 c$ for different mass fractions $w_{r}$ when varying the parameter of agglomeration $\mu_{1}$ with $\mu_{2}=1$. The Chebyshev-Gauss-Lobatto grid distribution was employed, with $I_{N}=31, I_{M}=21$.

\begin{tabular}{|c|c|c|c|c|c|c|}
\hline \multicolumn{7}{|c|}{ Theory: ED3 } \\
\hline \multicolumn{3}{|c|}{ Elastic Foundation: $\rho^{(-)}=1800 \mathrm{~kg} / \mathrm{m}^{3}$} & \multirow{2}{*}{$\begin{array}{r}\boldsymbol{h}_{f}^{(-)}=\mathbf{0 . 1 5} \boldsymbol{m}, \\
w_{r}=0.1\end{array}$} & \multicolumn{3}{|c|}{$k_{2 f}^{(-)}=20 \times 10^{7} \mathrm{~N} / \mathrm{m}^{3}, \quad k_{3 f}^{(-)}=35 \times 10^{7} \mathrm{~N} / \mathrm{m}^{3}$} \\
\hline & & & & & & \\
\hline$f[\mathrm{~Hz}]$ & $\mu_{1}=0.5$ & $\mu_{1}=0.6$ & $\mu_{1}=0.7$ & $\mu_{1}=0.8$ & $\mu_{1}=0.9$ & $\mu_{1}=1.0$ \\
\hline 1 & 97.923 & 102.473 & 106.891 & 111.217 & 115.504 & 119.827 \\
\hline 2 & 136.934 & 139.186 & 141.291 & 143.462 & 145.979 & 149.257 \\
\hline 3 & 144.473 & 147.288 & 150.539 & 154.345 & 158.914 & 164.658 \\
\hline 4 & 150.692 & 154.316 & 158.439 & 163.309 & 169.280 & 176.935 \\
\hline 5 & 152.674 & 156.842 & 161.834 & 167.905 & 175.458 & 185.121 \\
\hline 6 & 158.437 & 162.191 & 166.531 & 171.690 & 178.038 & 186.241 \\
\hline 7 & 162.172 & 167.380 & 173.350 & 180.339 & 188.783 & 199.441 \\
\hline 8 & 172.777 & 178.869 & 185.949 & 194.350 & 204.580 & 217.512 \\
\hline 9 & 176.005 & 182.475 & 190.106 & 199.356 & 210.936 & 226.005 \\
\hline 10 & 190.036 & 197.833 & 206.719 & 217.102 & 229.616 & 245.330 \\
\hline \multicolumn{7}{|c|}{$w_{r}=0.2$} \\
\hline$f[\mathrm{~Hz}]$ & $\mu_{1}=0.5$ & $\mu_{1}=0.6$ & $\mu_{1}=0.7$ & $\mu_{1}=0.8$ & $\mu_{1}=0.9$ & $\mu_{1}=1.0$ \\
\hline 1 & 100.754 & 106.423 & 112.081 & 117.800 & 123.744 & 130.430 \\
\hline 2 & 137.958 & 140.670 & 143.577 & 147.376 & 153.454 & 165.609 \\
\hline 3 & 145.803 & 149.890 & 155.056 & 161.909 & 171.944 & 189.519 \\
\hline 4 & 152.534 & 157.720 & 164.351 & 173.387 & 186.879 & 210.591 \\
\hline 5 & 154.937 & 161.215 & 169.564 & 181.109 & 196.806 & 222.172 \\
\hline 6 & 160.330 & 165.785 & 172.831 & 182.518 & 198.515 & 228.142 \\
\hline 7 & 165.116 & 172.631 & 182.140 & 194.863 & 213.485 & 245.460 \\
\hline 8 & 176.245 & 185.139 & 196.587 & 212.033 & 234.619 & 273.071 \\
\hline 9 & 179.805 & 189.423 & 202.157 & 219.962 & 246.808 & 293.288 \\
\hline 10 & 194.677 & 205.897 & 220.072 & 238.989 & 266.438 & 312.725 \\
\hline \multicolumn{7}{|c|}{$w_{r}=0.4$} \\
\hline$f[\mathrm{~Hz}]$ & $\mu_{1}=0.5$ & $\mu_{1}=0.6$ & $\mu_{1}=0.7$ & $\mu_{1}=0.8$ & $\mu_{1}=0.9$ & $\mu_{1}=1.0$ \\
\hline 1 & 101.896 & 108.283 & 114.751 & 121.426 & 128.773 & 140.880 \\
\hline 2 & 137.680 & 140.775 & 144.569 & 150.619 & 163.202 & 203.647 \\
\hline 3 & 145.834 & 150.940 & 157.858 & 168.175 & 186.743 & 239.132 \\
\hline 4 & 152.843 & 159.332 & 168.340 & 182.124 & 207.101 & 276.269 \\
\hline 5 & 155.614 & 163.655 & 175.181 & 191.816 & 218.751 & 292.619 \\
\hline 6 & 160.653 & 167.516 & 177.150 & 193.096 & 224.659 & 308.601 \\
\hline 7 & 166.148 & 175.525 & 188.329 & 207.518 & 241.480 & 332.332 \\
\hline 8 & 177.584 & 188.767 & 204.265 & 227.558 & 268.497 & 376.181 \\
\hline 9 & 181.419 & 193.713 & 211.408 & 238.996 & 288.374 & 417.729 \\
\hline 10 & 196.689 & 210.692 & 229.793 & 258.242 & 307.773 & 436.109 \\
\hline
\end{tabular}


Table 15. First ten natural frequency variations for $\mathrm{FSDT}_{R S}^{\kappa=5 / 6}$ theory of a CCFF helicoidal surface (Figure $4 \mathrm{c}$ ) reinforced by CNTs distributed as ing Figure $5 \mathrm{c}$ for different mass fractions $w_{r}$ when varying the parameter of agglomeration $\mu_{2}$ with $\mu_{1}=0.5$. The Chebyshev-Gauss-Lobatto grid distribution was employed, with $I_{N}=31, I_{M}=21$.

\begin{tabular}{|c|c|c|c|c|c|c|}
\hline \multicolumn{7}{|c|}{ Theory: $F S D T_{R S}^{\kappa=5 / 6}$} \\
\hline \multicolumn{3}{|c|}{ Elastic Foundations: $\rho^{(-)}=1800 \mathrm{~kg} / \mathrm{m}^{3}$} & \multirow{2}{*}{$\begin{array}{r}h_{f}^{(-)}=\mathbf{0 . 1 5} \boldsymbol{m} \\
w_{r}=0.1\end{array}$} & \multicolumn{3}{|c|}{$k_{2 f}^{(-)}=20 \times 10^{7} \mathrm{~N} / \mathrm{m}^{3}, \quad k_{3 f}^{(-)}=35 \times 10^{7} \mathrm{~N} / \mathrm{m}^{3}$} \\
\hline & & & & & & \\
\hline$f[\mathrm{~Hz}]$ & $\mu_{2}=0.5$ & $\mu_{2}=0.6$ & $\mu_{2}=0.7$ & $\mu_{2}=0.8$ & $\mu_{2}=0.9$ & $\mu_{2}=1.0$ \\
\hline 1 & 119.985 & 119.692 & 118.625 & 116.255 & 111.188 & 98.276 \\
\hline 2 & 149.375 & 149.118 & 148.233 & 146.499 & 143.536 & 137.440 \\
\hline 3 & 165.084 & 164.643 & 163.108 & 160.026 & 154.598 & 145.024 \\
\hline 4 & 177.039 & 176.439 & 174.353 & 170.184 & 162.969 & 150.836 \\
\hline 5 & 184.783 & 184.021 & 181.364 & 176.043 & 166.882 & 152.286 \\
\hline 6 & 186.827 & 186.176 & 183.924 & 179.456 & 171.782 & 158.895 \\
\hline 7 & 200.122 & 199.290 & 196.388 & 190.559 & 180.355 & 162.882 \\
\hline 8 & 218.417 & 217.403 & 213.865 & 206.755 & 194.304 & 173.308 \\
\hline 9 & 225.774 & 224.581 & 220.435 & 212.198 & 198.179 & 175.691 \\
\hline 10 & 246.221 & 244.983 & 240.665 & 231.986 & 216.776 & 190.617 \\
\hline \multicolumn{7}{|c|}{$w_{r}=0.2$} \\
\hline$f[\mathrm{~Hz}]$ & $\mu_{2}=0.5$ & $\mu_{2}=0.6$ & $\mu_{2}=0.7$ & $\mu_{2}=0.8$ & $\mu_{2}=0.9$ & $\mu_{2}=1.0$ \\
\hline 1 & 130.510 & 130.247 & 129.258 & 126.958 & 121.490 & 101.079 \\
\hline 2 & 165.713 & 165.077 & 162.808 & 158.254 & 150.703 & 138.378 \\
\hline 3 & 189.809 & 188.933 & 185.780 & 179.279 & 167.674 & 146.383 \\
\hline 4 & 210.870 & 209.686 & 205.416 & 196.578 & 180.727 & 152.605 \\
\hline 5 & 222.764 & 221.489 & 216.896 & 207.380 & 189.602 & 154.475 \\
\hline 6 & 228.181 & 226.700 & 221.359 & 210.274 & 190.940 & 160.765 \\
\hline 7 & 246.428 & 244.836 & 239.086 & 227.131 & 205.455 & 165.729 \\
\hline 8 & 274.407 & 272.498 & 265.589 & 251.188 & 224.945 & 176.702 \\
\hline 9 & 293.386 & 291.085 & 282.764 & 265.413 & 233.928 & 179.415 \\
\hline 10 & 314.272 & 311.964 & 303.617 & 286.188 & 254.304 & 195.088 \\
\hline \multicolumn{7}{|c|}{$w_{r}=0.4$} \\
\hline$f[\mathrm{~Hz}]$ & $\mu_{2}=0.5$ & $\mu_{2}=0.6$ & $\mu_{2}=0.7$ & $\mu_{2}=0.8$ & $\mu_{2}=0.9$ & $\mu_{2}=1.0$ \\
\hline 1 & 140.965 & 140.630 & 139.317 & 136.408 & 130.398 & 102.198 \\
\hline 2 & 203.983 & 202.646 & 197.476 & 186.422 & 167.062 & 138.047 \\
\hline 3 & 239.516 & 237.829 & 231.302 & 217.250 & 191.947 & 146.417 \\
\hline 4 & 277.085 & 274.885 & 266.346 & 247.848 & 214.086 & 152.875 \\
\hline 5 & 293.765 & 291.403 & 282.244 & 262.426 & 226.241 & 155.109 \\
\hline 6 & 309.188 & 306.533 & 296.237 & 273.856 & 232.491 & 161.061 \\
\hline 7 & 334.235 & 331.362 & 320.201 & 295.925 & 251.132 & 166.697 \\
\hline 8 & 378.771 & 375.384 & 362.210 & 333.476 & 280.140 & 177.994 \\
\hline 9 & 418.393 & 414.388 & 398.813 & 364.739 & 300.942 & 180.969 \\
\hline 10 & 439.392 & 435.351 & 419.642 & 385.338 & 321.356 & 196.973 \\
\hline
\end{tabular}


Table 16. First ten natural frequency variations for $\mathrm{FSDTZ}_{R S}^{\kappa=1}$ theory of a CCFF helicoidal surface (Figure $4 \mathrm{c}$ ) reinforced by CNTs distributed as in Figure $5 \mathrm{c}$ for different mass fractions $w_{r}$ when varying the parameter of agglomeration $\mu_{2}$ with $\mu_{1}=0.5$. The Chebyshev-Gauss-Lobatto grid distribution was employed, with $I_{N}=31, I_{M}=21$.

\begin{tabular}{|c|c|c|c|c|c|c|}
\hline \multicolumn{7}{|c|}{ Theory: FSDTZ $Z_{R S}^{\kappa=1}$} \\
\hline \multicolumn{3}{|c|}{ Elastic Foundations: $\rho^{(-)}=1800 \mathrm{~kg} / \mathrm{m}^{3}$, } & \multirow{2}{*}{$\begin{array}{r}h_{f}^{(-)}=\mathbf{0 . 1 5} \boldsymbol{m}, \\
w_{r}=0.1\end{array}$} & \multicolumn{3}{|c|}{$k_{2 f}^{(-)}=20 \times 10^{7} \mathrm{~N} / \mathrm{m}^{3}, \quad k_{3 f}^{(-)}=35 \times 10^{7} \mathrm{~N} / \mathrm{m}^{3}$} \\
\hline & & & & & & \\
\hline$f[\mathrm{~Hz}]$ & $\mu_{2}=0.5$ & $\mu_{2}=0.6$ & $\mu_{2}=0.7$ & $\mu_{2}=0.8$ & $\mu_{2}=0.9$ & $\mu_{2}=1.0$ \\
\hline 1 & 120.001 & 119.708 & 118.642 & 116.273 & 111.209 & 98.298 \\
\hline 2 & 149.382 & 149.126 & 148.240 & 146.506 & 143.543 & 137.451 \\
\hline 3 & 165.084 & 164.644 & 163.111 & 160.032 & 154.612 & 145.054 \\
\hline 4 & 177.053 & 176.455 & 174.371 & 170.209 & 163.005 & 150.895 \\
\hline 5 & 184.806 & 184.045 & 181.391 & 176.076 & 166.926 & 152.340 \\
\hline 6 & 186.843 & 186.194 & 183.946 & 179.489 & 171.833 & 158.975 \\
\hline 7 & 200.137 & 199.307 & 196.411 & 190.598 & 180.418 & 162.962 \\
\hline 8 & 218.460 & 217.449 & 213.922 & 206.835 & 194.419 & 173.457 \\
\hline 9 & 225.784 & 224.591 & 220.448 & 212.218 & 198.219 & 175.786 \\
\hline 10 & 246.291 & 245.058 & 240.755 & 232.109 & 216.959 & 190.891 \\
\hline \multicolumn{7}{|c|}{$w_{r}=0.2$} \\
\hline$f[\mathrm{~Hz}]$ & $\mu_{2}=0.5$ & $\mu_{2}=0.6$ & $\mu_{2}=0.7$ & $\mu_{2}=0.8$ & $\mu_{2}=0.9$ & $\mu_{2}=1.0$ \\
\hline 1 & 130.519 & 130.257 & 129.269 & 126.971 & 121.509 & 101.103 \\
\hline 2 & 165.717 & 165.081 & 162.814 & 158.263 & 150.715 & 138.388 \\
\hline 3 & 189.796 & 188.920 & 185.770 & 179.275 & 167.681 & 146.418 \\
\hline 4 & 210.852 & 209.669 & 205.406 & 196.581 & 180.756 & 152.671 \\
\hline 5 & 222.737 & 221.464 & 216.880 & 207.382 & 189.636 & 154.542 \\
\hline 6 & 228.171 & 226.692 & 221.356 & 210.285 & 190.981 & 160.863 \\
\hline 7 & 246.374 & 244.786 & 239.049 & 227.123 & 205.503 & 165.836 \\
\hline 8 & 274.340 & 272.436 & 265.546 & 251.194 & 225.039 & 176.891 \\
\hline 9 & 293.380 & 291.079 & 282.760 & 265.416 & 233.946 & 179.521 \\
\hline 10 & 314.205 & 311.904 & 303.582 & 286.213 & 254.445 & 195.423 \\
\hline \multicolumn{7}{|c|}{$w_{r}=0.4$} \\
\hline$f[\mathrm{~Hz}]$ & $\mu_{2}=0.5$ & $\mu_{2}=0.6$ & $\mu_{2}=0.7$ & $\mu_{2}=0.8$ & $\mu_{2}=0.9$ & $\mu_{2}=1.0$ \\
\hline 1 & 140.964 & 140.629 & 139.318 & 136.412 & 130.410 & 102.225 \\
\hline 2 & 203.953 & 202.618 & 197.452 & 186.412 & 167.071 & 138.058 \\
\hline 3 & 239.469 & 237.784 & 231.262 & 217.222 & 191.941 & 146.456 \\
\hline 4 & 276.974 & 274.777 & 266.252 & 247.787 & 214.084 & 152.949 \\
\hline 5 & 293.622 & 291.261 & 282.123 & 262.344 & 226.235 & 155.186 \\
\hline 6 & 309.093 & 306.440 & 296.156 & 273.806 & 232.496 & 161.176 \\
\hline 7 & 334.001 & 331.135 & 320.002 & 295.789 & 251.115 & 166.828 \\
\hline 8 & 378.432 & 375.056 & 361.918 & 333.284 & 280.128 & 178.222 \\
\hline 9 & 418.353 & 414.349 & 398.778 & 364.717 & 300.943 & 181.083 \\
\hline 10 & 438.995 & 434.963 & 419.299 & 385.118 & 321.362 & 197.364 \\
\hline
\end{tabular}


Table 17. First ten natural frequency variations for $\mathrm{FSDTZ}_{R S}^{\kappa=5 / 6}$ theory of a CCFF helicoidal surface (Figure $4 \mathrm{c}$ ) reinforced by CNTs distributed as in Figure $5 \mathrm{c}$ for different mass fractions $w_{r}$ when varying the parameter of agglomeration $\mu_{2}$ with $\mu_{1}=0.5$. The Chebyshev-Gauss-Lobatto grid distribution was employed, with $I_{N}=31, I_{M}=21$.

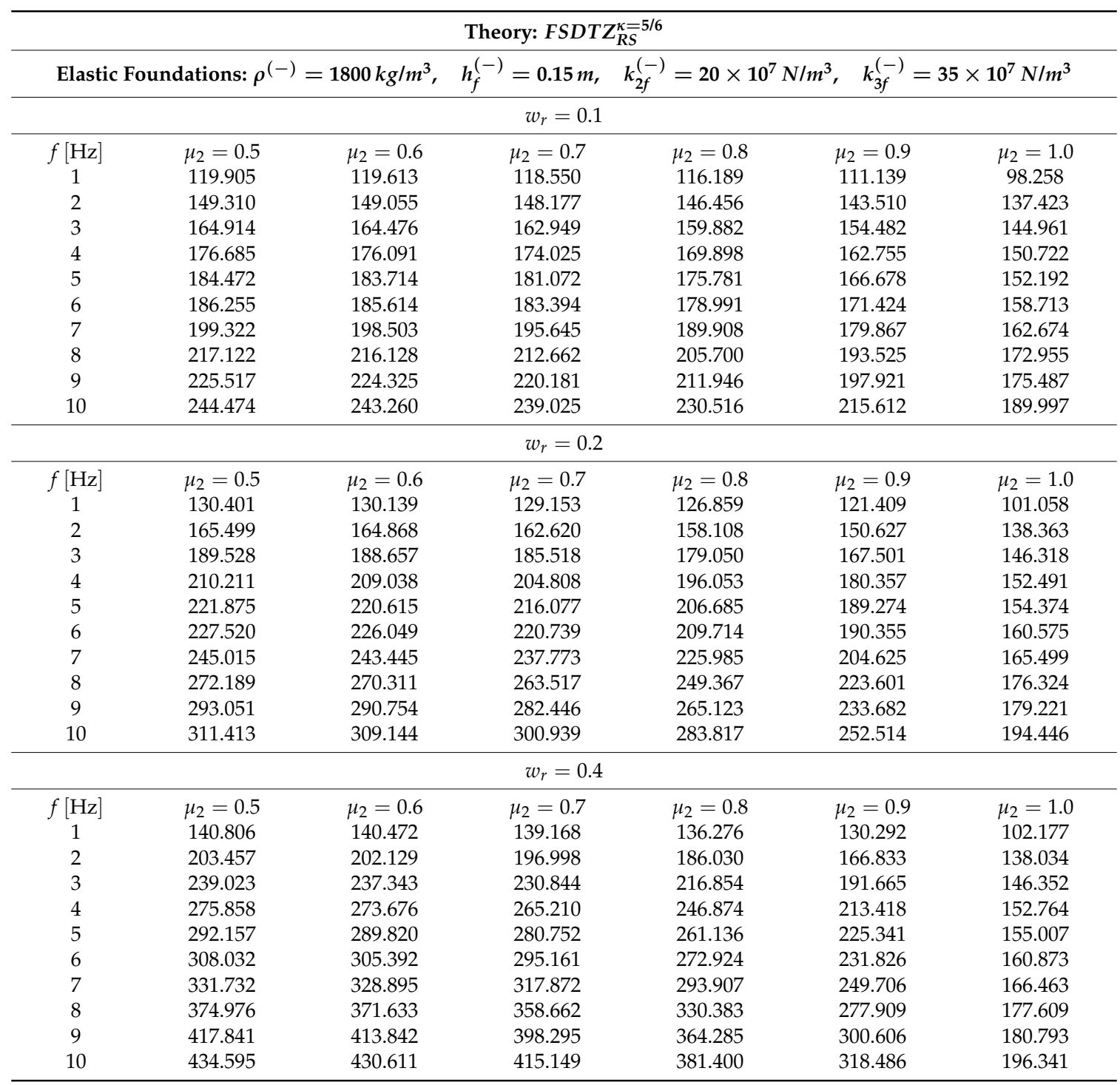


Table 18. First ten natural frequency variations for ED $2^{\kappa=5 / 6}$ theory of a CCFF helicoidal surface (Figure $4 \mathrm{c}$ ) reinforced by CNTs distributed as in Figure $5 \mathrm{c}$ for different mass fractions $w_{r}$ when varying the parameter of agglomeration $\mu_{2}$ with $\mu_{1}=0.5$. The Chebyshev-Gauss-Lobatto grid distribution was employed, with $I_{N}=31, I_{M}=21$.

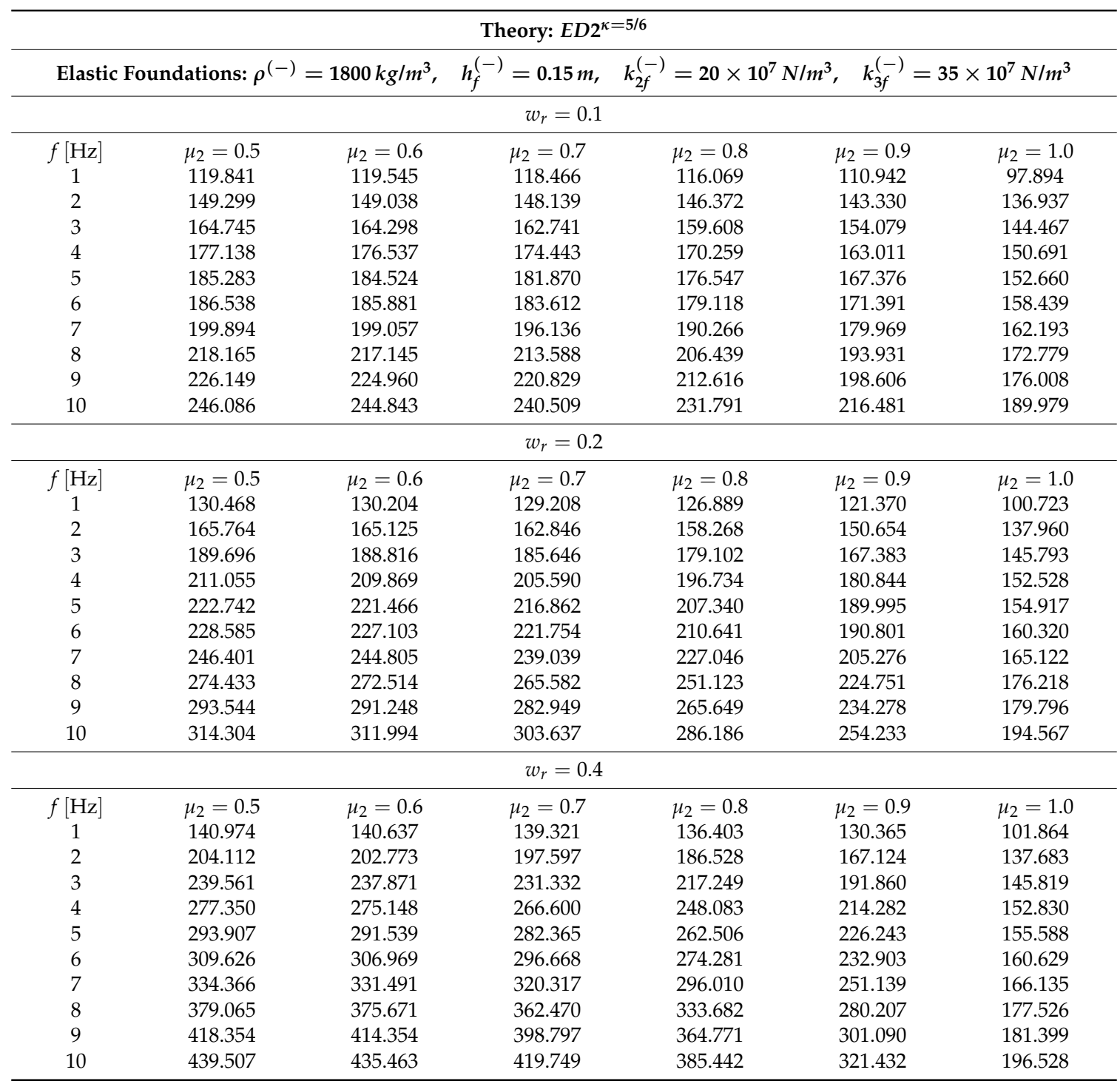


Table 19. First ten natural frequency variations for $E D Z 2^{\kappa=1}$ theory of a CCFF helicoidal surface (Figure $4 \mathrm{c}$ ) reinforced by CNTs distributed as in Figure $5 \mathrm{c}$ for different mass fractions $w_{r}$ when varying the parameter of agglomeration $\mu_{2}$ with $\mu_{1}=0.5$. The Chebyshev-Gauss-Lobatto grid distribution was employed, with $I_{N}=31, I_{M}=21$.

\begin{tabular}{|c|c|c|c|c|c|c|}
\hline \multicolumn{7}{|c|}{ Theory: $E D Z 2^{\kappa=1}$} \\
\hline \multicolumn{3}{|c|}{ Elastic Foundations: $\rho^{(-)}=1800 \mathrm{~kg} / \mathrm{m}^{3}$} & \multirow{2}{*}{$\begin{array}{r}h_{f}^{(-)}=\mathbf{0 . 1 5} \boldsymbol{m}, \\
w_{r}=0.1\end{array}$} & \multirow{2}{*}{$k_{2 f}^{(-)}=20 \times 10^{7} \mathrm{~N} / \mathrm{m}^{3}$} & \multicolumn{2}{|c|}{$k_{3 f}^{(-)}=35 \times 10^{7} \mathrm{~N} / \mathrm{m}^{3}$} \\
\hline & & & & & & \\
\hline$f[\mathrm{~Hz}]$ & $\mu_{2}=0.5$ & $\mu_{2}=0.6$ & $\mu_{2}=0.7$ & $\mu_{2}=0.8$ & $\mu_{2}=0.9$ & $\mu_{2}=1.0$ \\
\hline 1 & 119.872 & 119.575 & 118.498 & 116.102 & 110.976 & 97.929 \\
\hline 2 & 149.303 & 149.043 & 148.144 & 146.378 & 143.336 & 136.950 \\
\hline 3 & 164.761 & 164.315 & 162.759 & 159.629 & 154.108 & 144.509 \\
\hline 4 & 177.160 & 176.560 & 174.470 & 170.295 & 163.061 & 150.770 \\
\hline 5 & 185.314 & 184.556 & 181.907 & 176.593 & 167.437 & 152.733 \\
\hline 6 & 186.584 & 185.929 & 183.665 & 179.181 & 171.473 & 158.543 \\
\hline 7 & 199.938 & 199.102 & 196.190 & 190.337 & 180.067 & 162.309 \\
\hline 8 & 218.277 & 217.260 & 213.715 & 206.591 & 194.121 & 173.013 \\
\hline 9 & 226.173 & 224.984 & 220.857 & 212.653 & 198.665 & 176.110 \\
\hline 10 & 246.301 & 245.063 & 240.744 & 232.058 & 216.806 & 190.373 \\
\hline \multicolumn{7}{|c|}{$w_{r}=0.2$} \\
\hline$f[\mathrm{~Hz}]$ & $\mu_{2}=0.5$ & $\mu_{2}=0.6$ & $\mu_{2}=0.7$ & $\mu_{2}=0.8$ & $\mu_{2}=0.9$ & $\mu_{2}=1.0$ \\
\hline 1 & 130.493 & 130.229 & 129.234 & 126.918 & 121.404 & 100.761 \\
\hline 2 & 165.761 & 165.123 & 162.847 & 158.273 & 150.663 & 137.972 \\
\hline 3 & 189.702 & 188.822 & 185.654 & 179.116 & 167.408 & 145.840 \\
\hline 4 & 211.031 & 209.847 & 205.577 & 196.739 & 180.883 & 152.615 \\
\hline 5 & 222.738 & 221.463 & 216.870 & 207.367 & 190.044 & 155.004 \\
\hline 6 & 228.577 & 227.097 & 221.756 & 210.662 & 190.872 & 160.445 \\
\hline 7 & 246.363 & 244.770 & 239.020 & 227.063 & 205.359 & 165.268 \\
\hline 8 & 274.428 & 272.515 & 265.605 & 251.201 & 224.929 & 176.498 \\
\hline 9 & 293.548 & 291.253 & 282.956 & 265.665 & 234.313 & 179.911 \\
\hline 10 & 314.394 & 312.090 & 303.760 & 286.371 & 254.538 & 195.033 \\
\hline \multicolumn{7}{|c|}{$w_{r}=0.4$} \\
\hline$f[\mathrm{~Hz}]$ & $\mu_{2}=0.5$ & $\mu_{2}=0.6$ & $\mu_{2}=0.7$ & $\mu_{2}=0.8$ & $\mu_{2}=0.9$ & $\mu_{2}=1.0$ \\
\hline 1 & 140.988 & 140.652 & 139.337 & 136.422 & 130.392 & 101.905 \\
\hline 2 & 204.066 & 202.729 & 197.559 & 186.506 & 167.129 & 137.694 \\
\hline 3 & 239.533 & 237.845 & 231.310 & 217.240 & 191.875 & 145.872 \\
\hline 4 & 277.198 & 274.999 & 266.470 & 247.999 & 214.277 & 152.926 \\
\hline 5 & 293.766 & 291.400 & 282.247 & 262.442 & 226.265 & 155.685 \\
\hline 6 & 309.501 & 306.847 & 296.564 & 274.217 & 232.913 & 160.772 \\
\hline 7 & 334.099 & 331.229 & 320.089 & 295.865 & 251.143 & 166.309 \\
\hline 8 & 378.733 & 375.349 & 362.195 & 333.522 & 280.270 & 177.849 \\
\hline 9 & 418.316 & 414.319 & 398.768 & 364.755 & 301.104 & 181.523 \\
\hline 10 & 439.228 & 435.198 & 419.534 & 385.362 & 321.609 & 197.055 \\
\hline
\end{tabular}


Table 20. First ten natural frequency variations for $E D Z 2^{\kappa=5 / 6}$ theory of a CCFF helicoidal surface (Figure $4 \mathrm{c}$ ) reinforced by CNTs distributed as in Figure $5 \mathrm{c}$ for different mass fractions $w_{r}$ when varying the parameter of agglomeration $\mu_{2}$ with $\mu_{1}=0.5$. The Chebyshev-Gauss-Lobatto grid distribution was employed, with $I_{N}=31, I_{M}=21$.

\begin{tabular}{|c|c|c|c|c|c|c|}
\hline \multicolumn{7}{|c|}{ Theory: $E D Z 2^{\kappa=5 / 6}$} \\
\hline \multicolumn{3}{|c|}{ Elastic Foundations: $\rho^{(-)}=1800 \mathrm{~kg} / \mathrm{m}^{3}$} & \multirow{2}{*}{$\begin{array}{r}h_{f}^{(-)}=\mathbf{0 . 1 5} \boldsymbol{m} \\
w_{r}=0.1\end{array}$} & \multicolumn{3}{|c|}{$k_{2 f}^{(-)}=20 \times 10^{7} \mathrm{~N} / \mathrm{m}^{3}, \quad k_{3 f}^{(-)}=35 \times 10^{7} \mathrm{~N} / \mathrm{m}^{3}$} \\
\hline & & & & & & \\
\hline$f[\mathrm{~Hz}]$ & $\mu_{2}=0.5$ & $\mu_{2}=0.6$ & $\mu_{2}=0.7$ & $\mu_{2}=0.8$ & $\mu_{2}=0.9$ & $\mu_{2}=1.0$ \\
\hline 1 & 119.772 & 119.477 & 118.403 & 116.013 & 110.903 & 97.885 \\
\hline 2 & 149.229 & 148.971 & 148.079 & 146.326 & 143.302 & 136.918 \\
\hline 3 & 164.585 & 164.140 & 162.591 & 159.473 & 153.974 & 144.416 \\
\hline 4 & 176.776 & 176.180 & 174.108 & 169.968 & 162.794 & 150.582 \\
\hline 5 & 184.972 & 184.217 & 181.578 & 176.287 & 167.181 & 152.576 \\
\hline 6 & 185.980 & 185.333 & 183.100 & 178.676 & 171.061 & 158.287 \\
\hline 7 & 199.096 & 198.272 & 195.398 & 189.623 & 179.495 & 162.001 \\
\hline 8 & 216.896 & 215.896 & 212.412 & 205.413 & 193.174 & 172.434 \\
\hline 9 & 225.898 & 224.710 & 220.583 & 212.378 & 198.383 & 175.865 \\
\hline 10 & 244.435 & 243.217 & 238.968 & 230.425 & 215.431 & 189.471 \\
\hline \multicolumn{7}{|c|}{$w_{r}=0.2$} \\
\hline$f[\mathrm{~Hz}]$ & $\mu_{2}=0.5$ & $\mu_{2}=0.6$ & $\mu_{2}=0.7$ & $\mu_{2}=0.8$ & $\mu_{2}=0.9$ & $\mu_{2}=1.0$ \\
\hline 1 & 130.372 & 130.108 & 129.115 & 126.803 & 121.301 & 100.712 \\
\hline 2 & 165.537 & 164.905 & 162.647 & 158.114 & 150.573 & 137.944 \\
\hline 3 & 189.423 & 188.547 & 185.392 & 178.882 & 167.221 & 145.740 \\
\hline 4 & 210.370 & 209.195 & 204.960 & 196.194 & 180.468 & 152.419 \\
\hline 5 & 221.836 & 220.574 & 216.027 & 206.624 & 189.621 & 154.827 \\
\hline 6 & 227.918 & 226.446 & 221.134 & 210.098 & 190.281 & 160.162 \\
\hline 7 & 244.960 & 243.387 & 237.704 & 225.890 & 204.454 & 164.913 \\
\hline 8 & 272.209 & 270.326 & 263.513 & 249.319 & 223.448 & 175.859 \\
\hline 9 & 293.209 & 290.917 & 282.631 & 265.361 & 234.039 & 179.657 \\
\hline 10 & 311.516 & 309.246 & 301.037 & 283.905 & 252.558 & 194.046 \\
\hline \multicolumn{7}{|c|}{$w_{r}=0.4$} \\
\hline$f[\mathrm{~Hz}]$ & $\mu_{2}=0.5$ & $\mu_{2}=0.6$ & $\mu_{2}=0.7$ & $\mu_{2}=0.8$ & $\mu_{2}=0.9$ & $\mu_{2}=1.0$ \\
\hline 1 & 140.826 & 140.492 & 139.184 & 136.283 & 130.271 & 101.852 \\
\hline 2 & 203.553 & 202.225 & 197.089 & 186.114 & 166.884 & 137.668 \\
\hline 3 & 239.065 & 237.382 & 230.872 & 216.855 & 191.588 & 145.767 \\
\hline 4 & 276.049 & 273.866 & 265.398 & 247.060 & 213.592 & 152.724 \\
\hline 5 & 292.251 & 289.906 & 280.829 & 261.187 & 225.333 & 155.498 \\
\hline 6 & 308.409 & 305.770 & 295.539 & 273.311 & 232.232 & 160.473 \\
\hline 7 & 331.756 & 328.915 & 317.892 & 293.924 & 249.692 & 165.925 \\
\hline 8 & 375.161 & 371.817 & 358.831 & 330.532 & 277.985 & 177.170 \\
\hline 9 & 417.794 & 413.801 & 398.274 & 364.315 & 300.757 & 181.270 \\
\hline 10 & 434.675 & 430.699 & 415.243 & 381.526 & 318.649 & 196.020 \\
\hline
\end{tabular}


Table 21. First ten natural frequency variations for ED3 theory of a CCFF helicoidal surface (Figure 4c) reinforced by CNTs distributed as in Figure $5 c$ for different mass fractions $w_{r}$ when varying the parameter of agglomeration $\mu_{2}$ with $\mu_{1}=0.5$. The Chebyshev-Gauss-Lobatto grid distribution was employed, with $I_{N}=31, I_{M}=21$.

\begin{tabular}{|c|c|c|c|c|c|c|}
\hline \multicolumn{7}{|c|}{ Theory: ED3 } \\
\hline \multicolumn{3}{|c|}{ Elastic Foundations: $\rho^{(-)}=1800 \mathrm{~kg} / \mathrm{m}^{3}$} & \multirow{2}{*}{$\begin{array}{r}h_{f}^{(-)}=\mathbf{0 . 1 5} \boldsymbol{m}, \\
w_{r}=0.1\end{array}$} & \multicolumn{3}{|c|}{$k_{2 f}^{(-)}=20 \times 10^{7} \mathrm{~N} / \mathrm{m}^{3}, \quad k_{3 f}^{(-)}=35 \times 10^{7} \mathrm{~N} / \mathrm{m}^{3}$} \\
\hline & & & & & & \\
\hline$f[\mathrm{~Hz}]$ & $\mu_{2}=0.5$ & $\mu_{2}=0.6$ & $\mu_{2}=0.7$ & $\mu_{2}=0.8$ & $\mu_{2}=0.9$ & $\mu_{2}=1.0$ \\
\hline 1 & 119.831 & 119.536 & 118.460 & 116.069 & 110.954 & 97.923 \\
\hline 2 & 149.260 & 149.001 & 148.106 & 146.348 & 143.316 & 136.934 \\
\hline 3 & 164.665 & 164.220 & 162.668 & 159.547 & 154.043 & 144.473 \\
\hline 4 & 176.944 & 176.347 & 174.270 & 170.120 & 162.929 & 150.692 \\
\hline 5 & 185.132 & 184.376 & 181.736 & 176.440 & 167.319 & 152.674 \\
\hline 6 & 186.251 & 185.601 & 183.357 & 178.913 & 171.269 & 158.437 \\
\hline 7 & 199.453 & 198.625 & 195.740 & 189.942 & 179.770 & 162.172 \\
\hline 8 & 217.527 & 216.523 & 213.019 & 205.982 & 193.666 & 172.777 \\
\hline 9 & 226.023 & 224.835 & 220.709 & 212.508 & 198.524 & 176.005 \\
\hline 10 & 245.348 & 244.123 & 239.852 & 231.264 & 216.186 & 190.036 \\
\hline \multicolumn{7}{|c|}{$w_{r}=0.2$} \\
\hline$f[\mathrm{~Hz}]$ & $\mu_{2}=0.5$ & $\mu_{2}=0.6$ & $\mu_{2}=0.7$ & $\mu_{2}=0.8$ & $\mu_{2}=0.9$ & $\mu_{2}=1.0$ \\
\hline 1 & 130.437 & 130.173 & 129.180 & 126.868 & 121.365 & 100.754 \\
\hline 2 & 165.628 & 164.993 & 162.729 & 158.181 & 150.614 & 137.958 \\
\hline 3 & 189.544 & 188.667 & 185.508 & 178.988 & 167.312 & 145.803 \\
\hline 4 & 210.625 & 209.447 & 205.203 & 196.420 & 180.660 & 152.534 \\
\hline 5 & 222.209 & 220.940 & 216.380 & 206.949 & 189.828 & 154.937 \\
\hline 6 & 228.184 & 226.709 & 221.391 & 210.342 & 190.561 & 160.330 \\
\hline 7 & 245.505 & 243.926 & 238.226 & 226.374 & 204.864 & 165.116 \\
\hline 8 & 273.124 & 271.235 & 264.395 & 250.147 & 224.165 & 176.245 \\
\hline 9 & 293.353 & 291.061 & 282.773 & 265.497 & 234.171 & 179.805 \\
\hline 10 & 312.790 & 310.509 & 302.266 & 285.064 & 253.579 & 194.677 \\
\hline \multicolumn{7}{|c|}{$w_{r}=0.4$} \\
\hline$f[\mathrm{~Hz}]$ & $\mu_{2}=0.5$ & $\mu_{2}=0.6$ & $\mu_{2}=0.7$ & $\mu_{2}=0.8$ & $\mu_{2}=0.9$ & $\mu_{2}=1.0$ \\
\hline 1 & 140.902 & 140.567 & 139.257 & 136.353 & 130.339 & 101.896 \\
\hline 2 & 203.733 & 202.401 & 197.258 & 186.262 & 166.988 & 137.680 \\
\hline 3 & 239.241 & 237.556 & 231.040 & 217.010 & 191.718 & 145.834 \\
\hline 4 & 276.411 & 274.225 & 265.746 & 247.387 & 213.870 & 152.843 \\
\hline 5 & 292.774 & 290.426 & 281.332 & 261.660 & 225.735 & 155.614 \\
\hline 6 & 308.769 & 306.127 & 295.887 & 273.641 & 232.520 & 160.653 \\
\hline 7 & 332.515 & 329.668 & 318.623 & 294.614 & 250.285 & 166.148 \\
\hline 8 & 376.390 & 373.033 & 360.016 & 331.658 & 278.974 & 177.584 \\
\hline 9 & 417.984 & 413.990 & 398.458 & 364.489 & 300.912 & 181.419 \\
\hline 10 & 436.360 & 432.364 & 416.868 & 383.072 & 320.016 & 196.689 \\
\hline
\end{tabular}




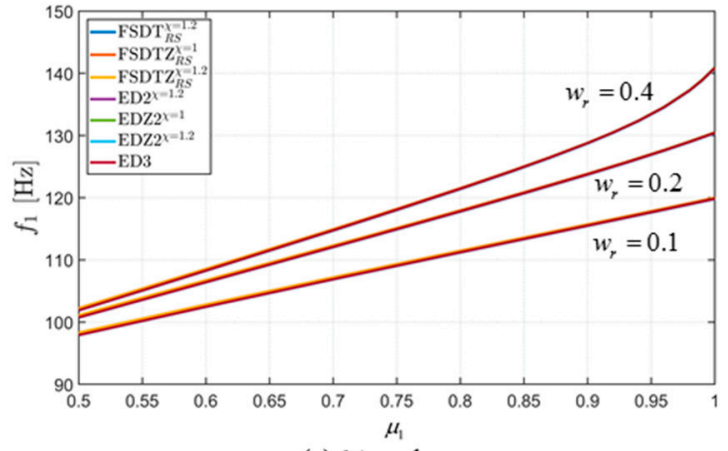

(a) $1^{\text {st }}$ mode

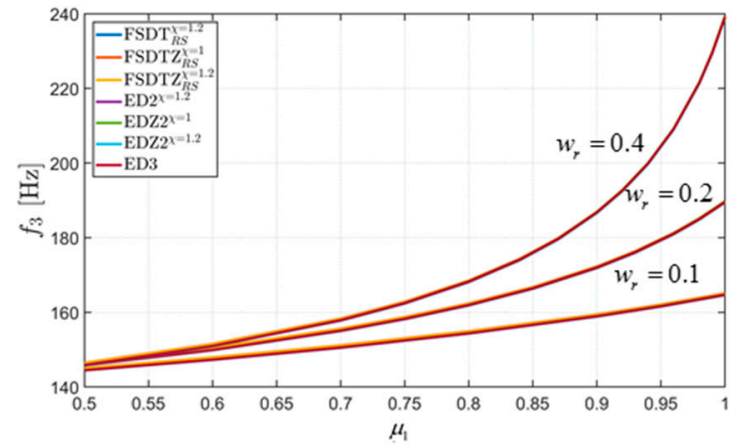

(c) $3^{\text {rd }}$ mode

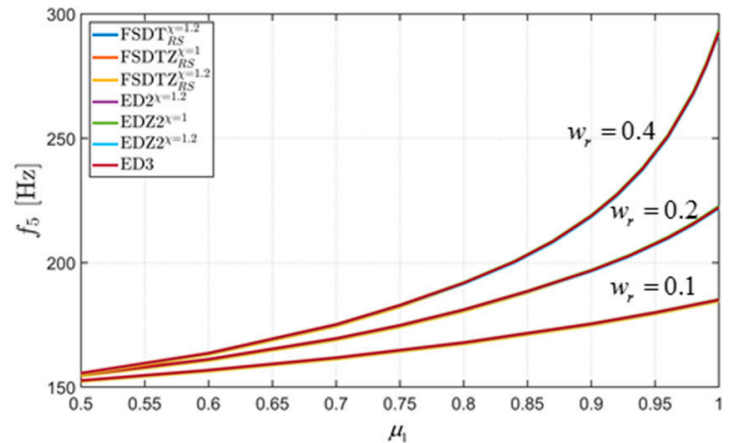

(e) $5^{\text {th }}$ mode

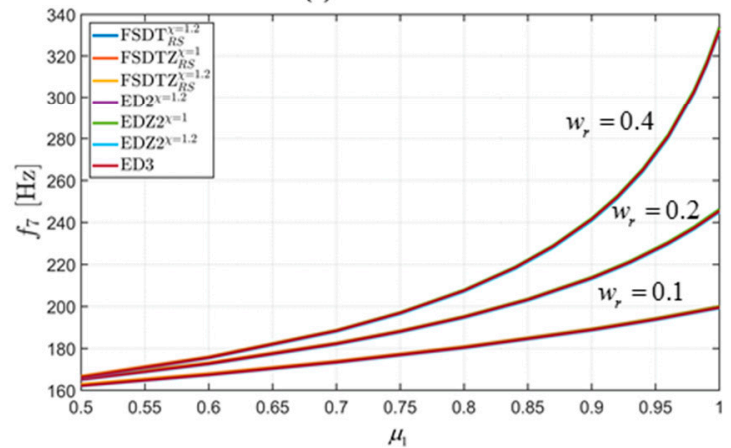

(g) $7^{\text {th }}$ mode

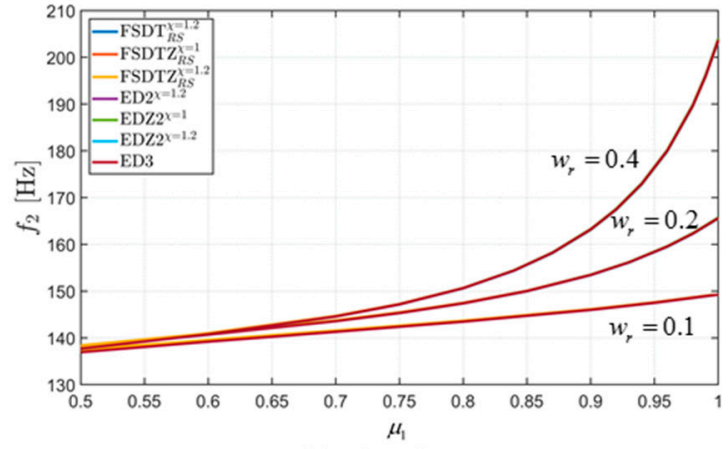

(b) $2^{\text {nd }}$ mode

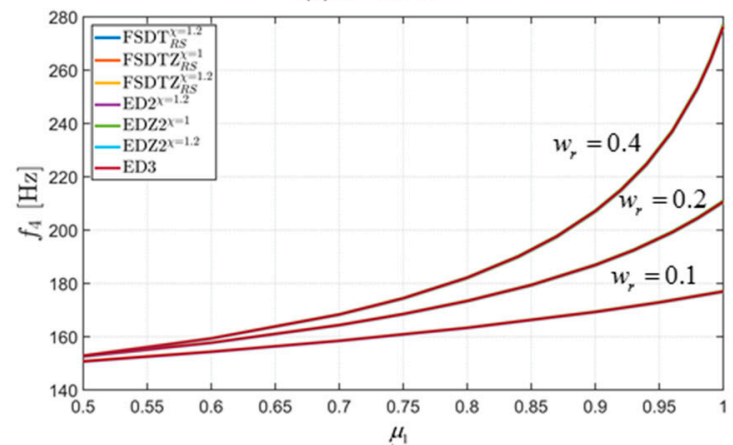

(d) $4^{\text {th }}$ mode

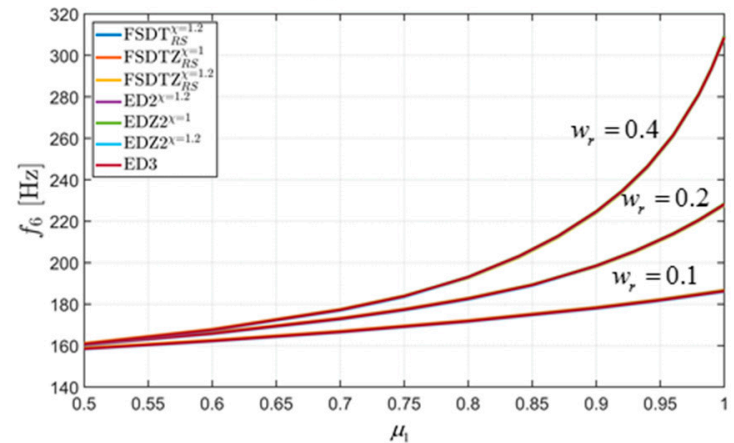

(f) $6^{\text {th }}$ mode

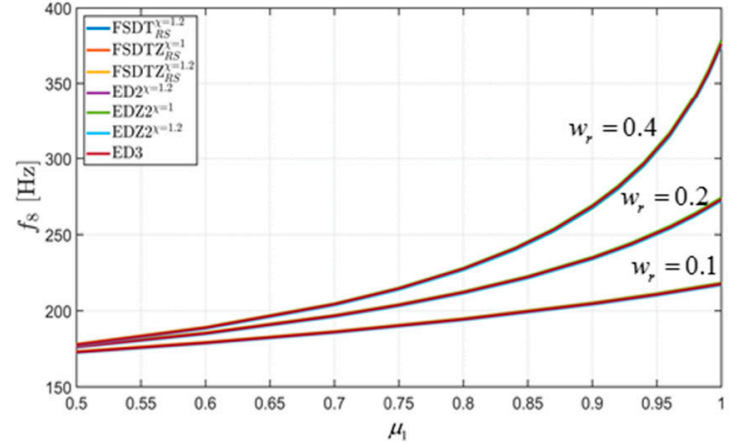

(h) $8^{\text {th }}$ mode

Figure 12. Frequency variations of a CCFF helicoidal surface (Figure 4c) reinforced by CNTs distributed as in Figure $5 \mathrm{c}$ for different mass fractions $w_{r}$ when varying the parameter of agglomeration $\mu_{1}$ with $\mu_{2}=1$. The Chebyshev-Gauss-Lobatto grid distribution was employed, with $I_{N}=31, I_{M}=21$. The following mode shapes are considered: (a) 1st mode; (b) 2nd mode; (c) 3rd mode; (d) 4th mode; (e) 5th mode; (f) 6th mode; (g) 7th mode; (h) 8th mode. 


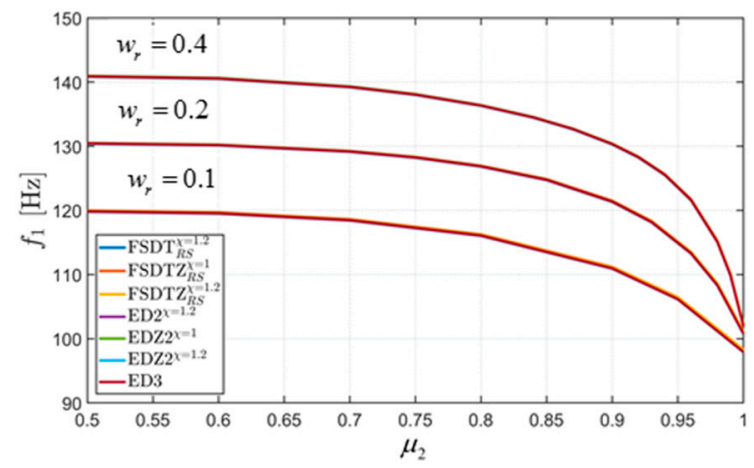

(a) $1^{\text {st }}$ mode

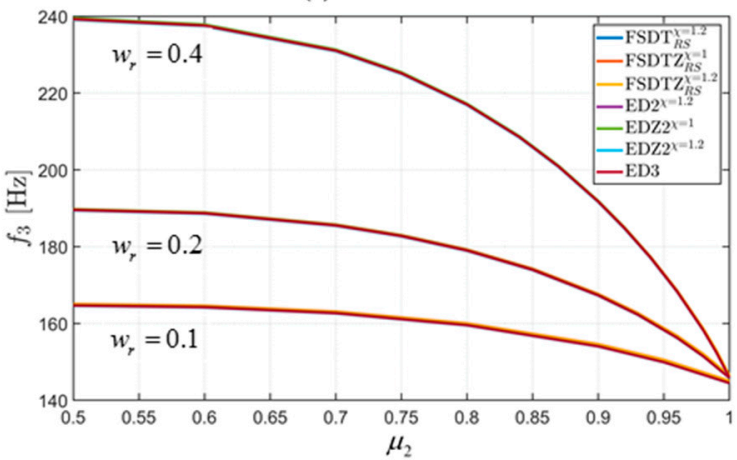

(c) $3^{\text {rd }}$ mode

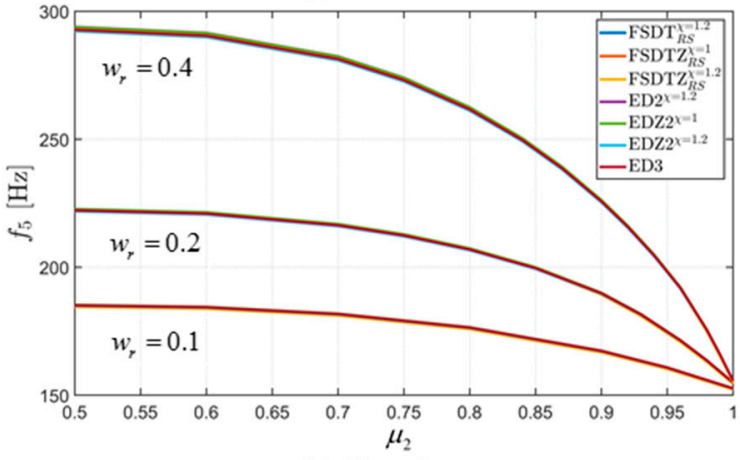

(e) $5^{\text {th }}$ mode

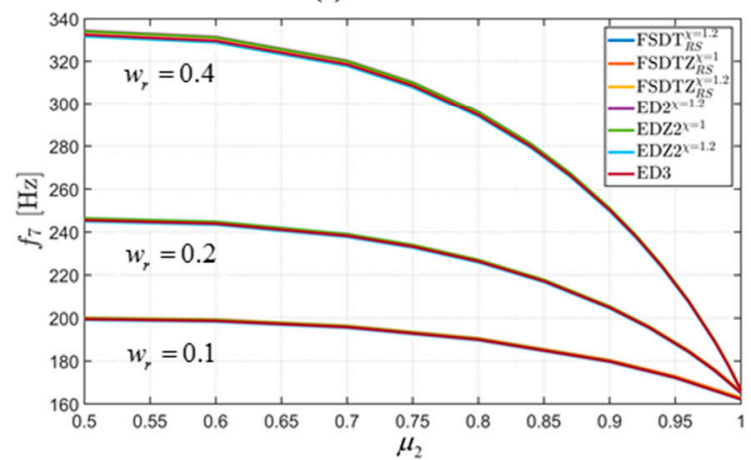

(g) $7^{\text {th }}$ mode

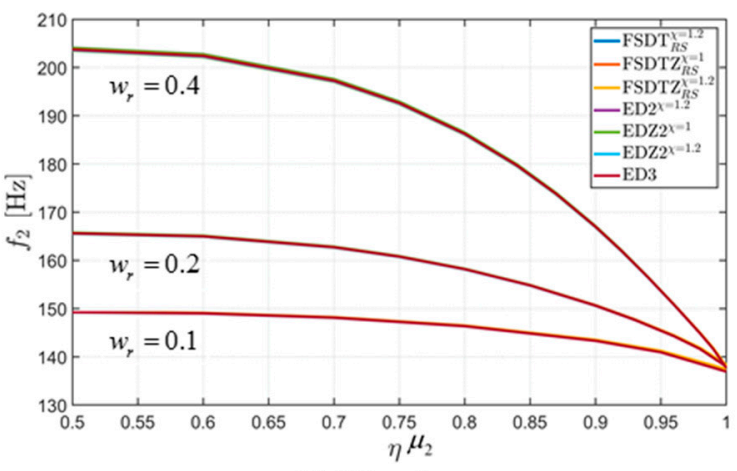

(b) $2^{\text {nd }}$ mode

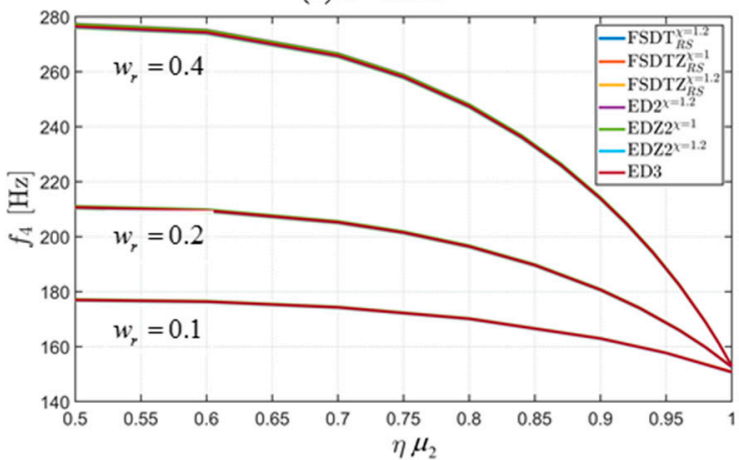

(d) $4^{\text {th }}$ mode

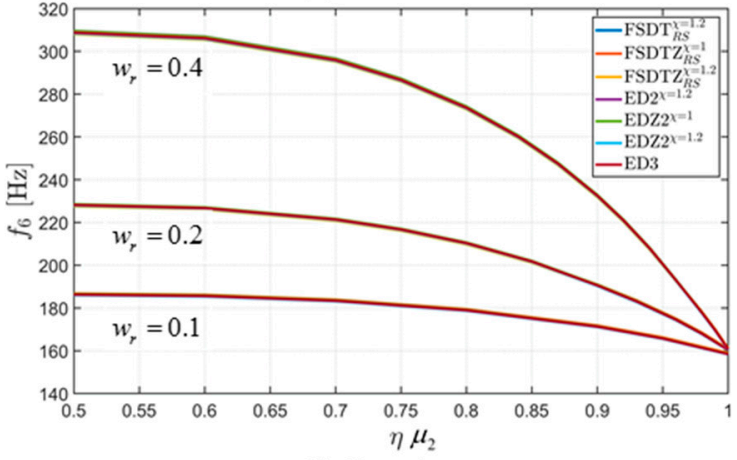

(f) $6^{\text {th }}$ mode

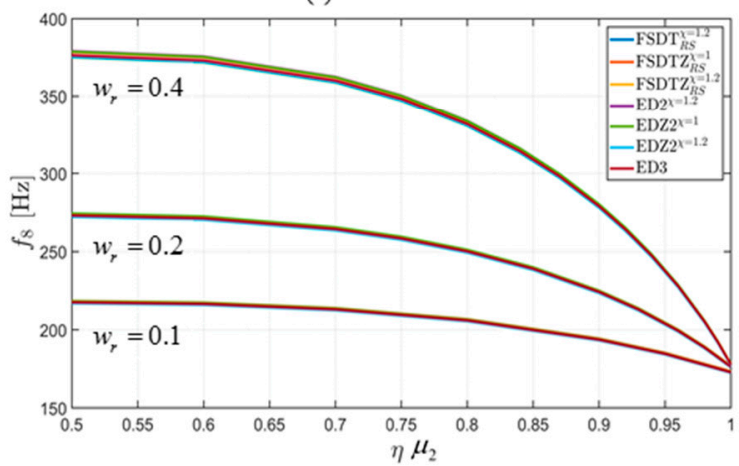

(h) $8^{\text {th }}$ mode

Figure 13. Frequency variations of a CCFF helicoidal surface (Figure 4c) reinforced by CNTs distributed as in Figure $5 \mathrm{c}$ for different mass fractions $w_{r}$ when varying the parameter of agglomeration $\mu_{2}$ with $\mu_{1}=0.5$. The Chebyshev-Gauss-Lobatto grid distribution was employed, with $I_{N}=31, I_{M}=21$. The following mode shapes are considered: (a) 1st mode; (b) 2nd mode; (c) 3rd mode; (d)4th mode; (e) 5th mode; (f) 6th mode; (g) 7th mode; (h) 8th mode. 


\section{Conclusions}

In this paper, various investigations were conducted with regard to the free vibration analysis of laminated doubly-curved shells and plates resting on elastic foundation and reinforced by Carbon Nanotubes (CNTs). The results for different higher-order ESL models have been shown, which may also include the Murakami's function to capture the zig-zag effect when a soft core is considered. Once the fundamental system of equations had been developed, the corresponding differential equations were solved numerically by means of the GDQ method, due to its features of accuracy and reliability. The various parametric studies prove that dynamic behavior in terms of natural frequencies is highly affected by several mechanical parameters. In particular, the effects of Winkler-Pasternak foundation, CNT agglomeration and mass fraction were investigated and discussed through several graphs and tables. The following observations can be made:

- the choice and variation of the mechanical parameters that characterize the elastic foundation have a significant impact on the values of natural frequencies;

- interesting behaviors can be observed in terms of natural frequencies when the mechanical parameters of the foundation are increased; in particular, bifurcation points and peculiar overlapping can be noted;

- analogously, the natural frequency values are considerably affected by the agglomeration of CNTs; this aspect is extremely clear when the mass fraction of CNTs reaches higher values;

- the dynamic response of the structure can be modified by varying the parameters that define the through-the-thickness volume fraction distribution of CNTs;

- $\quad$ several analytical distributions can be chosen to describe peculiar through-the-thickness volume fraction distributions, such as power law, exponential and Weibull functions; it should be noted that, at the present time, these distributions are not available in FEM commercial codes;

- $\quad$ the comparison with the commercial FEM software shows good agreement of results, for those cases that can be analyzed and compared.

Finally, the authors believe that the present investigations could help engineers and researchers in studying and designing shell structures reinforced by CNTs and resting on elastic foundations, by providing the proper values for CNT agglomeration, and a more suitable foundation model for obtaining the optimal dynamic response.

Acknowledgments: The research topic is one of the subjects of the Centre of Study and Research for the Identification of Materials and Structures (CIMEST)-“M. Capurso” of the University of Bologna (Italy). The first author gratefully acknowledges the financial support of the Croatian Science Foundation (project No. 6876) and the University of Rijeka (13.09.1.1.03).

Author Contributions: Damjan Banić, Michele Bacciocchi, Francesco Tornabene, and Antonio J. M. Ferreira contributed equally to the development of the research topic and to the writing of the manuscript.

Conflicts of Interest: The authors declare no conflict of interest.

\section{References}

1. Iijima, S. Helical Microtubles of Graphitic Carbon. Nature 1991, 354, 56-58. [CrossRef]

2. Iijima, S.; Ichihashi, T. Single-shell carbon nanotubes of 1-nm diameter. Nature 1993, 363, 603-605. [CrossRef]

3. Popov, V.N.; Van Doren, V.E.; Balkanski, M. Elastic properties of crystals of single-walled carbon nanotubes. Solid State Commun. 2000, 114, 395-399. [CrossRef]

4. Popov, V.N.; Van Doren, V.E. Elastic properties of single-walled carbon nanotubes. Phys. Rev. B 2000, 61, 3078-3084. [CrossRef]

5. Qian, D.; Wagner, G.J.; Liu, W.K.; Yu, M.-F.; Ruoff, R.S. Mechanics of carbon nanotubes. Appl. Mech. Rev. 2002, 55, 495-533. [CrossRef]

6. Thostenson, E.T.; Chou, T.-W. On the elastic properties of carbon nanotube-based composites: Modelling and characterization. J. Phys. D Appl. Phys. 2003, 36, 573-582. [CrossRef] 
7. Odegard, G.M.; Gates, T.S.; Wise, K.E.; Park, C.; Siochi, E.J. Constitutive modeling of nanotube-reinforced polymer composites. Compos. Sci. Technol. 2003, 63, 1671-1687. [CrossRef]

8. Shen, L.; Li, J. Transversely isotropic elastic properties of single-walled carbon nanotubes. Phys. Rev. B 2004, 69, 1129-1133. [CrossRef]

9. Ray, M.C.; Batra, R.C. Effective Properties of Carbon Nanotube and Piezoelectric Fiber Reinforced Hybrid Smart Composites. J. Appl. Mech. 2009, 76, 540-545. [CrossRef]

10. Wang, J.F.; Liew, K.M. On the study of elastic properties of CNT-reinforced composites based on element-free MLS method with nanoscale cylindrical representative volume element. Compos. Struct. 2015, 124, 1-9. [CrossRef]

11. Liew, K.M.; Lei, Z.X.; Zhang, L.W. Mechanical analysis of functionally graded carbon nanotube reinforced composites: A review. Compos. Struct. 2015, 120, 90-97. [CrossRef]

12. Shen, H.-S. Nonlinear bending of functionally graded carbon nanotube-reinforced composite plates in thermal environments. Compos. Struct. 2009, 91, 9-19. [CrossRef]

13. Raney, J.R.; Fraternali, F.; Amendola, A.; Daraio, C. Modeling and in situ identification of material parameters for layered structures based on carbon nanotube arrays. Compos. Struct. 2011, 93, 3013-3018. [CrossRef]

14. Blesgen, T.; Fraternali, F.; Raney, J.R.; Amendola, A.; Daraio, C. Continuum limits of bistable spring models of carbon nanotube arrays accounting for material damage. Mech. Res. Commun. 2012, 45, 58-63. [CrossRef]

15. Jam, J.E.; Pourasghar, A.; Kamarian, S. Effect of the Aspect Ratio and Waviness of Carbon Nanotubes on the Vibrational Behavior of Functionally Graded Nanocomposite Cylindrical Panels. Polym. Compos. 2012, 33, 2036-2044. [CrossRef]

16. Alibeigloo, A.; Liew, K.M. Thermoelastic analysis of functionally graded carbon nanotube-reinforced composite plate using theory of elasticity. Compos. Struct. 2013, 106, 873-881. [CrossRef]

17. Alibeigloo, A. Free vibration analysis of functionally graded carbon nanotube-reinforced composite cylindrical panel embedded in piezoelectric layers by using theory of elasticity. Eur. J. Mech. 2014, 44, 104-115. [CrossRef]

18. Brischetto, S. A continuum elastic three-dimensional model for natural frequencies of single-walled carbon nanotubes. Compos. Part B Eng. 2014, 61, 222-228. [CrossRef]

19. Brischetto, S. A continuum shell model including van der Waals interaction for free vibrations of double-walled carbon nanotubes. Comput. Model. Eng. Sci. 2015, 104, 305-327.

20. Zhang, L.W.; Lei, Z.X.; Liew, K.M. Free vibration analysis of functionally graded carbon nanotube-reinforced composite triangular plates using the FSDT and element-free IMLS-Ritz method. Compos. Struct. 2015, 120, 189-199. [CrossRef]

21. Zhang, L.W.; Lei, Z.X.; Liew, K.M. Vibration characteristic of moderately thick functionally graded carbon nanotube reinforced composite skew plates. Compos. Struct. 2015, 122, 172-183. [CrossRef]

22. Lei, Z.X.; Zhang, L.W.; Liew, K.M. Free vibration analysis of laminated FG-CNT reinforced composite rectangular plates using the kp-Ritz method. Compos. Struct. 2015, 127, 245-259. [CrossRef]

23. Mareishi, S.; Kalhori, H.; Rafiee, M.; Hosseini, S.M. Nonlinear forced vibration response of smart two-phase nano-composite beams to external harmonic excitations. Curved Layer. Struct. 2015, 2, 150-161. [CrossRef]

24. Tornabene, F.; Fantuzzi, N.; Bacciocchi, M.; Viola, E. Effect of agglomeration on the natural frequencies of functionally graded carbon nanotube-reinforced laminated composite doubly-curved shells. Compos. Part B Eng. 2016, 89, 187-218. [CrossRef]

25. Tornabene, F.; Fantuzzi, N.; Bacciocchi, M. Linear Static Response of Nanocomposite Plates and Shells Reinforced by Agglomerated Carbon Nanotubes. Compos. Part B Eng. 2017, 115, 449-476. [CrossRef]

26. Fantuzzi, N.; Tornabene, F.; Bacciocchi, M.; Dimitri, R. Free vibration analysis of arbitrarily shaped Functionally Graded Carbon Nanotube-reinforced plates. Compos. Part B Eng. 2017, 115, 384-408. [CrossRef]

27. Tornabene, F.; Bacciocchi, M.; Fantuzzi, N.; Reddy, J.N. Multiscale approach for three-phase $\mathrm{CNT}$ /polymer/fiber laminated nanocomposite structures. Polym. Compos. 2017. [CrossRef]

28. Akgöz, B.; Civalek, Ö. A size-dependent beam model for stability of axially loaded carbon nanotubes surrounded by Pasternak elastic foundation. Compos. Struct. 2017, 176, 1028-1038. [CrossRef]

29. Civalek, Ö. Free vibration of carbon nanotubes reinforced (CNTR) and functionally graded shells and plates based on FSDT via discrete singular convolution method. Compos. Part B Eng. 2017, 111, 45-59. [CrossRef]

30. Chamis, C.C. Failure Criteria for Filamentary Composites; TN D-5367; NASA: Washington, DC, USA, 1969. 
31. Chamis, C.C. Thermoelastic Properties of Unidirectional Filamentary Composites by a Semiempirical Micromechanics Theory; Union Carbide Corp Cleveland Ohio Carbon Products Div: Cleveland, OH, USA, 1974.

32. Shi, D.-L.; Huang, Y.Y.; Hwang, K.-C.; Gao, H. The Effect of Nanotube Waviness and Agglomeration on the Elastic Property of Carbon Nanotube-Reinforced Composites. J. Eng. Mater. Technol. 2004, 126, 250-257. [CrossRef]

33. Mori, T.; Tanaka, K. Average stress in matrix and average elastic energy of materials with Misfitting inclusions. Acta Metall. 1973, 21, 571-574. [CrossRef]

34. Hill, R. Theory of Mechanical Properties of Fibre-Strengthened Materials: I. Elastic Behavior. J. Mech. Phys. Solids 1964, 12, 199-212. [CrossRef]

35. Hill, R. Theory of Mechanical Properties of Fibre-Strengthened Materials: II. Inelastic Behavior. J. Mech. Phys. Solids 1964, 12, 213-218. [CrossRef]

36. Hedayati, H.; Sobhani Aragh, B. Influence of graded agglomerated CNTs on vibration of CNT-reinforced annular sectorial plates resing on Pasternak foundation. Appl. Math. Comput. 2012, 218, 8715-8735.

37. Aragh, B.S.; Barati, A.H.N.; Hedayati, H. Eshelby-Mori-Tanaka approach for vibrational behavior of continuously graded carbon nanotube-reinforced cylindrical panels. Compos. Part B Eng. 2012, 43, 1943-1954. [CrossRef]

38. Aragh, B.S.; Farahani, E.B.; Barati, A.H.N. Natural frequency analysis of continuously graded carbon nanotube-reinforced cylindrical shells based on third-order shear deformation theory. Math. Mech. Solids 2013, 18, 264-284. [CrossRef]

39. Reddy, J.N. A Simple Higher-Order Theory for Laminated Composite Plates. J. Appl. Mech. 1984, 51, 745-752. [CrossRef]

40. Bert, C.W. A Critical Evaluation of New Plate Theories Applied to Laminated Composites. Compos. Struct. 1984, 2, 329-347. [CrossRef]

41. Reddy, J.N.; Liu, C.F. A higher-order shear deformation theory for laminated elastic shells. Int. J. Eng. Sci. 1985, 23, 319-330. [CrossRef]

42. Reddy, J.N. A Generalization of the Two-Dimensional Theories of Laminated Composite Plates. Commun. Appl. Numer. Methods Biomed. Eng. 1987, 3, 173-180. [CrossRef]

43. Librescu, L.; Reddy, J.N. A few remarks concerning several refined theories of anisotropic composite laminated plates. Int. J. Eng. Sci. 1989, 27, 515-527. [CrossRef]

44. Reddy, J.N. On Refined Theories of Composite Laminates. Meccanica 1990, 25, 230-238. [CrossRef]

45. Robbins, D.H.; Reddy, J.N. Modeling of Thick Composites Using a Layer-Wise Laminate Theory. Int. J. Numer. Methods Eng. 1993, 36, 655-677. [CrossRef]

46. Reddy, J.N. Mechanics of Laminated Composite Plates and Shells; CRC Press: Boca Raton, FL, USA, 2004.

47. Alibeigloo, A.; Shakeri, M.; Kari, M.R. Free vibration analysis of antisymmetric laminated rectangular plates with distributed patch mass using third-order shear deformation theory. Ocean Eng. 2008, 35, 183-190. [CrossRef]

48. Demasi, L. $\infty 3$ Hierarchy plate theories for thick and thin composite plates: The generalized unified formulation. Compos. Struct. 2008, 84, 256-270. [CrossRef]

49. Amabili, M.; Reddy, J.N. A new non-linear higher-order shear deformation theory for large-amplitude vibrations of laminated doubly curved shells. Int. J. Nonlinear Mech. 2010, 45, 409-418. [CrossRef]

50. Mantari, J.L.; Oktem, A.S.; Soares, C.G. A new trigonometric layerwise shear deformation theory for the finite element analysis of laminated composite and sandwich plates. Comput. Struct. 2012, 94-95, 45-53. [CrossRef]

51. Mantari, J.L.; Soares, C.G. Generalized layerwise HSDT and finite element formulation for symmetric laminated and sandwich composite plates. Compos. Struct. 2013, 105, 319-331. [CrossRef]

52. Vo, T.P.; Thai, H.-T.; Nguyen, T.-K.; Lanc, D.; Karamanli, A. Flexural analysis of laminated composite and sandwich beams using a four-unknown shear and normal deformation theory. Compos. Struct. 2017, 176, 388-397. [CrossRef]

53. D'Ottavio, M. A Sublaminate Generalized Unified Formulation for the analysis of composite structures. Compos. Struct. 2016, 142, 187-199. [CrossRef]

54. D'Ottavio, M.; Dozio, L.; Vescovini, R.; Polit, O. Bending analysis of composite laminated and sandwich structures using sublaminate variable-kinematic Ritz models. Compos. Struct. 2016, 155, 45-62. [CrossRef] 
55. Tornabene, F.; Fantuzzi, N.; Bacciocchi, M.; Reddy, J.N. An Equivalent Layer-Wise Approach for the Free Vibration Analysis of Thick and Thin Laminated Sandwich Shells. Appl. Sci. 2017, 7, 1-34. [CrossRef]

56. Tornabene, F.; Fantuzzi, N.; Bacciocchi, M. Linear Static Behavior of Damaged Laminated Composite Plates and Shells. Materials 2017, 10, 1-52. [CrossRef] [PubMed]

57. Reddy, J.N.; Chin, C.D. Thermomechanical Analysis of Functionally Graded Cylinders and Plates. J. Therm. Stress. 1998, 21, 593-626. [CrossRef]

58. Loy, C.T.; Lam, K.Y.; Reddy, J.N. Vibration of functionally graded cylindrical shells. Int. J. Mech. Sci. 1999, 41, 309-324. [CrossRef]

59. Pradhan, S.C.; Loy, C.T.; Lam, K.Y.; Reddy, J.N. Vibration characteristics of functionally graded cylindrical shells under various boundary conditions. Appl. Acoust. 2000, 61, 111-129. [CrossRef]

60. Reddy, J.N. Analysis of functionally graded plates. Int. J. Numer. Methods Eng. 2000, 47, 663-684. [CrossRef]

61. Arshad, S.H.; Naeem, M.N.; Sultana, N. Frequency analysis of functionally graded material cylindrical shells with various volume fractions laws. J. Mech. Eng. Sci. 2007, 221, 1483-1495. [CrossRef]

62. Amabili, M. Nonlinear Vibrations and Stability of Shells and Plates; Cambridge University Press: New York, NY, USA, 2008.

63. Reddy, J.N. Microstructure-dependent couple stress theories of functionally graded beams. J. Mech. Phys. Solids 2011, 59, 2382-2399. [CrossRef]

64. Reddy, J.N.; Kim, J. A nonlinear modified couple stress-based third-order theory of functionally graded plates. Compos. Struct. 2012, 94, 1128-1143. [CrossRef]

65. Strozzi, M.; Pellicano, F. Nonlinear vibrations of functionally graded cylindrical shells. Thin-Walled Struct. 2013, 67, 63-77. [CrossRef]

66. Kim, J.; Reddy, J.N. A general third-order theory of functionally graded plates with modified couple stress effect and the von Kármán nonlinearity: Theory and finite element analysis. Acta Mech. 2015, 226, 2973-2998. [CrossRef]

67. Sofiyev, A.H.; Kuruoglu, N. Dynamic instability of three-layered cylindrical shells containing an FGM interlayer. Thin-Walled Struct. 2015, 93, 10-21. [CrossRef]

68. Sofiyev, A.H.; Kuruoglu, N. Domains of dynamic instability of FGM conical shells under time dependent periodic loads. Compos. Struct. 2016, 136, 139-148. [CrossRef]

69. Rivera, M.G.; Reddy, J.N. Stress analysis of functionally graded shells using a 7-parameter shell element. Mech. Res. Commun. 2016, 78, 60-70. [CrossRef]

70. Tornabene, F.; Viola, E. Free Vibration Analysis of Functionally Graded Panels and Shells of Revolution. Meccanica 2009, 44, 255-281. [CrossRef]

71. Viola, E.; Tornabene, F. Free Vibrations of Three Parameter Functionally Graded Parabolic Panels of Revolution. Mech. Res. Commun. 2009, 36, 587-594. [CrossRef]

72. Tornabene, F. Free Vibration Analysis of Functionally Graded Conical, Cylindrical Shell and Annular Plate Structures with a Four-parameter Power-Law Distribution. Comput. Methods Appl. Mech. Eng. 2009, 198, 2911-2935. [CrossRef]

73. Akgöz, B.; Civalek, Ö. Bending analysis of FG microbeams resting on Winkler elastic foundation via strain gradient elasticity. Compos. Struct. 2015, 134, 294-301. [CrossRef]

74. Lanc, D.; Vo, T.P.; Turkalj, G.; Lee, J. Buckling analysis of thin-walled functionally graded sandwich box beams. Thin-Walled Struct. 2015, 86, 148-156. [CrossRef]

75. Tornabene, F.; Fantuzzi, N.; Viola, E.; Batra, R.C. Stress and strain recovery for functionally graded free-form and doubly-curved sandwich shells using higher-order equivalent single layer theory. Compos. Struct. 2015, 119, 67-89. [CrossRef]

76. Lanc, D.; Turkalj, G.; Vo, T.P.; Brnić, J. Nonlinear buckling behaviours of thin-walled functionally graded open section beams. Compos. Struct. 2016, 152, 829-839. [CrossRef]

77. Fazzolari, F.A. Reissner's Mixed Variational Theorem and Variable Kinematics in the Modelling of Laminated Composite and FGM Doubly-Curved Shells. Compos. Part B Eng. 2016, 89, 408-423. [CrossRef]

78. Fazzolari, F.A. Stability Analysis of FGM Sandwich Plates by Using Variable-kinematics Ritz Models. Mech. Adv. Mater. Struct. 2016, 23, 1104-1113. [CrossRef]

79. Tornabene, F.; Brischetto, S.; Fantuzzi, N.; Bacciocchi, M. Boundary Conditions in 2D Numerical and 3D Exact Models for Cylindrical Bending Analysis of Functionally Graded Structures. Shock Vib. 2016, 2016, 1-17. [CrossRef] 
80. Brischetto, S.; Tornabene, F.; Fantuzzi, N.; Viola, E. 3D Exact and 2D Generalized Differential Quadrature Models for Free Vibration Analysis of Functionally Graded Plates and Cylinders. Meccanica 2016, 51, 2059-2098. [CrossRef]

81. Fantuzzi, N.; Brischetto, S.; Tornabene, F.; Viola, E. 2D and 3D Shell Models for the Free Vibration Investigation of Functionally Graded Cylindrical and Spherical Panels. Compos. Struct. 2016, 154, 573-590. [CrossRef]

82. Civalek, Ö. Vibration of laminated composite panels and curved plates with different types of FGM composite constituent. Compos. Part B Eng. 2017, 122, 89-108. [CrossRef]

83. Tornabene, F.; Fantuzzi, N.; Bacciocchi, M.; Viola, E.; Reddy, J.N. A Numerical Investigation on the Natural Frequencies of FGM Sandwich Shells with Variable Thickness by the Local Generalized Differential Quadrature Method. Appl. Sci. 2017, 7, 1-39. [CrossRef]

84. Barretta, R.; Feo, L.; Luciano, R. Some closed-form solutions of functionally graded beams undergoing nonuniform torsion. Compos. Struct. 2015, 123, 132-136. [CrossRef]

85. Barretta, R.; Brčić, M.; Čanađija, M.; Luciano, R.; Marotti de Sciarra, F. Application of gradient elasticity to armchair carbon nanotubes: Size effects and constitutive parameters assessment. Eur. J. Mech. A Solids 2017, 65, 1-13. [CrossRef]

86. Romano, G.; Barretta, R. Nonlocal elasticity in nanobeams: The stress-driven integral model. Int. J. Eng. Sci. 2017, 115, 14-27. [CrossRef]

87. Romano, G.; Barretta, R.; Diaco, M. On nonlocal integral models for elastic nano-beams. Int. J. Mech. Sci. 2017, 131-132, 490-499. [CrossRef]

88. Marotti de Sciarra, F.; Barretta, R. A new nonlocal bending model for Euler-Bernoulli nanobeams. Mech. Res. Commun. 2014, 62, 25-30. [CrossRef]

89. Apuzzo, A.; Barretta, R.; Luciano, R.; Marotti de Sciarra, F.; Penna, R. Free vibrations of Bernoulli-Euler nano-beams by the stress-driven nonlocal integral model. Compos. Part B Eng. 2017, 123, 105-111. [CrossRef]

90. Barretta, R. Analogies between Kirchhoff plates and Saint-Venant beams under flexure. Acta Mech. 2014, 225, 2075-2083. [CrossRef]

91. Barretta, R. On the relative position of twist and shear centres in the orthotropic and fiberwise homogeneous Saint-Venant beam theory. Int. J. Solids Struct. 2012, 49, 3038-3046. [CrossRef]

92. Barretta, R. Analogies between Kirchhoff plates and Saint-Venant beams under torsion. Acta Mech. 2013, 224, 2955-2964. [CrossRef]

93. Barretta, R. On Cesàro-Volterra Method in Orthotropic Saint-Venant Beam. J. Elast. 2013, 112, $233-253$. [CrossRef]

94. Carrera, E. A refined multi-layered finite-element model applied to linear and non-linear analysis of sandwich plates. Compos. Sci. Technol. 1998, 58, 1553-1569. [CrossRef]

95. Carrera, E. Theories and Finite Elements for Multilayered, Anisotropic, Composite Plates and Shells. Arch. Comput. Methods Eng. 2002, 9, 87-140. [CrossRef]

96. Carrera, E. Theories and Finite Elements for Multilayered Plates and Shells: A Unified Compact Formulation with Numerical Assessment and Benchmarking. Arch. Comput. Methods Eng. 2003, 10, 215-296. [CrossRef]

97. Carrera, E. Historical review of zig-zag theories for multilayered plates and shells. Appl. Mech. Rev. 2003, 56, 287-308. [CrossRef]

98. Carrera, E. On the use of the Murakami's zig-zag function in the modeling of layered plates and shells. Comput. Struct. 2004, 82, 541-554. [CrossRef]

99. Tornabene, F.; Fantuzzi, N.; Bacciocchi, M.; Viola, E. Laminated Composite Doubly-Curved Shell Structures. Differential Geometry. Higher-Order Structural Theories; Esculapio: Bologna, Italy, 2016.

100. Tornabene, F.; Fantuzzi, N.; Bacciocchi, M.; Viola, E. Laminated Composite Doubly-Curved Shell Structures. Differential and Integral Quadrature. Strong Formulation Finite Element Method; Esculapio: Bologna, Italy, 2016.

101. Tornabene, F.; Viola, E.; Fantuzzi, N. General higher-order equivalent single layer theory for free vibrations of doubly-curved laminated composite shells and panels. Compos. Struct. 2013, 104, 94-117. [CrossRef]

102. Tornabene, F.; Fantuzzi, N.; Viola, E.; Carrera, E. Static Analysis of Doubly-Curved Anisotropic Shells and Panels Using CUF Approach, Differential Geometry and Differential Quadrature Method. Compos. Struct. 2014, 107, 675-697. [CrossRef] 
103. Tornabene, F.; Fantuzzi, N.; Bacciocchi, M. The Local GDQ Method for the Natural Frequencies of Doubly-Curved Shells with Variable Thickness: A General Formulation. Compos. Part B Eng. 2016, 92, 265-289. [CrossRef]

104. Tornabene, F.; Fantuzzi, N.; Viola, E. Inter-Laminar Stress Recovery Procedure for Doubly-Curved, Singly-Curved, Revolution Shells with Variable Radii of Curvature and Plates Using Generalized Higher-Order Theories and the Local GDQ Method. Mech. Adv. Mater. Struct. 2016, 23, 1019-1045. [CrossRef]

105. Tornabene, F.; Fantuzzi, N.; Bacciocchi, M. The GDQ Method for the Free Vibration Analysis of Arbitrarily Shaped Laminated Composite Shells Using a NURBS-Based Isogeometric Approach. Compos. Struct. 2016, 154, 190-218. [CrossRef]

106. Bacciocchi, M.; Eisenberger, M.; Fantuzzi, N.; Tornabene, F.; Viola, E. Vibration Analysis of Variable Thickness Plates and Shells by the Generalized Differential Quadrature Method. Compos. Struct. 2016, 156, 218-237. [CrossRef]

107. Tornabene, F.; Fantuzzi, N.; Bacciocchi, M. On the Mechanics of Laminated Doubly-Curved Shells Subjected to Point and Line Loads. Int. J. Eng. Sci. 2016, 109, 115-164. [CrossRef]

108. Tornabene, F.; Fantuzzi, N.; Bacciocchi, M. A New Doubly-Curved Shell Element for the Free Vibrations of Arbitrarily Shaped Laminated Structures Based on Weak Formulation IsoGeometric Analysis. Compos. Struct. 2017, 171, 429-461. [CrossRef]

109. Tornabene, F.; Fantuzzi, N.; Bacciocchi, M. Foam core composite sandwich plates and shells with variable stiffness: Effect of the curvilinear fiber path on the modal response. J. Sandw. Struct. Mater. 2017. [CrossRef]

110. Tornabene, F.; Fantuzzi, N.; Bacciocchi, M. Refined Shear Deformation Theories for Laminated Composite Arches and Beams with Variable Thickness: Natural Frequency Analysis. Eng. Anal. Bound. Elem. 2017. [CrossRef]

111. Cheung, Y.K.; Zienkiewicz, O.C. Plates and tanks on elastic foundations-An application of finite element method. Int. J. Solids Struct. 1965, 1, 451-461. [CrossRef]

112. Bezine, G. A new boundary element method for bending of plates on elastic foundation. Int. J. Solids Struct. 1988, 24, 557-565. [CrossRef]

113. Katsikadelis, J.T. Large deflection analysis of plates on elastic foundation by the boundary element method. Int. J. Solids Struct. 1991, 27, 1867-1878. [CrossRef]

114. Qin, Q.H.; Diao, S. Nonlinear analysis of thick plates on an elastic foundation by HT FE with p-extension capabilities. Int. J. Solids Struct. 1996, 33, 4583-4604. [CrossRef]

115. Akbarov, S.D.; Kocatürk, T. On the bending problems of anisotropic (orthotropic) plates resting on elastic foundations that react in compression only. Int. J. Solids Struct. 1997, 34, 3673-3689. [CrossRef]

116. Shen, H.-S.; Li, Q.S. Postbuckling of shear deformable laminated plates resting on a tensionless elastic foundation subjected to mechanical or thermal loading. Int. J. Solids Struct. 2004, 41, 4769-4785. [CrossRef]

117. Civalek, O. Geometrically nonlinear dynamic analysis of doubly curved isotropic shells resting on elastic foundation by a combination of harmonic differential quadrature-finite difference methods. Int. J. Press. Vessels Pip. 2005, 82, 753-761. [CrossRef]

118. Avramidis, I.E.; Morfidis, K. Bending of beams on three-parameter elastic foundation. Int. J. Solids Struct. 2006, 43, 357-375. [CrossRef]

119. Golovko, G.B.; Lugovoi, P.Z.; Meish, V.F. Solution of axisymmetric dynamic problems for cylindrical shells on an elastic foundation. Int. Appl. Mech. 2007, 43, 785-793. [CrossRef]

120. Malekzadeh, P.; Farid, M. A DQ large deformation analysis of composite plates on nonlinear elastic foundations. Compos. Struct. 2007, 79, 251-260. [CrossRef]

121. Malekzadeh, P.; Setoodeh, A.R. Large deformation analysis of moderately thick laminated plates on nonlinear elastic foundations by DQM. Compos. Struct. 2007, 80, 569-579. [CrossRef]

122. Sofiyev, A.H. Buckling analysis of FGM circular shells under combined loads and resting on Pasternak type elastic foundations. Mech. Res. Commun. 2010, 37, 539-544. [CrossRef]

123. Wang, J.; Zhang, C. A three-parameter elastic foundation model for interface stresses in curved beams externally strengthened by a thin FRP plate. Int. J. Solids Struct. 2010, 47, 998-1006. [CrossRef]

124. Sofiyev, A.H.; Kuruoglu, N. Natural frequency of laminated orthotropic shells with different boundary conditions and resting on the Pasternak type elastic foundation. Compos. Part B Eng. 2011, 42, 1562-1570. [CrossRef] 
125. Thai, H.-T.; Choi, D.-H. A refined shear deformation theory for free vibration of functionally graded plates on elastic foundation. Compos. Part B Eng. 2012, 43, 2335-2347. [CrossRef]

126. Tornabene, F.; Ceruti, A. Free-form Laminated Doubly-Curved Shells and Panels of Revolution on Winkler-Pasternak Elastic Foundations: A 2D GDQ Solution for Static and Free Vibration Analysis. World J. Mech. 2013, 3, 1-25. [CrossRef]

127. Tornabene, F.; Reddy, J.N. FGM and Laminated Doubly-Curved and degenerate Shells resting on Nonlinear Elastic Foundation: A GDQ Solution for Static Analysis with a Posteriori Stress and strain Recovery. J. Indian Inst. Sci. 2013, 93, 635-688.

128. Tornabene, F.; Fantuzzi, N.; Viola, E.; Reddy, J.N. Winkler-Pasternak Foundation Effect on the Static and Dynamic Analyses of Laminated Doubly-Curved and Degenerate Shells and Panels. Compos. Part B Eng. 2014, 57, 269-296. [CrossRef]

129. Duc, N.D.; Thang, P.T. Nonlinear response of imperfect eccentrically stiffened ceramic-metal-ceramic FGM thin circular cylindrical shells surrounded on elastic foundations and subjected to axial compression. Compos. Struct. 2014, 110, 200-206. [CrossRef]

130. Duc, N.D.; Anh, V.T.T.; Cong, P.H. Nonlinear axisymmetric response of FGM shallow spherical shells on elastic foundations under uniform external pressure and temperature. Eur. J. Mech. A-Solids 2014, 45, 80-89. [CrossRef]

131. Zhang, D.-G. Nonlinear bending analysis of FGM rectangular plates with various supported boundaries resting on two-parameter elastic foundations. Arch. Appl. Mech. 2014, 84, 1-20. [CrossRef]

132. Shariyat, M.; Asemi, K. Three-dimensional non-linear elasticity-based 3D cubic B-spline finite element shear buckling analysis of rectangular orthotropic FGM plates surrounded by elastic foundations. Compos. Part B Eng. 2014, 56, 934-947. [CrossRef]

133. Zhang, L.W.; Liew, K.M. Postbuckling analysis of axially compressed CNT reinforced functionally graded composite plates resting on Pasternak foundations using an element-free approach. Compos. Struct. 2016, 138, 40-51. [CrossRef]

134. Civalek, Ö. Nonlinear dynamic response of laminated plates resting on nonlinear elastic foundations by the discrete singular convolution-differential quadrature coupled approaches. Compos. Part B Eng. 2013, 50, 171-179. [CrossRef]

135. Tornabene, F.; Fantuzzi, N.; Bacciocchi, M.; Reddy, J.N. A Posteriori Stress and Strain Recovery Procedure for the Static Analysis of Laminated Shells Resting on Nonlinear Elastic Foundation. Compos. Part B Eng. 2017, 126, 162-191. [CrossRef]

136. Shu, C. Differential Quadrature and Its Application in Engineering; Springer: Berlin, Germany, 2000.

137. Tornabene, F.; Fantuzzi, N.; Ubertini, F.; Viola, E. Strong formulation finite element method based on differential quadrature: A survey. Appl. Mech. Rev. 2015, 67, 145-175. [CrossRef]

138. Viola, E.; Tornabene, F.; Fantuzzi, N.; Bacciocchi, M. Numerical Investigation of Composite Materials with Inclusions and Discontinuities. Key Eng. Mater. 2017, 747, 69-76. [CrossRef]

139. Fantuzzi, N.; Tornabene, F.; Bacciocchi, M.; Neves, A.M.A.; Ferreira, A.J.M. Stability and Accuracy of Three Fourier Expansion-Based Strong Form Finite Elements for the Free Vibration Analysis of Laminated Composite Plates. Int. J. Numer. Methods Eng. 2017, 111, 354-382. [CrossRef]

140. Tornabene, F.; Fantuzzi, N.; Bacciocchi, M. Mechanical Behaviour of Composite Cosserat Solids in Elastic Problems with Holes and Discontinuities. Compos. Struct. 2017, 179, 468-481. [CrossRef]

141. Di.Qu.M.A.S.P.A.B. Software. Available online: http://software.dicam.unibo.it/diqumaspab-project (accessed on 1 June 2017).

(C) 2017 by the authors. Licensee MDPI, Basel, Switzerland. This article is an open access article distributed under the terms and conditions of the Creative Commons Attribution (CC BY) license (http:/ / creativecommons.org/licenses/by/4.0/). 